Check for updates

Cite this: RSC Adv., 2018, 8, 32832

Received 29th July 2018

Accepted 13th September 2018

DOI: $10.1039 / \mathrm{c} 8 \mathrm{ra06384b}$

rsc.li/rsc-advances

\section{Recovery and purification of ionic liquids from solutions: a review}

Jingjing Zhou, ${ }^{\text {ab }}$ Hong Sui, ${ }^{\text {abc }}$ Zhidan Jia, ${ }^{\text {ab }}$ Ziqi Yang, ${ }^{\text {ab }}$ Lin He (DD *abc and Xingang $\mathrm{Li}^{\text {abc }}$

With low melting point, extremely low vapor pressure and non-flammability, ionic liquids have been attracting much attention from academic and industrial fields. Great efforts have been made to facilitate their applications in catalytic processes, extraction, desulfurization, gas separation, hydrogenation, electronic manufacturing, etc. To reduce the cost and environmental effects, different technologies have been proposed to recover the ionic liquids from different solutions after their application. This review is mainly focused on the recent advances of the recovery and purification of ionic liquids from solutions. Several methods for recovery of ionic liquids including distillation, extraction, adsorption, membrane separation, aqueous two-phase extraction, crystallization and external force field separation, are introduced and discussed systematically. Some industrial applications of ionic liquid recovery and purification methods are selected for discussion. Additionally, considerations on the combined design of different methods and process optimization have also been touched on to provide potential insights for future development of ionic liquid recovery and purification.
${ }^{a}$ School of Chemical Engineering and Technology, Tianjin University, 300072 Tianjin, China. E-mail: linhe@tju.edu.cn; Tel: +86-022-27404701

${ }^{b}$ National Engineering Research Center of Distillation Technology, 300072 Tianjin, China

${ }^{c}$ Collaborative Innovation Center of Chemical Science and Engineering, 300072 Tianjin, China

\section{Introduction}

Ionic liquids (ILs) are a class of molten salts with melting points below $100{ }^{\circ} \mathrm{C}$. Generally, this kind of chemical is composed of organic cations and organic/inorganic anions. The cations are mainly, but not limited to alkylated imidazole, pyrrole or pyridine derivatives, quaternized alkyl amines and alkyl phosphines (Table 1), etc. Some representative anions of ionic liquids are halides, alkyl sulfates, fluorinated hydrocarbons, carboxylic acids and amino acids, ${ }^{1-3}$ as shown in Table 2 .

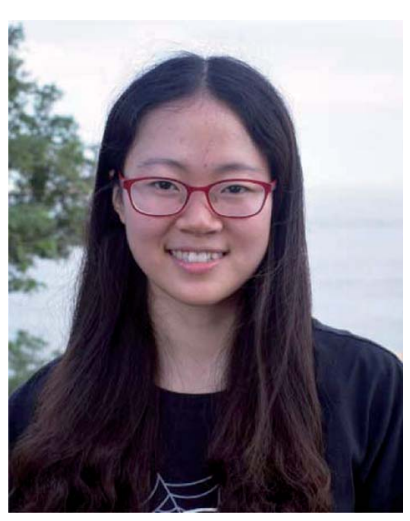

Jingjing Zhou was born in Hebei, China. She received her B.Sc. degree in chemical engineering from Dalian University of Technology in 2016. And she majored in the process simulation of waste heat recovery system of coke oven gas. After that, she joined Prof. Xingang Li's group as a master student in School of Chemical Engineering and Technology, Tianjin University. At present she is focusing on the recovery of ionic liquids after applications of ionic liquids in oilsolid separation, interfacial characterization, etc.

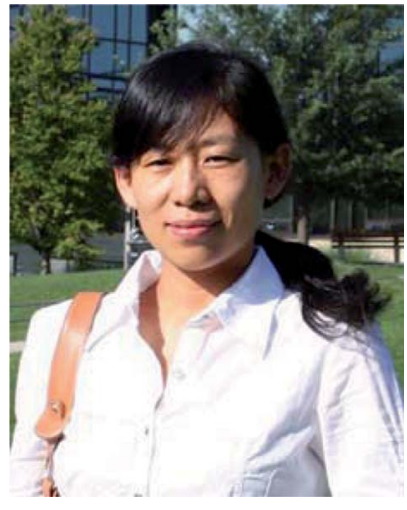

Professor Hong Sui received her B.Sc. degree from Hebei University of Technology and Ph.D. degree in Chemical Engineering from Tianjin University. She worked as a postdoctoral fellow in National Pei Yang Distillation Technology Engineering Limited Company and then joined the faculty of Tianjin University as a professor. She has published more than 100 scientific papers and about 40 invention patents granted as the first inventor or co-inventors. Her main research areas are related to the surface science in complex fluid, oil-solid separation, solvent extraction, adsorption, functional chemicals synthesis and applications and also the advanced methodologies for remediating contaminated sites. 
In addition to the two most common IL types, i.e., protic and aprotic ILs, ${ }^{4}$ some other ILs subclasses have also been reported, including polymeric ILs, ${ }^{5}$ double salt ILs, ${ }^{6}$ dicationic ILs, ${ }^{7}$ deep eutectic solvent, ${ }^{8}$ chiral ILs, ${ }^{9}$ solvate ILs, ${ }^{10}$ etc. Some ionic liquids mentioned in the review are listed in Table 3. During the past decades, ILs have attracted much attention from researchers and engineers due to their unique characteristics such as negligible vapour pressure, nonflammability, high thermal stability and a wide electrochemical (conductivity) window. In addition, the physical and chemical properties (e.g., solubility, polarity, viscosity and acidity) of ILs are also found to be able to be designed by combination and modification of their cations and anions. In this way, the ILs have been applied in certain processes, such as catalytic reactions, ${ }^{\mathbf{1 1 , 1 2}}$ separations, ${ }^{\mathbf{1 3 , 1 4}}$ desulfurization, ${ }^{\mathbf{1 5 , 1 6}}$ hydrogenation, ${ }^{17,18}$ and electrochemistry. ${ }^{19,20}$

However, ILs are, at least, partially miscible with water or hydrocarbons, which will inevitably end up in the aqueous or

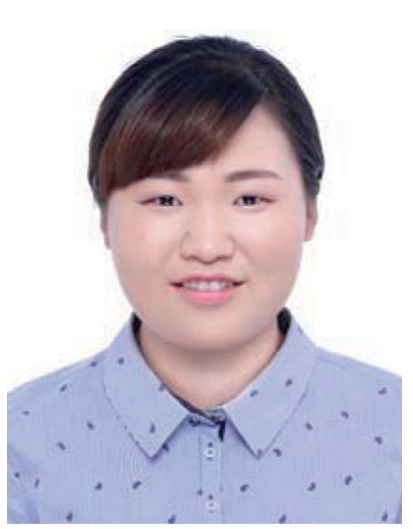

Zhidan Jia was born in Hebei, China. She received her B.Sc. degree from Hebei University of Technology in 2016. And she focused on the preparation of crystal whiskers with $\mathrm{MgSO}_{4}$. After that, she studied in Tianjin University as a master student and joined Prof. Xingang Li's group. She is majoring in behaviors of ionic liquids at oilwater interface and applications of ionic liquid in oil industry.

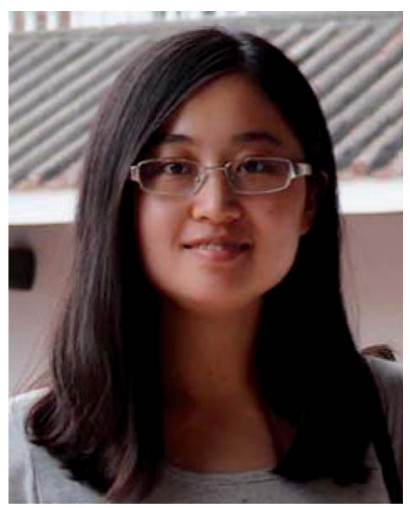

Ziqi Yang received her B.Sc. degree in Chemistry from Nankai University in 2015. During her pursuing the bachelor degree, she focused on the synthesis of functionalized graphene for glycoproteins enrichment. After that, she joined Prof. Xingang Li's group, majoring in the research on the synthesis of $\mathrm{CO}_{2}$-responsive materials and their applications in oil-solid separation. She received her M.Sc. degree in Chemical Engineering from Tianjin University in 2018. Now, she is a Ph.D candidate in chemical engineering. non-aqueous environment through industrial waste stream. ${ }^{\mathbf{2 1 , 2 2}}$ Although there are multiple ILs created from GRAS (Generally Recognized As Safe) list ions, ${ }^{23,24}$ the leaking of some ILs with certain toxicity may cause potential environmental impact. ${ }^{25}$ On the other hand, a major concern associated with adopting ILs in large scale industrial processes is their relatively high cost in comparison with conventional solvents. The expense can be offset to some extent if ILs are recycled. ${ }^{26}$ Therefore, efficient separation and recovery of ILs from different solutions are essential for their ecological and economic applications.

During the past decades, great attempts have been made by researchers for the recovery and recycling of ILs, including distillation, ${ }^{27}$ extraction, ${ }^{28}$ adsorption, ${ }^{29}$ membrane separation, ${ }^{30}$ aqueous two-phase extraction, ${ }^{31}$ crystallization $^{32}$ and force field separation, ${ }^{33}$ etc., shown in Fig. 1. Among these methods, distillation and extraction are two of the most commonly used ways. Distillation, especially vacuum distillation, is usually employed as the final step for separation of

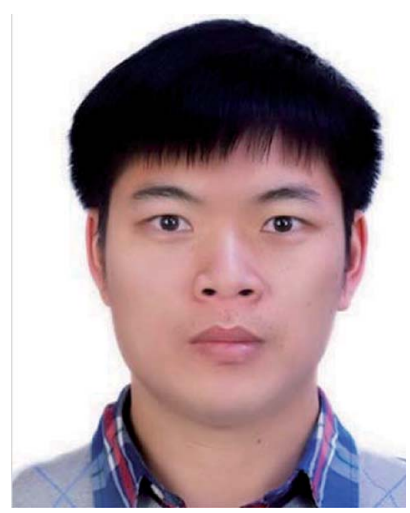

Lin He was born in Jiangxi, China. He received his B.Sc. degree from Wuhan University of Science \& Technology in 2009. After that, he joined Prof. Xingang Li's group as a Ph.D. candidate. Then, he worked as a postdoctoral fellow in Collaborative Innovation Center of Chemical Science and Engineering. In 2017, he joined the faculty of Tianjin University as an assistant professor. His research focuses on the interfacial sciences of unconventional oil processing, gas adsorption and desorption, interfacially active materials synthesis and applications, soil remediation. He published over 35 papers and obtained over 10 granted patents.

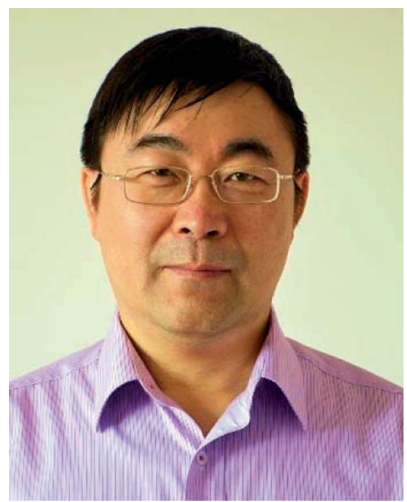

Xingang $L i$ received his Ph.D. from Tianjin University in 1992. He is now a full-professor in School of Chemical Engineering \& Technology, in Tianjin University. He is also the head of National Engineering Research Centre of Distillation Technology, China. His research focuses mainly on the separation fields, including distillation, extraction, soil remediation, unconventional oil exploitation, waste gas treatment, chemical synthesis, chemical processing of coal, etc. He obtained the National Progress Awards in Science and Technology (2007), National Invention Award (2013) and other scientific awards. He has published more than 300 articles including original papers, reviews and chapters of books. 
Table 1 Cations of ionic liquids

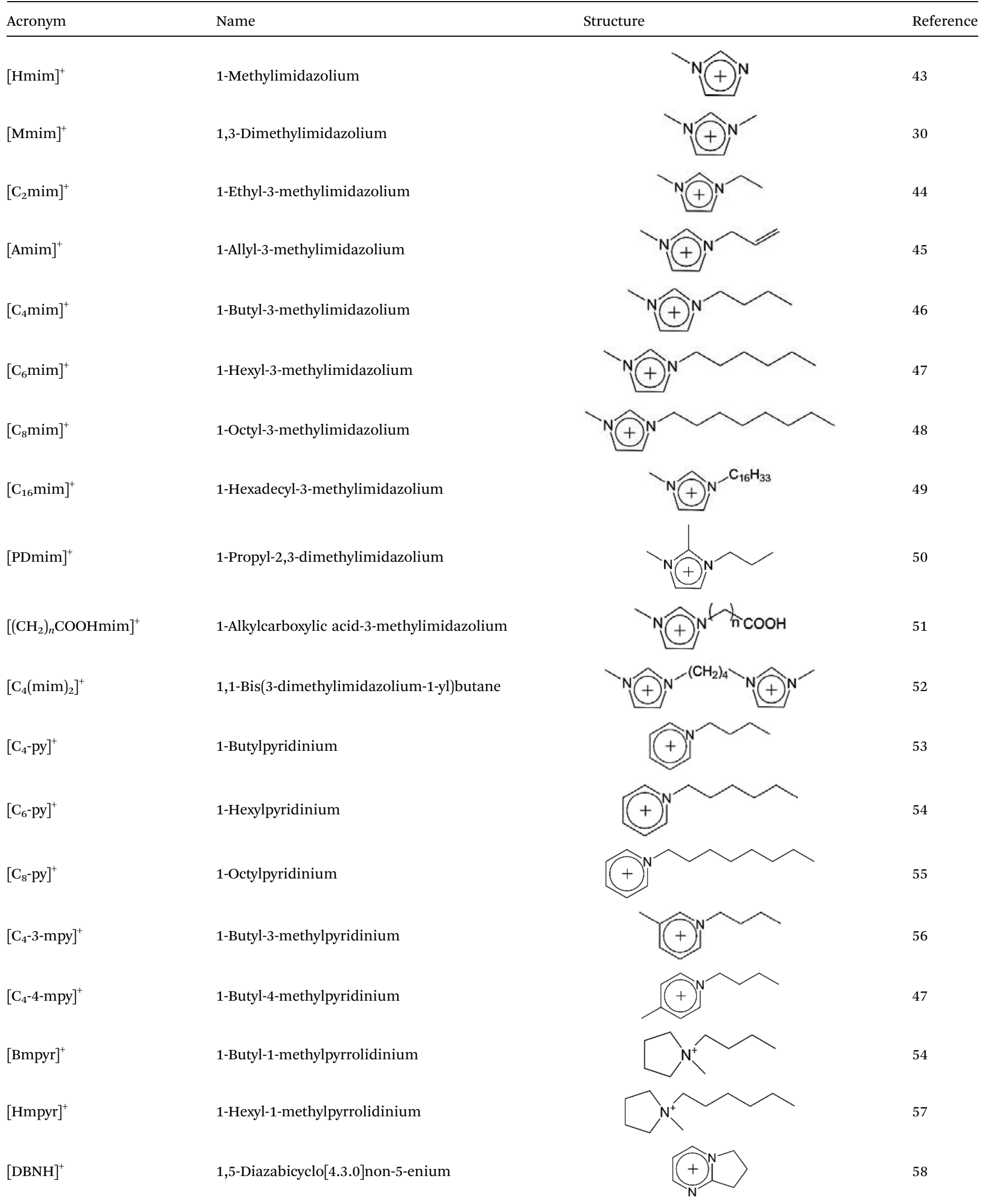


Table 1 (Contd.)

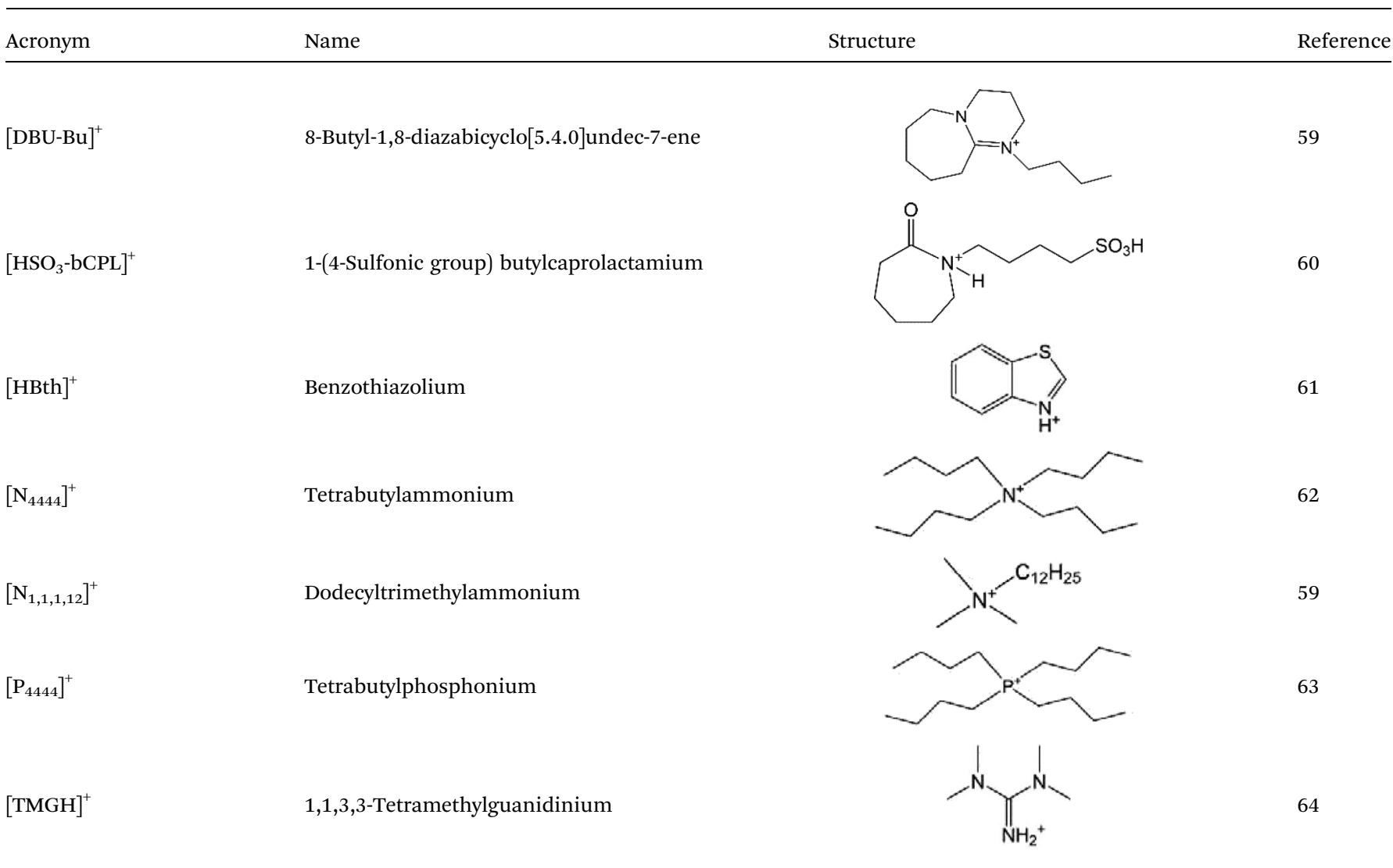

volatile products from ILs. When it comes to non-volatile or thermally sensitive substances, extraction is a more preferable choice. Adsorption is considered to be a robust and nondestructive way to recover ILs from aqueous solution. Nonetheless, the desorption of the adsorbed ILs still has a long way. Membrane technology is also employed to separate ILs, where ILs could be remained in the feed side or permeate through the membrane. The aqueous two-phase system, where there is no use of traditional volatile organic solvents in the whole process, is usually applied for recovering hydrophilic ILs. Other technologies such as crystallization and force field separation have also been developed to obtain ionic liquids with high purity or save much energy.

There are some comprehensive reviews on the synthesis and application of ionic liquids. ${ }^{34-42}$ In this review, the recent advances regarding the methods used for the recovery and recycling of ILs, either single or combination of these methods have been reviewed and discussed. We hope this review could provide some basic information and strategy for researchers and engineers in choosing and designing suitable recovery methods in practice.

\section{Methods for recovery and purification of ionic liquids from solutions}

\subsection{Distillation}

Distillation is the most commonly used process for separating liquid mixtures through gradient boiling and condensation based on the differences in the volatility of the components in the mixture. Due to simple operation, the distillation has been widely applied for the recovery of ILs. During the process, according to the types of the distillates, the distillation could be operated in three ways. One is the distillation of volatile species while leaving the ionic liquids in the distillation equipment. Another way is distillation through the reaction of ILs, where ILs form distillable carbene or decompose into distillable neutral compounds. The third way is that ILs are distilled out as intact ion pairs.

\subsubsection{Distillation of volatile compounds}

Conventional distillation methods. Separation of ILs and low boiling point compounds by conventional distillation could be achieved in a rotary evaporator ${ }^{27,57,58,78-81}$ or a thin film evaporator. ${ }^{82-85}$ The rotary evaporator works on the basis of reducing the pressure above a bulk liquid thus lowering the boiling 
Table 2 Anions of ionic liquids

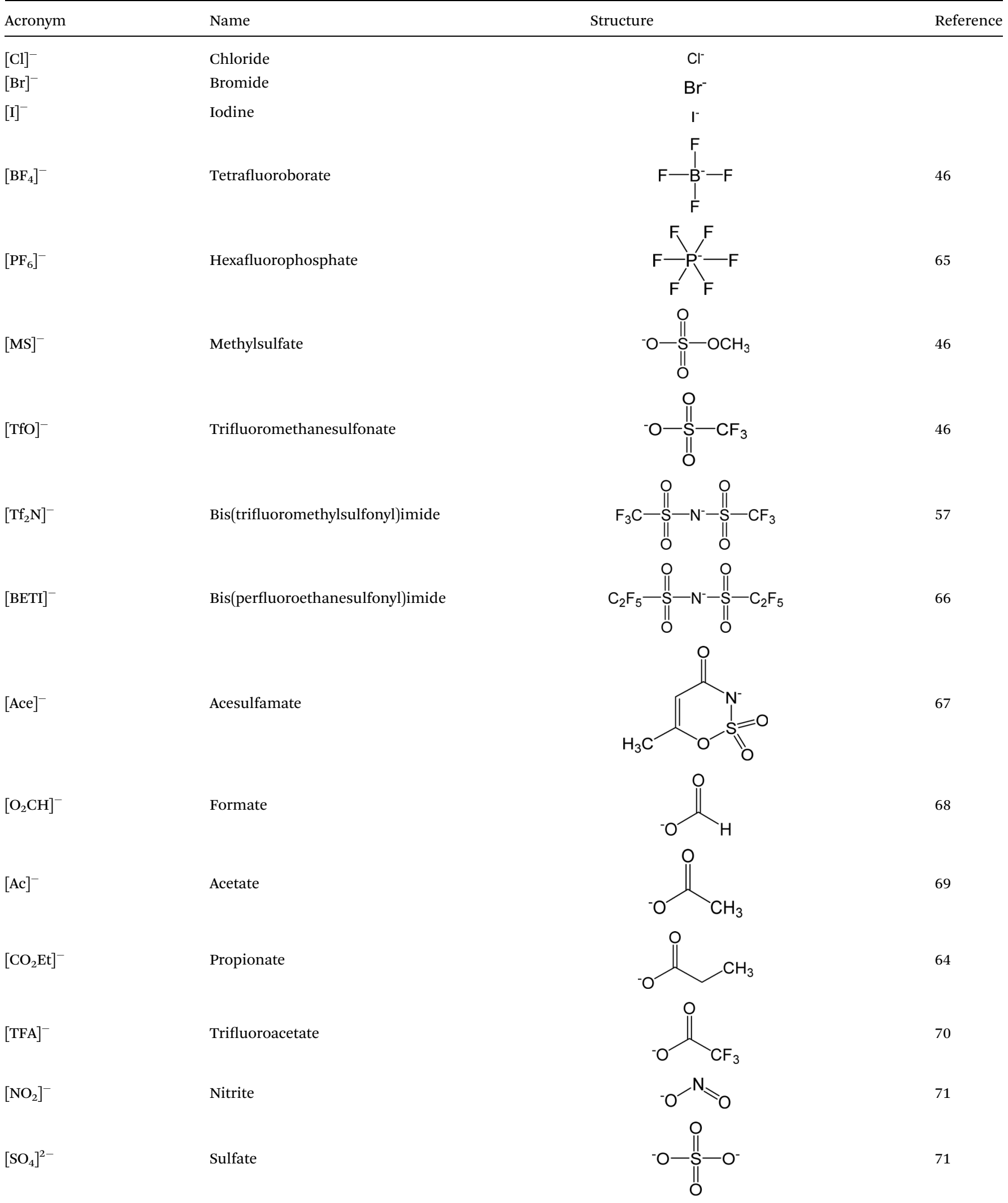


Table 2 (Contd.)

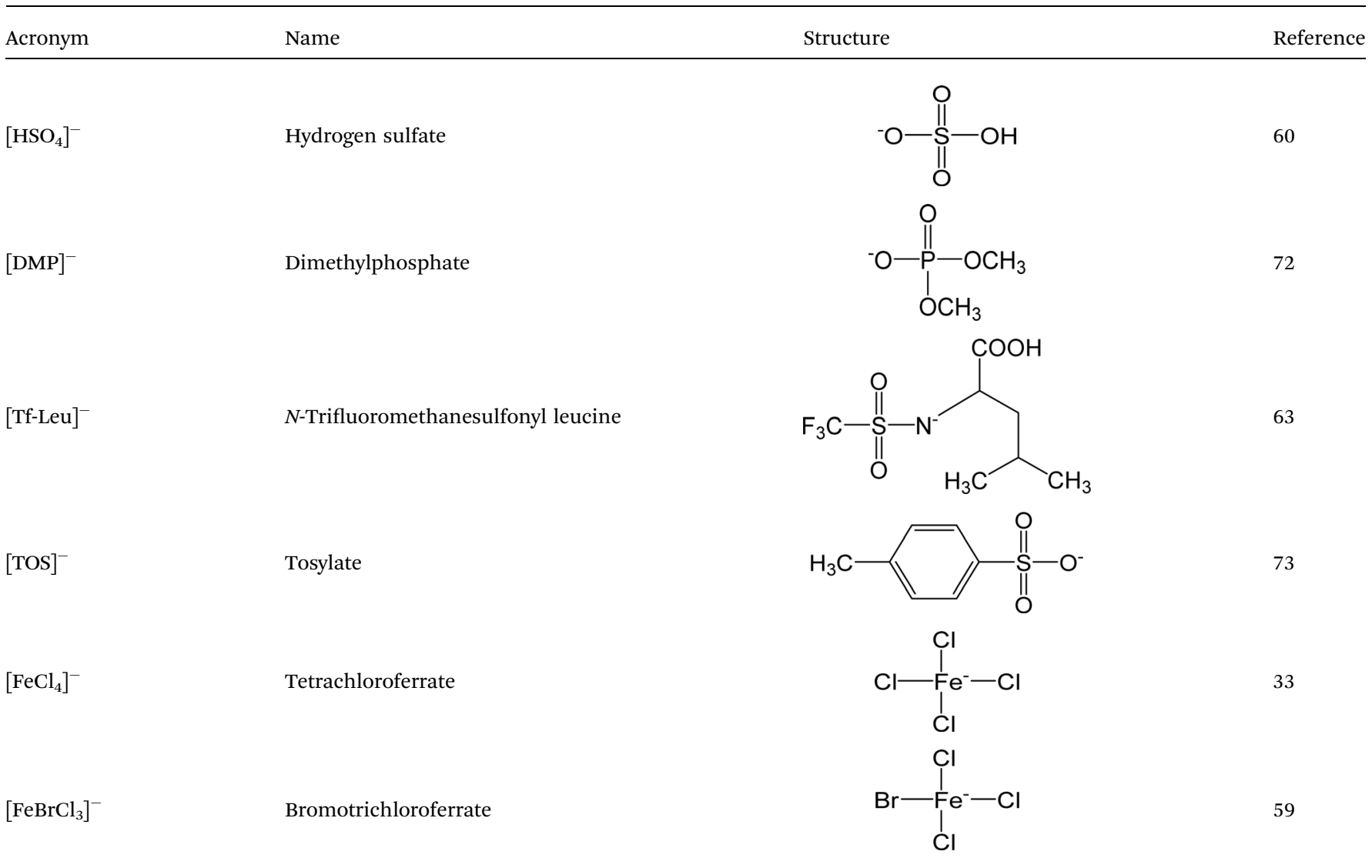

points of components in the liquid mixture. Compared to the standard organic distillation glassware, the heating surface in rotary evaporator is enlarged due to the formation of a thin film of warm solvent, which is caused by the centrifugal force and the frictional force between the wall of the rotating flask and the liquid sample. Therefore, the rotary evaporator is a commonly used device in laboratories to distillate out high boiling and/or air sensitive compounds. Dennewald et al. ${ }^{57}$ applied the rotary evaporator to recover the 1-hexyl-1-methylpyrrolidinium bis(trifluoromethylsulfonyl)imide ([Hmpyr $\left.]\left[\mathrm{Tf}_{2} \mathrm{~N}\right]\right)$ from solutions. This kind of ionic liquid was used as solvent in biotransformation of 2-octanone into $(R)$-2-octanol, where the IL formed emulsions with the aqueous phase containing biocatalyst due to their immiscibility. Therefore, before the distillation, the emulsions should be pretreated for complete separation by centrifugation. After the pretreatment, the IL phase was introduced in a rotary evaporator for distillation under the minimal pressure $(P<5 \mathrm{mbar})$ at $130{ }^{\circ} \mathrm{C}$ for $5 \mathrm{~h}$. The product $((R)-2-$ octanol) and nonconverted 2-octanone were distilled out and IL was remained as residue. After using the ILs for 25 cycles, they obtained an average recovery of $[\mathrm{Hmpyr}]\left[\mathrm{Tf}_{2} \mathrm{~N}\right]$ at about $82.78 \pm$ $0.83 \%$. Parviainen et $a .^{58}$ evaluated the recyclability of 1,5 diazabicyclo[4.3.0]non-5-enium acetate ([DBNH][Ac]) that was used as a dissolution solvent for cellulose. The rotary evaporator (1-3 mbar) was applied to remove traces of water from the $[\mathrm{DBNH}][\mathrm{Ac}]$ at $60{ }^{\circ} \mathrm{C}$ for $2 \mathrm{~h}$. The IL could be recycled from aqueous media with an average recovery rate of $95.6 \mathrm{wt} \%$.
However, they proposed that the residence time for this kind of batch distillation apparatus was very long, thus leading to the significant hydrolysis of ILs. In addition, these hydrolysis products would deteriorate the cellulose dissolution capability of ILs.

Different from the rotary evaporator, the thin film evaporator could be operated continuously and applied at pilot scale. During the thin film evaporation, the liquid mixture flows downwards the evaporator wall by gravity or assisted by mechanical wipers, forming a continuous thin film that covers the evaporator surface. One of the advantages of the falling film evaporator is the high heat transfer coefficients and short residence time of the liquid, making it ideal to separate heatsensitive, viscous or low thermal conductivity substances. ${ }^{\mathbf{8 6}}$ Ahmad et $a l .{ }^{85}$ tested the feasibility of a thin film evaporator in recovering [DBNH][Ac] from a solution containing $80 \mathrm{wt} \%$ water at pilot scale. The detailed diagram of the evaporation system is shown in Fig. 2. The IL solution was pumped from the vessel through the preheater and fed to the top of the evaporator. The feed was distributed around the evaporator walls under centrifugation force by the wiper system. The IL rich residue was collected at the bottom of evaporator while the vapor product with the high proportion of water was collected at the top as distillate. The operational parameters, such as feed flow rate, operation pressure and evaporator jacket temperature have been systematically investigated. The flow rate was observed to exert slight effect on the product composition, while the 
Table 3 Some special ionic liquids mentioned in the review

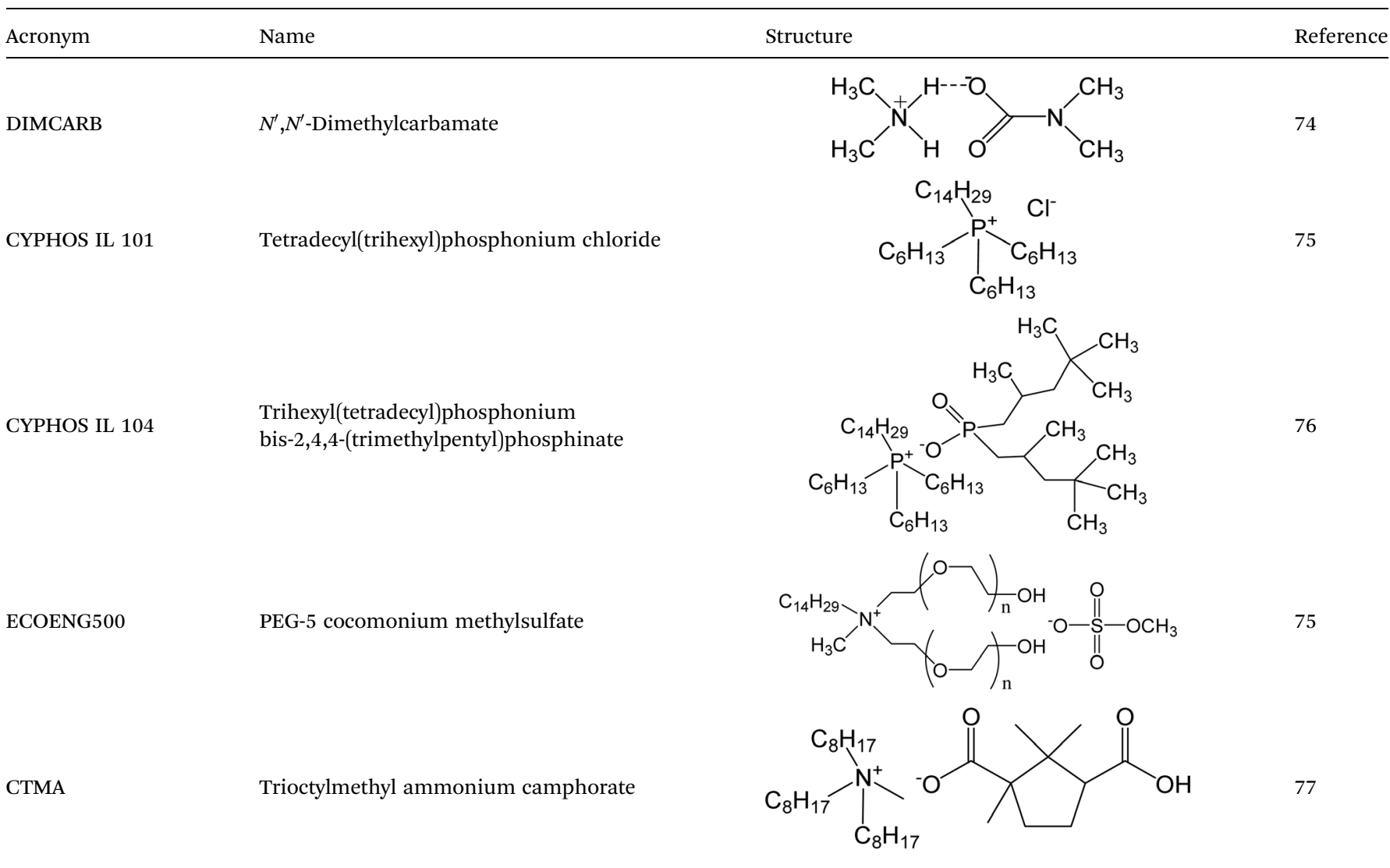

separation efficiency increased with higher jacket temperature and lower pressure. It was found that the $[\mathrm{DBNH}][\mathrm{Ac}]$ product with low water contents (5-11.7 wt\%) was obtained.

The conventional distillation technology has been employed for industrial application. A process of the chlorination of butanediol with gaseous $\mathrm{HCl}$ was developed by BASF (Germany), where the ionic liquid acts as solvent. ${ }^{87}$ After the reaction, the upper organic phase which was consisted of the reaction product (1,4-dichlorobutane) was easily separated from the lower IL phase. The water that was formed as by-product could be distilled off from the IL phase (not explicitly mentioned). Thus the IL could be used for the next run without any further processing. BASF has also run an extractive distillation process in a pilot plant. ${ }^{73,88}$ The 1-ethyl-3-methylimidazolium tosylate $\left(\left[\mathrm{C}_{2} \mathrm{mim}\right][\mathrm{TOS}]\right)$ was used as an entrainer for the separation of azeotropic mixtures (methanol-trimethylborate ( $\mathrm{MeOH}-\mathrm{TMB})$ ). Fig. 3 shows a flow sheet of the extraction distillation process involving the recovery of IL by thin film evaporation. The TMB was distilled and obtained at the top of the column. The $\mathrm{MeOH}$ was drawn at the bottom. The mixture of IL and residual $\mathrm{MeOH}$ was removed to a falling film evaporator, where the $\mathrm{MeOH}$ was distilled and the recovered IL was fed at the top of the extraction column and reused. The $\left[\mathrm{C}_{2} \mathrm{mim}\right][\mathrm{TOS}]$ showed stable performance for the separation of $\mathrm{MeOH}-\mathrm{TMB}$ during a period of 3 months.
Microwave-assisted distillation. Microwaves are electromagnetic waves with radio frequencies in the range from $300 \mathrm{MHz}$ to $300 \mathrm{GHz}$ (wavelengths from $1.0 \mathrm{~mm}$ to $1.0 \mathrm{~m}$ ). Compared with the traditional heating, the microwave irradiation could be used to heat the materials to high temperature in a fast way through excitation of polar molecules (via dipole rotation) or ions (via

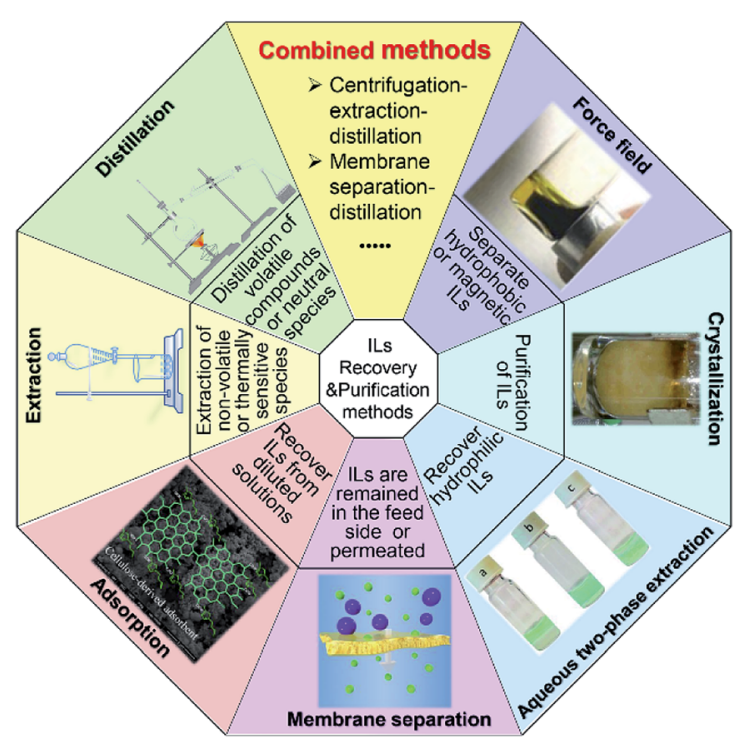

Fig. 1 Schematic of ionic liquids recovery and purification methods. 


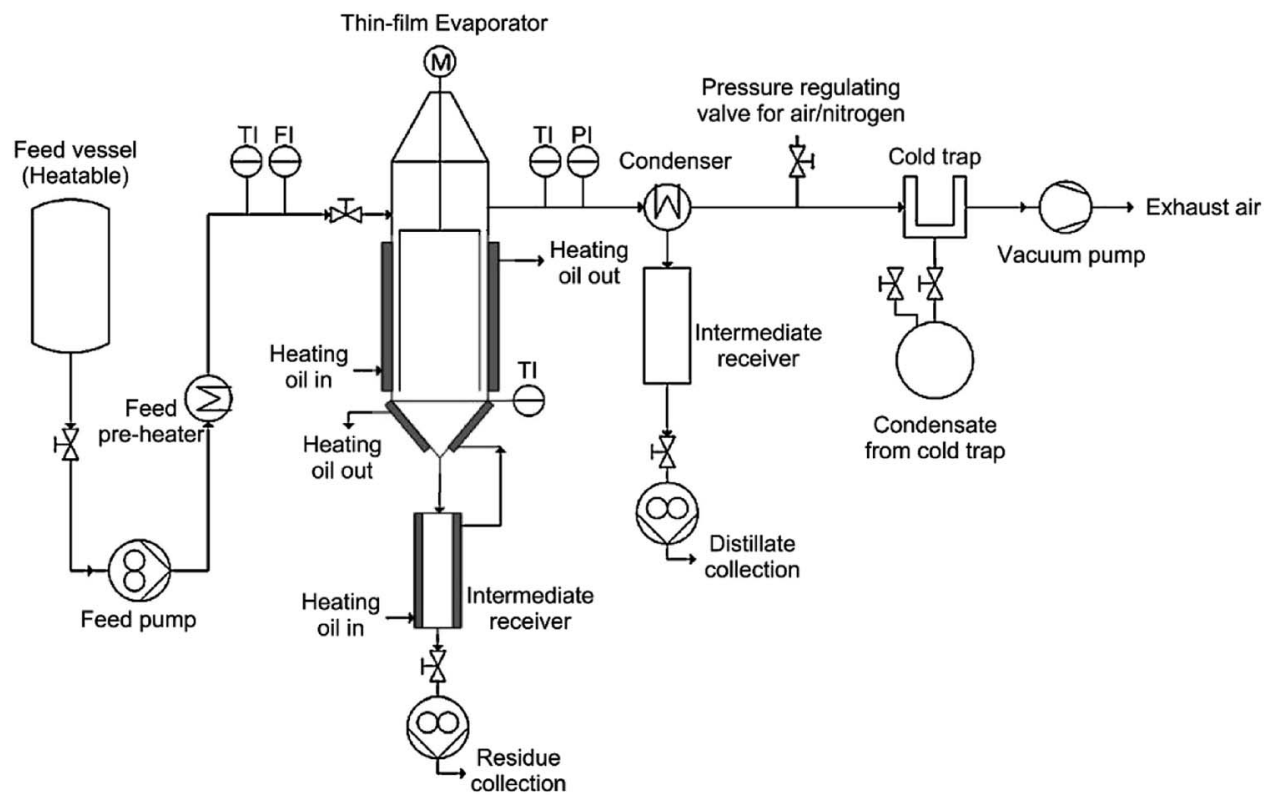

Fig. 2 Flow sheet of the agitated thin-film evaporation system. (TI) Temperature indicator; (FI) flow indicator; (PI) pressure indicator. Reproduced with permission from ref. 85. Copyright 2016 Elsevier Ltd.

ionic conduction) in the microwave field. ${ }^{89,90}$ Due to this property, the microwave irradiation has been widely applied in many processes such as organic synthesis, ${ }^{91}$ biomass pretreatment, ${ }^{92}$ extraction ${ }^{93}$ and evaporation, ${ }^{94}$ etc. Ha et al. ${ }^{46}$ investigated the microwave-assisted distillation for separation of three hydrophilic ILs (1-butyl-3-methylimidazolium tetrafluoroborate $\left(\left[\mathrm{C}_{4} \mathrm{mim}\right]\left[\mathrm{BF}_{4}\right]\right), \quad$ 1-butyl-3-methylimidazolium trifluoromethanesulfonate $\left(\left[\mathrm{C}_{4} \mathrm{mim}\right][\mathrm{TfO}]\right)$ and 1-ethyl-3methylimidazolium methylsulfate $\left.\left(\left[\mathrm{C}_{2} \mathrm{mim}\right][\mathrm{MS}]\right)\right)$ and two hydrophobic ILs $\left(\left[\mathrm{C}_{4} \mathrm{mim}\right]\left[\mathrm{PF}_{6}\right]\right.$ and $\left.\left[\mathrm{C}_{4} \mathrm{mim}\right]\left[\mathrm{Tf}_{2} \mathrm{~N}\right]\right)$ from ILs/ water mixture. It was found that for the homogeneous mixture of hydrophilic ILs and water $(1: 1, \mathrm{w} / \mathrm{w})$, the energy efficiency was at least 52 times higher than those in conventional vacuum distillation. However, for the oil-water dual

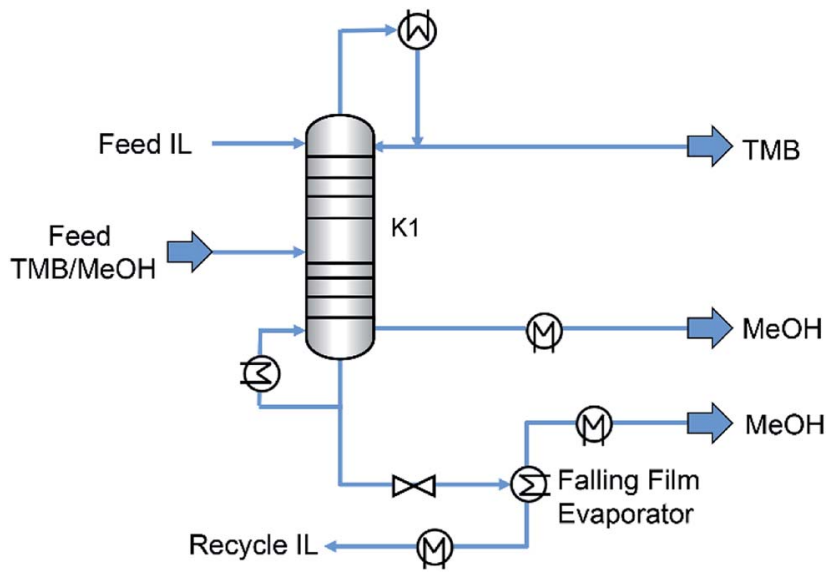

Fig. 3 Flow sheet of extraction distillation process involving the recovery of IL by thin film evaporation. Reproduced with permission from ref. 73. Copyright 2005 Wiley-VCH. phases, although the water content in hydrophobic ILs was less than that in hydrophilic ILs, much more energy was observed to be required to distill the water from the water-saturated hydrophobic ILs. Unfortunately, the detailed mechanisms for this phenomenon are still not clear.

Molecular distillation. Molecular distillation, a type of shortpath vacuum distillation, has been used for the separation of heat-sensitive materials based on the differences in the mean free path of gas molecules. ${ }^{95}$ This method is characterized by a short-term exposure of the distilled liquid at elevated and high vacuum in the distillation column, and a short distance (20-50 $\mathrm{mm}$ ) for vapor from the evaporator to reach the condenser. ${ }^{96}$ Blahušiak et al. ${ }^{76}$ employed molecular distillation for regeneration of butanoic acid from a hydrophobic phosphonium IL (commercial name CYPHOS IL 104). The IL was diluted with dodecane to decrease its viscosity. Results showed that $88 \%$ of the butanoic acid and almost $90 \%$ of dodecane was distillated out. Huang et $a l .^{45}$ applied molecular distillation to recover 1allyl-3-methylimidazolium chloride $([\mathrm{Amim}][\mathrm{Cl}])$ used in a homogenous cellulose acetylation system. Their results showed that the volatile impurities were distilled while the $[\mathrm{Amim}][\mathrm{Cl}]$ remained as a residue which was recycled and reused for 5 times without any change in the structure.

\subsubsection{Distillation through reaction of ILs}

Distillation by formation of carbene. For some imidazoliumbased ILs, the neutral carbene molecules could be formed by deprotonation of the cations of ILs in the presence of base at heating (Fig. 4a). ${ }^{97-99}$ The carbene could be distilled out and reacted with protic acid to re-form the ILs, thus allowing the recovery or purification of ILs. Maase et al. ${ }^{99}$ reported a process in which 1,3-substituted imidazolium salt could be purified. In this process, the IL prepared by a conventional route was heated with the addition of a strong base (e.g., alkoxide) under reduced 


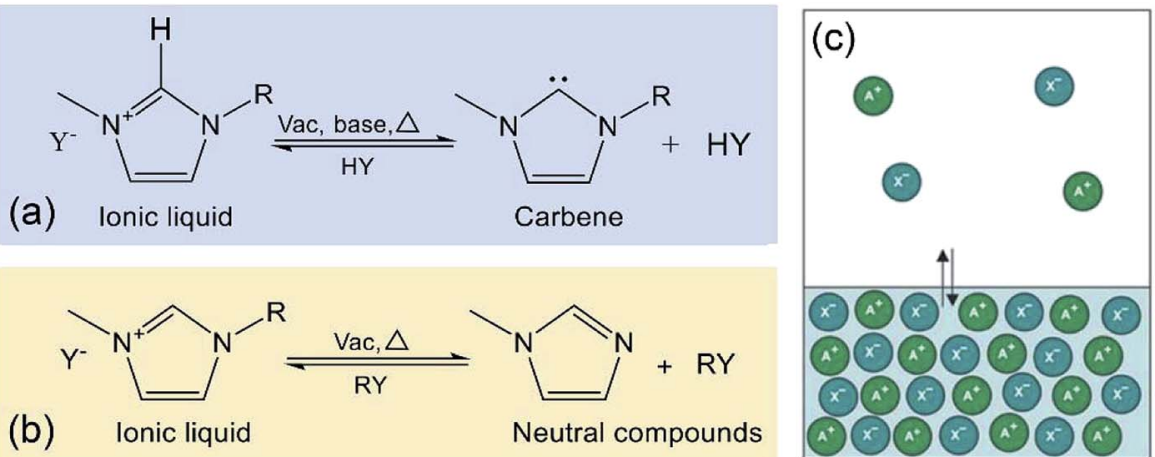

Fig. 4 Distillation of ILs as: (a) carbenes; ${ }^{97}$ (b) neutral compounds; ${ }^{88}$ (c) intact ion pairs, reproduced with permission from ref. 109. Copyright 2006 Nature Publishing Group.

pressure. Then the corresponding carbene, 1,3-substituted imidazol-2-ylidene, was formed and distilled off. Since the anions of ILs were not distilled and remained as residual, the condensed carbene was subsequently reacted with the fresh protic acid which contained the anions of ILs to be purified. Consequently, the purified 1,3-substituted imidazolium salt was re-formed. However, in this method, the distillable carbene need to be re-reacted with the protic acid in molar stoichiometry, which would increase the operational difficulty and the cost of the process compared to simple distillation of volatile compounds.

Distillation by decomposition reaction. When being heated, the ILs would decompose into uncharged distillable compounds via protonation or alkylation of the anions at elevated temperature under vacuum (Fig. 4b).4,100,101 These neutral decomposition compounds could be distilled out and re-reacted to IL. Take the recycling of 1-methyl-3-ethylimidazolium chloride $\left(\left[\mathrm{C}_{2} \mathrm{mim}\right]\right.$ [Cl]) from contaminants (not pointed out by the author) as example, ${ }^{44}$ when the $\left[\mathrm{C}_{2} \mathrm{mim}\right][\mathrm{Cl}]$ was heated at a temperature ranging from $200{ }^{\circ} \mathrm{C}$ to $300{ }^{\circ} \mathrm{C}$ under reduced pressure, the $\mathrm{IL}$ would be partially decomposed to give 1-methylimidizole, 1ethylimidizole, chloromethane and chloroethane. These neutral imidazole and alkylated agents could be distilled, followed by being collected and reacted to produce a mixture of 1,3-dimethylimidazolium chloride, 1,3-diethylimidazolium chloride and $\left[\mathrm{C}_{2} \mathrm{mim}\right][\mathrm{Cl}]$. However, this process is based on the decomposition of ILs and often not controlled, thus the pure ILs are difficult to be obtained. Recently, some acid-base conjugate ILs (e.g. 1,1,3,3-tetramethylguanidinium propionate ([TMGH] $\left.\left[\mathrm{CO}_{2} \mathrm{Et}\right]\right)^{64}$ and 1,5-diazabicyclo[4.3.0]non-5-enium propionate $\left.\left([\mathrm{DBNH}]\left[\mathrm{CO}_{2} \mathrm{Et}\right]\right)^{102}\right)$ were synthesized for efficient biomass treatment. It is found that their distillable characteristic is attributed to the higher acidity of the cations, allowing for the dissociation of ILs to the neutral acid and base IL precursors at elevated temperatures. For example, when being heated at 100$200{ }^{\circ} \mathrm{C}$ under reduced pressure $(1 \mathrm{mmHg})$, the $[\mathrm{TMGH}]\left[\mathrm{CO}_{2} \mathrm{Et}\right]$ was dissociated into the 1,1,3,3-tetramethylguanidine (TMG) and carboxylate $\left(\mathrm{HCO}_{2} \mathrm{Et}\right)$, which could be vaporized and reacted to re-form the $[\mathrm{TMGH}]\left[\mathrm{CO}_{2} \mathrm{Et}\right]{ }^{64}$

In addition to the above ILs going through deprotonation of the cations or alkylation of the anions during distillation, a series of distillable amide-derived aprotic ILs were also synthetized. ${ }^{103-105}$ The amide O-alkylation reaction is readily reversible varying with temperature. The volatile molecular precursors were found to be vacuum distilled and reverted to ILs at room temperature. ${ }^{103}$ Furthermore, the distillable ILs from the family of alkyl carbamate salts have also been reported. ${ }^{74,106-108}$ Separation of these ILs can be achieved at moderate temperatures due to the release of the neutral species $\left(\mathrm{CO}_{2}\right.$ and the dialkylamine) when being heated. The reformation of the ILs could be realized by subsequent recombination of the two compounds when cooling. For instance, during the aldol-condensation reactions, the $N^{\prime}, N^{\prime}$-dimethylcarbamate (DIMCARB) was used as the medium. This kind of ionic liquid would be dissociated to dialkylamine and $\mathrm{CO}_{2}$ under high vacuum and relatively low temperature $\left(60-105{ }^{\circ} \mathrm{C}\right)$. These dissociated components could be re-associated by condensation. $^{74}$

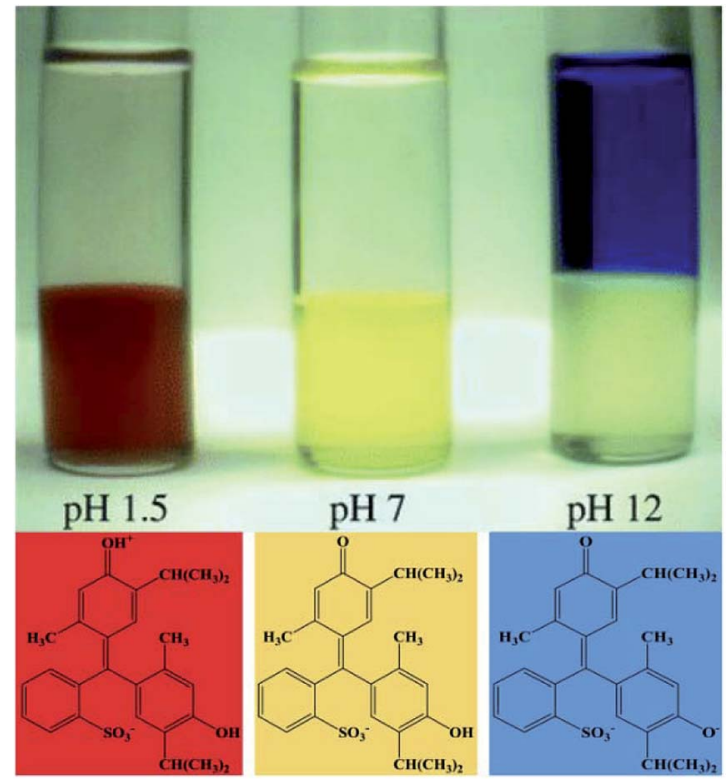

Fig. 5 The phase preference of the three forms of thymol blue in $\left[\mathrm{C}_{4} \mathrm{mim}\right]\left[\mathrm{PF}_{6}\right]$ at different $\mathrm{pH}$. Reproduced with permission from ref. 110. Copyright 2000 The Royal Society of Chemistry. 
2.1.3. Distillation of ILs as intact ion pairs. Different from the above process by distillating the ionic liquids as carbene or other decomposited neutral compounds, a range of pure, aprotic ILs could be vaporized as intact ion pairs and then condensed at lower temperatures without decomposition (Fig. 4c). After careful tests, Earle et al. ${ }^{109}$ demonstrated that ILs derived from tetraalkylammonium cations, $N, N$-pyrrolidinium cations and 1-alkyl-1,8-diazabicyclo[5.4.0]undec-7-enium could be vacuum distilled out as ion pairs, either alone or aggregated. However, the low distillation rate and harsh operation conditions (high vacuum and high temperature) make this method difficult for further application at present.

\subsection{Extraction}

Liquid-liquid extraction is a separation method based on the difference in solubility of the separated components in two immiscible liquid phases. It has been proved to be an efficient method for recovering ILs. Different solvents such as water, organic solvents and supercritical carbon dioxide $\left(\mathrm{scCO}_{2}\right)$ have been employed during the extraction processes.

2.2.1. Extraction with water. Basically, the hydrophilic solutes could be separated from hydrophobic ILs by means of extraction with water. Huddleston et $a{ }^{65}{ }^{65}$ initially studied the partitioning of substituted-benzene derivatives between a hydrophobic IL (i.e., 1-butyl-3-methylimidazolium hexafluorophosphate $\left.\left(\left[\mathrm{C}_{4} \mathrm{mim}\right]\left[\mathrm{PF}_{6}\right]\right)\right)$ and water. Later on, a reversible pH-dependent liquid-liquid partitioning of an indicator dye (thymol blue) between an IL ([ $\left.\left.\mathrm{C}_{4} \mathrm{mim}\right]\left[\mathrm{PF}_{6}\right]\right)$ phase and an aqueous phase was reported. ${ }^{110}$ As shown in Fig. 5, at low pH, the thymol blue was displayed as its red form which preferred to stay in the lower IL phase. As pH was further increased, a rising concentration of the yellow monoanion was detected in the upper aqueous phase. When the $\mathrm{pH}$ was above 10, the blue dianion was almost completely partitioned to the upper phase. Though the work provided insights on separation of ILs and solutes through $\mathrm{pH}$ adjustment, the distribution differences of the dye solutes between these two phases were not such significant, which limited the amount of solute being extracted out.

Additionally, the acid aqueous solution could also be used to separate metal complexes from IL after using IL for extraction of metal ions from aqueous solutions. Generally, traces of metal ions could be extracted from aqueous phase into the IL phase in the form of metal complexes by adding metal chelator. The metal complexes in IL phase would be dissociated when the acid solution is added to decrease the $\mathrm{pH}$ value, allowing metal ions to be separated from IL. Wei et al. ${ }^{111}$ utilized $\left[\mathrm{C}_{4} \mathrm{mim}\right]\left[\mathrm{PF}_{6}\right]$ to extract $\mathrm{Pb}^{2+}(20 \mathrm{ppm})$ from aqueous solution at $\mathrm{pH}$ 6.5, where a metal chelator (dithizone) was employed as extractant to form neutral metal-dithizone complexes. The complexes were then stripped from IL through mixing with $0.1 \mathrm{M} \mathrm{HNO}_{3}$ solution. The average extraction efficiency of $\mathrm{Pb}^{2+}$ was up to $98.4 \pm 0.2 \%$. Recently, a task-specific ILs with carboxyl-functional group have been proposed for the extraction of metal ions from aqueous phase. In the work of Chen et al., ${ }^{51}$ the carboxyl-functionalized imidazolium ILs (1-alkylcarboxylic acid-3-methylimidazolium bis(trifluoromethanesulfonyl)imide $\left(\left[\left(\mathrm{CH}_{2}\right)_{n} \mathrm{COOHmim}\right]\left[\mathrm{Tf}_{2} \mathrm{~N}\right]\right.$ $(n=3,5,7))$ ) were employed as extractants and four imidazolium-based ILs $\left(\left[\mathrm{C}_{n} \mathrm{mim}\right]\left[\mathrm{Tf}_{2} \mathrm{~N}\right](n=4,6,8,10)\right)$ were used as diluents to extract $\mathrm{Sc}^{3+}$ from aqueous solution at $30^{\circ} \mathrm{C}$. A cation exchange mechanism was proposed for the extraction process that when one mole of metal ion migrated to the IL phase, two moles protons of extractant and one mole cations of the diluent were transferred to aqueous phase simulataneously, which could be described by eqn (1):

$$
\begin{gathered}
\mathrm{Sc}^{3+}+2\left[\left(\mathrm{CH}_{2}\right)_{7} \mathrm{COOHmim}\right]\left[\mathrm{Tf}_{2} \mathrm{~N}\right]+\left[\mathrm{C}_{4} \mathrm{mim}\right]\left[\mathrm{Tf}_{2} \mathrm{~N}\right]= \\
\mathrm{Sc}\left[\left(\mathrm{CH}_{2}\right)_{7} \mathrm{COOmim}\right]_{2}\left[\mathrm{Tf}_{2} \mathrm{~N}\right]_{3}+2 \mathrm{H}^{+}+\left[\mathrm{C}_{4} \mathrm{mim}\right]^{+}
\end{gathered}
$$

After the formation of metal complex by ionic liquids extraction, the IL phase loaded with $\mathrm{Sc}^{3+}$ was mixed with diluted acid. Through this way, the formed metal complex would be decomposed into $\mathrm{Sc}^{3+}$ and the IL extractant, resulting in the separation of metal ions and the regeneration of IL. Results showed that $97.8 \%$ of $\mathrm{Sc}^{3+}$ could be extracted from the IL phase in a single step by using $0.03 \mathrm{M} \mathrm{HNO}_{3}$ aqueous solution.

2.2.2. Extraction with organic solvents. Different from the above process, when the solutes exhibiting immiscibility with water are mixed with ionic liquids, it is preferable to use organic solvents to extract the solutes from the ionic liquids. A range of organic solvents, including ethyl acetate, ${ }^{\mathbf{1 1 2}}$ diethyl ether, ${ }^{7 \mathbf{8 , 1 1 3 - 1 1 6}}$ toluene, ${ }^{60}$ hexane, ${ }^{113,117}$ cyclohexane ${ }^{118}$ and the mixture of ethanol and acetone, ${ }^{77}$ etc., have been applied to extract hydrophobic solutes from ILs. Mathews et al. ${ }^{\mathbf{1 1 4}}$ conducted palladium catalyzed Suzuki cross-coupling reactions of a series of arylhalide and arylboronic acid in 1-butyl-3methylimidazolium tetrafluoroborate $\left(\left[\mathrm{C}_{4} \mathrm{mim}\right]\left[\mathrm{BF}_{4}\right]\right)$. It is found that the extraction with diethyl ether was a generally applicable method for all biaryls and led to the highest yields (lack of the specific value) without obvious leaching of palladium species into the product. Luo et al. ${ }^{60}$ investigated the regeneration of a caprolactam-based acidic IL, 1-(4-sulfonic group) butylcaprolactamium hydrogen sulfate ([ $\left.\mathrm{HSO}_{3}-\mathrm{bCPL}\right]$ $\left.\left[\mathrm{HSO}_{4}\right]\right)$, which was used as catalyst during the transesterification of Jatropha oil with methanol. After the reaction, the mixture was cooled to room temperature and allowed to separate into two layers. The upper layer was consisted of biodiesel and unreacted oil, while the lower layer contained glycerol, unreacted methanol and the IL. The methanol and glycerol in the lower layer were extracted from IL with toluene followed by vacuum distillation. To recover the catalytic activity of the deactivated IL, the concentrated sulfuric acid was added dropwise into the IL. Results showed that the biodiesel yield was decreased by only about $5 \%$ and remained $91.9 \%$ after reusing the IL for 8 times. However, it is worth noticing that the aromatic solvents such as benzene and toluene are soluble in some ILs (e.g. imidazolium-, pyrrolidinium- and pyridiniumbased ILs) and could result in the formation of liquid clathrates. ${ }^{119}$ Therefore, one should consider this characteristic of the IL-aromatic systems when choosing the extraction solvents.

In addition to extracting the hydrophobic compounds, ILs would also be extracted out as solutes. For instance, the mixture of alkali lignin (200 mg) and 1-ethyl-3-methylimidazolium 


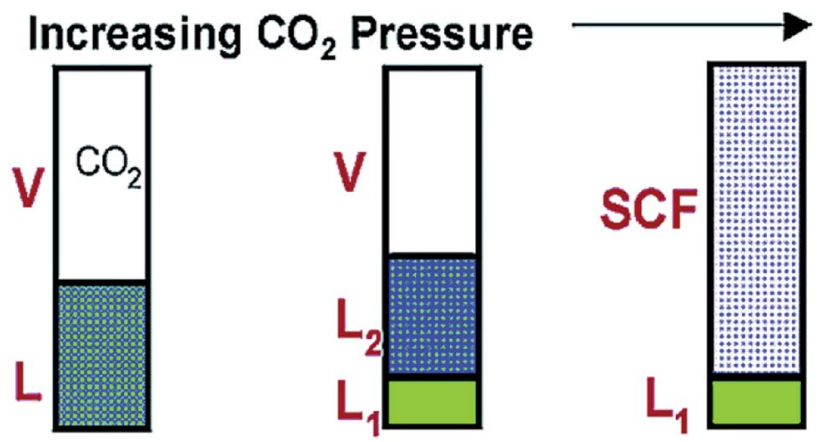

Fig. 6 Schematic of $\left[\mathrm{C}_{4} \mathrm{mim}\right]\left[\mathrm{PF}_{6}\right] /$ methanol phase behavior with increasing $\mathrm{CO}_{2}$ pressure. Reproduced with permission from ref. 128 . Copyright 2002 American Chemical Society.

acetate $\left(\left[\mathrm{C}_{2} \mathrm{mim}\right][\mathrm{Ac}]\right)(2 \mathrm{~mL})$ could be separated by adding a specific amount of selected solvents (isopropanol, ethanol, acetonitrile, allyl alcohol, methanol) $(5-100 \mathrm{~mL})$ at room temperature. ${ }^{69}$ The IL was extracted into the solvent phase under stirring, while the lignin pulp was precipitated after centrifugation. The four solvents were all able to extract IL thoroughly. However, some lignin was still present in the solvent phase. The isopropanol proved to be the most effective solvent, allowing the lowest amount of lignin in the supernatant liquid ( $13 \mathrm{wt} \%$ when $100 \mathrm{~mL}$ solvent was added), followed by ethanol and acetonitrile (25-27 wt\%). Relatively high amounts of lignin being about 54 and 67 wt $\%$ were provided by allyl alcohol and methanol, respectively.

The method of organic solvent extraction has been applied in industry for IL recovery. The Central Glass Company (Japan) has developed and commercialised a Sonogashira coupling reaction using a tetraalkylphosphonium ionic liquid as the solvent. ${ }^{39}$ The aryl halide (3,5-bis(trifluoromethyl)bromobenzen) was reacted with a terminal alkyl-alkyne (1,1-dimethyl-2propyn-1-ol) catalysed by palladium-copper. After the reaction, the product was separated by extraction with hexane, and the by-product salt $\left(\left[\mathrm{HNEt}_{3}\right][\mathrm{Br}]\right)$ was removed with a countercurrent flow of water. The remaining ionic liquid-catalyst solution could be recycled several times with little loss of the catalytic activity. However, the environmental impact maybe come up with the utilizing of organic solvent. Therefore, employing more environmentally friendly solvents as replacements has become one of the attractive directions.

2.2.3. Extraction with supercritical carbon dioxide. The supercritical fluid refers to the substance above the critical point, where the distinct liquid-gas interface disappears. Small changes in pressure or temperature near the critical point could result in large change in density, allowing properties of a supercritical fluid to be "fine-tuned". The supercritical fluids have been considered as excellent solvents in a range of processes. ${ }^{120}$ Supercritical carbon dioxide $\left(\mathrm{scCO}_{2}\right)$ is one of the most attractive supercritical fluids because it is nontoxic, nonflammable, inexpensive and has moderate critical temperature and pressure $\left(31.1^{\circ} \mathrm{C}\right.$ and $\left.7.38 \mathrm{MPa}\right) .{ }^{121}$

The application of $\mathrm{scCO}_{2}$ as extraction solvent for separation of IL and solute was based on three aspects: (i) the $\mathrm{CO}_{2}$ can be easily dissolved in the IL phase. This is not only favorable for the

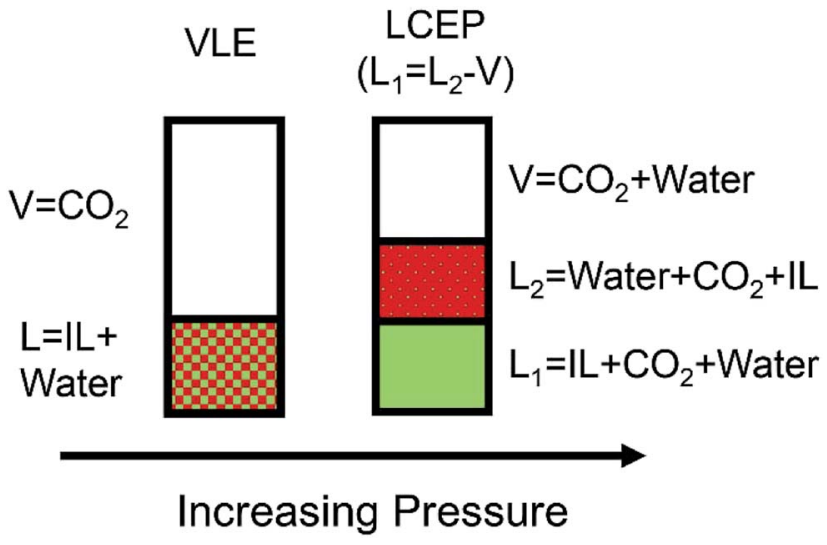

Fig. 7 Phase behavior of IL/water/ $\mathrm{CO}_{2}$ mixture at increasing pressure at near-ambient temperatures. Reproduced with permission from ref. 50. Copyright 2003 The Royal Society of Chemistry.

contact of $\mathrm{CO}_{2}$ with the desired solute, but also decreases the viscosity of the ILs. ${ }^{122}$ (ii) The dissolved $\mathrm{CO}_{2}$ in the IL phase can be completely removed by depressurization, thus pure IL is able to be remained after extraction. (iii) Since most of ILs are not appreciably solubilized in the $\mathrm{CO}_{2}$ phase, the problem of interactive contamination of the gas phase is eliminated as well. ${ }^{123}$

The $\mathrm{scCO}_{2}$ was firstly introduced by Blanchard et al. ${ }^{28}$ for the quantitative extraction of non-volatile organic compounds, naphthalene, from $\left[\mathrm{C}_{4} \mathrm{mim}\right]\left[\mathrm{PF}_{6}\right]$. It was reported that $94-96 \%$ of naphthalene was separated with $\mathrm{CO}_{2}$ at $13.8 \mathrm{MPa}$ and $40^{\circ} \mathrm{C}$. Subsequently, a variety of other organic solutes (aromatic and aliphatic) were reported to be extracted from $\left[\mathrm{C}_{4} \mathrm{mim}\right]\left[\mathrm{PF}_{6}\right]$ by using the $\mathrm{scCO}_{2}$ with recovery over $95 \%{ }^{123}$ However, it was found that the $\left[\mathrm{C}_{4} \mathrm{mim}\right]\left[\mathrm{PF}_{6}\right]$ could be dramatically dissolved in $\mathrm{scCO}_{2}$ when polar organic compounds (e.g., ethanol and acetone) were extracted into the $\mathrm{scCO}_{2}$ phase, especially when the concentration of these polar solutes in $\mathrm{scCO}_{2}$ exceeded $10 \mathrm{~mol} \% .{ }^{124}$ This finding presented a challenge when trying to remove high concentration polar organics from ILs. More recently, the separation of metal ions from ILs by employing $\mathrm{scCO}_{2}{ }^{125}$ or modified $\mathrm{scCO}_{2}{ }^{126,127}$ has been explored. Mekki et al. ${ }^{125}$ proved that the stripping of metal complexes of lanthanides $\left(\mathrm{La}^{3+}\right.$ and $\left.\mathrm{Eu}^{3+}\right)$ from 1-butyl-3-methylimidazolium bis[(trifluoromethyl)sulfonyl]imide $\left(\left[\mathrm{C}_{4} \mathrm{mim}\right]\left[\mathrm{Tf}_{2} \mathrm{~N}\right]\right)$ could be achieved by $\mathrm{scCO}_{2}$ coordinated with $\beta$-diketone extractants.

In addition to the extraction with $\mathrm{scCO}_{2}$, it was also observed by Scurto and coworkers ${ }^{50,128}$ that the relatively low-pressure $\mathrm{CO}_{2}$ could also be used to separate some hydrophobic and hydrophilic ILs. They found that the solutions of methanol and $\left[\mathrm{C}_{4} \mathrm{mim}\right]\left[\mathrm{PF}_{6}\right]$ could be induced to form three phases in the presence of $\mathrm{CO}_{2}{ }^{128}$ As illustrated in Fig. 6, the methanol and $\left[\mathrm{C}_{4} \mathrm{mim}\right]\left[\mathrm{PF}_{6}\right]$ were completely miscible at ambient conditions. When a pressure of $\mathrm{CO}_{2}$ was placed upon the mixture, a second liquid phase would appear. If the pressure of $\mathrm{CO}_{2}$ was further increased, the upper liquid layer which was rich in methanol, could merge with the $\mathrm{CO}_{2}$-rich gas phase. Then the newly formed phase was completely free of the ILs. The mechanism 
for this phenomenon would be ascribed to the expansion of the organic methanol phase by the $\mathrm{CO}_{2}$. This phase expansion decreases the dielectric constant, forcing a significant amount of ILs into a separated liquid phase. Zhang et al. ${ }^{129} \mathrm{com}-$ plemented that in the $\left[\mathrm{C}_{4} \mathrm{mim}\right]\left[\mathrm{PF}_{6}\right] / \mathrm{methanol} / \mathrm{CO}_{2}$ system, increasing the $\mathrm{CO}_{2}$ pressure and decreasing the temperature could enhance the separation of IL from methanol. Scurto et al. ${ }^{50}$ pointed out the introduction of gaseous or liquid $\mathrm{CO}_{2}$ could be favourable to the separation of both the hydrophobic $\left(\left[\mathrm{C}_{4} \mathrm{mim}\right]\left[\mathrm{PF}_{6}\right]\right.$ and 1-propyl-2,3-dimethylimidazolium bis(trifluoromethylsulfonylimide) ([PDmim] $\left.\left[\mathrm{Tf}_{2} \mathrm{~N}\right]\right)$ ), and the hydrophilic $\left(\left[\mathrm{C}_{4} \mathrm{mim}\right]\left[\mathrm{BF}_{4}\right]\right.$ and $\left.\left[\mathrm{C}_{4} \mathrm{mim}\right][\mathrm{TfO}]\right)$ ILs from aqueous solutions. As shown in Fig. 7, at low $\mathrm{CO}_{2}$ pressure, mixture of IL and water presented as one homogeneous phase. As the pressure of $\mathrm{CO}_{2}$ increased, two liquid phases could appear. The lower liquid phase was rich in IL, the middle liquid phase was rich in water while the upper phase was mostly $\mathrm{CO}_{2}$ with a small amount of dissolved water. However, it was difficult to achieve an IL-rich phase with more than $75.63 \mathrm{wt} \%$ of IL because this phase still contained water and $\mathrm{CO}_{2}$ even at high pressure of $20 \mathrm{MPa}^{130}$

\subsection{Adsorption}

Adsorption has been utilized as a robust and non-destructive method to promote recovery or removal of ILs. Up to date, a variety of adsorbents, such as activated carbons, soils and sediments, ion exchange resins and biosorbents, etc., have been investigated.

2.3.1. Adsorption by activated carbons. Activated carbons (ACs) are commonly used adsorbents to remove organics from water or gas. Recently, they have been employed for the removal or recovery of various ILs from aqueous solution. ${ }^{21,48,55,70,131-137}$ Anthony et al. ${ }^{21}$ firstly put forward the use of ACs for the removal of $\left[\mathrm{C}_{4} \mathrm{mim}\right]\left[\mathrm{PF}_{6}\right]$ from wastewater. Afterwards, the adsorption of ILs onto ACs was further investigated from different aspects.

Effect of ILs structure. The adsorption efficiency is highly dependent on ILs structures, i.e., cation, chain length, and anion of ILs. Palomar et al. ${ }^{70}$ investigated the separation of a series of 1-butyl-3-methylimidazolium ILs with different anions from aqueous solution using a commercial AC (AC$\mathrm{MkU}$ ). The adsorption capacity of adsorbents to ILs varied from 0.1 to $1 \mathrm{mmol} \mathrm{g}^{-1}$, following the order of hydrophobicity of the ILs anions $\left[\mathrm{Tf}_{2} \mathrm{~N}\right]^{-}>\left[\mathrm{PF}_{6}\right]^{-}>[\mathrm{TfO}]^{-}>\left[\mathrm{BF}_{4}\right]^{-}>[\mathrm{TFA}]^{-}>[\mathrm{Cl}]^{-}$. Similar result was also obtained by Lemus et al. ${ }^{48}$ who examined the adsorption of the 1-alkyl-3-methylimidazolium based ILs at molecular level using COSMO-RS method. Ushiki et al. ${ }^{137}$ investigated the adsorption of three ILs with different alkyl chain length $\left(\left[\mathrm{C}_{8} \mathrm{mim}\right][\mathrm{Cl}],\left[\mathrm{C}_{6} \mathrm{mim}\right][\mathrm{Cl}]\right.$ and $\left.\left[\mathrm{C}_{4} \mathrm{mim}\right][\mathrm{Cl}]\right)$ onto AC. It was observed that when increasing the length of alkyl chains, the adsorption efficiency was also found to be improved, which was consistent with those of Farooq et al..$^{55}$ and Lemus et al. ${ }^{132}$ Moreover, with respect to the cation families, uptake of ILs was enhanced in the sequence: ammonium $>$ phosphonium $>$ pyridinium $>$ imidazolium $>$ pyrrolidinium $>$ piperidinium, ${ }^{132}$ which was in consistent with the content of unsaturated bond in the carbon. ${ }^{134}$
Effect of properties of ACs. In addition to the chemical structures of ILs, the adsorption of ILs was also highly dependent on the porous structure and surface chemistry of ACs. Lemus et al. ${ }^{48}$ found that the ACs with micropore and narrow mesopore (with high content of pore lower than $8 \mathrm{~nm}$ ) presented the highest adsorption capacity for 1-octyl-3-methylimidazolium hexafluorophosphate $\left(\left[\mathrm{C}_{8} \mathrm{mim}\right]\left[\mathrm{PF}_{6}\right]\right)$, with the maximum uptake of up to $1 \mathrm{~g}$ IL per gram of the adsorbent. Likewise, Jesús ${ }^{136}$ observed similar result that the adsorption capacity of $\mathrm{AC}$ for $\left[\mathrm{C}_{8} \mathrm{mim}\right]\left[\mathrm{PF}_{6}\right]$ was closely related to the available narrow mesopores within the size range from 2 to $8 \mathrm{~nm}$. According to the findings from Farooq et al.'s work, ${ }^{55}$ it was found that the ILs with length $<1.5 \mathrm{~nm}$ and thickness $<0.2 \mathrm{~nm}\left(e . g\right.$. , [ $\left.\mathrm{C}_{8} \mathrm{mim}\right][\mathrm{Cl}]$, $\left[\mathrm{C}_{4} \mathrm{mim}\right][\mathrm{Cl}]$ and $\left.\left[\left[\mathrm{C}_{8}-\mathrm{py}\right]\right][\mathrm{Br}]\right)$ were preferentially adsorbed in the ultramicropores, and partially adsorbed in the supermicropores and mesopores of ACs. In addition, the adsorption of hydrophilic ILs could be enhanced by introducing oxygenated groups on the ACs surface. Conversely, the hydrophobic ILs were more effectively removed by the thermally treated ACs with lower polarity of surface..$^{55,70}$

Effect of solution chemistry. Generally, the uptake of imidazolium based ILs could be improved when the $\mathrm{pH}$ is increased..$^{55,135}$ In basic media, the hydroxyl ions tend to be adsorbed at the ACs interface and deprotonate the surface, thus allowing the surface to become negatively charged. Consequently, the adsorption of ILs was facilitated owing to the increase of electrostatic binding sites for IL cations. ${ }^{138}$ The adsorption of ILs on the ACs is also found to be highly dependent on the salinity of the solution. Neves et al. ${ }^{133}$ observed that the addition of $\mathrm{Na}_{2} \mathrm{SO}_{4}$ salt in solution could improve the adsorption of ILs onto ACs, particularly for the hydrophilic ILs (e.g., $\left[\mathrm{C}_{4} \mathrm{mim}\right][\mathrm{Cl}]$ and $\left[\mathrm{C}_{4} \mathrm{mim}\right][\mathrm{TfO}]$ ) that were poorly removed by ACs. This is because that the formation of salt-ion-hydration complexes reduced the solubility of ILs in water and therefore favoured the partition of ILs onto the ACs.

2.3.2. Adsorption by soils and sediments. It has been found that the ILs can be adsorbed by soils and sediments after their release to the environment. This phenomenon has attracted much attention from researchers who have devoted to investigating the adsorption behaviors of ILs onto soils ${ }^{47,139-145}$ and sediments. ${ }^{140,146}$ Gorman-Lewis et al. ${ }^{139}$ tested the adsorption feasibility of $\left[\mathrm{C}_{4} \mathrm{mim}\right][\mathrm{Cl}]$ by a range of bacterial and mineral species. In contrast to the Bacillus subtilis, the gibbsite and the quartz, the smectite clay (Na-montmorillonite) was the only one to show significant adsorption for $\left[\mathrm{C}_{4} \mathrm{mim}\right][\mathrm{Cl}]$ under the conditions in their study. Nearly $80 \%$ of IL was adsorbed onto the montmorillonite $\left(2.0 \mathrm{~g} \mathrm{~L}^{-1}\right)$ at an ionic strength of $10^{-4} \mathrm{M}$ agitated for $3 \mathrm{~h}$. The mechanistic study showed that the adsorption of $\left[\mathrm{C}_{4} \mathrm{mim}\right][\mathrm{Cl}]$ on the clay surface is ascribed to the interlayer cation exchange and/or the electrostatic interactions from the permanent charge on the clay. The Bacillus subtilis is a kind of Gram-positive soil bacterial species. It has carboxyl, phosphoryl, and hydroxyl functional groups on the surface. As the $\mathrm{pH}$ increases, these sites deprotonate and create a negatively charged surface. The author pointed out that the low adsorption of IL onto the Bacillus subtilis was due to the insignificant 
electrostatic attraction and the hydrophobic interaction between the IL and the bacterial surface. Similarly, the adsorption of ionic liquids on the soils and sediments is also found to be IL type- and soil type-dependent.

Effect of ILs structure. Stepnowski et al. ${ }^{47}$ tested the adsorption of three ILs ([ $\left.\mathrm{C}_{4} \mathrm{mim}\right][\mathrm{Cl}]$, 1-hexyl-3-methylimidazolium chloride $\left(\left[\mathrm{C}_{6} \mathrm{mim}\right][\mathrm{Cl}]\right)$ and 1-butyl-4-methylpyridinium chloride $\left(\left[\mathrm{C}_{4}-4\right.\right.$ $\mathrm{mPy}][\mathrm{Cl}])$ ) onto the selected natural soils. They found that the uptake of ILs by the soil was increased as the increase of the length of the alkyl chain, showing that the hydrophobicity of cation exerts significant influence on the sorption efficiency. This result also suggests that the adsorption of ILs is mainly ascribed to the van der Waals interactions between the nonpolar groups of the IL cations and the organic matter of soils and sediments. This was in accordance with the results obtained by Matzke et al. ${ }^{\mathbf{1 4 2}}$ However, the adsorption amounts of ILs on Na-montmorillonite were evidenced to be decreased in the order $\left[\mathrm{C}_{4}-\mathrm{py}\right][\mathrm{Br}]>\left[\mathrm{C}_{8}-\mathrm{Py}\right][\mathrm{Br}] \sim[\mathrm{Amim}][\mathrm{Cl}] \sim\left[\mathrm{C}_{4} \mathrm{mim}\right] \mathrm{Cl}>$ $\left[\mathrm{C}_{8} \mathrm{mim}\right][\mathrm{Cl}] .{ }^{\mathbf{1 4 4}}$ The highest adsorption capacity was obtained for $\left[\mathrm{C}_{4}-\mathrm{py}\right][\mathrm{Br}](96 \mathrm{mmol} / 100 \mathrm{~g})$ and the lowest one for $\left[\mathrm{C}_{8} \mathrm{mim}\right]$ [Cl] $(72 \mathrm{mmol} / 100 \mathrm{~g})$. Beaulieu et al. ${ }^{\mathbf{1 4 6}}$ found that increasing alkyl chain length did not lead to increased sorption of ILs to four types of aquatic sediments. They postulated this might be due to the fact that hydrophobic interactions were not the dominant adsorption mechanism.

Effect of properties of adsorbents. Physicochemical properties of the soils and sediments such as total organic carbon (TOC), cation exchange capacity (CEC) and clay minerals also play significant roles in the uptake of ILs. Studzinska et al. ${ }^{\mathbf{1 4 1}}$ found that the sorption capacity of imidazolium based ILs was positively related to the total organic carbon (TOC) content in soils. Mrozik et al. ${ }^{143}$ tested the adsorption of nine ILs (imidazolium and pyridinium chlorides) on 11 types of soils. Through chemometric study, it was found that the main soil parameter responsible for the sorption was cation exchange capacity (CEC). Matzke et al. ${ }^{\mathbf{1 4 2}}$ investigated the influence of mineral type (kaolinite and smectite) on the cation sorption and desorption behaviors of three imidazolium based ILs $\left(\left[\mathrm{C}_{4} \mathrm{mim}\right]\left[\mathrm{BF}_{4}\right]\right.$, $\left[\mathrm{C}_{8} \mathrm{mim}\right]\left[\mathrm{BF}_{4}\right]$ and $\left[\mathrm{C}_{4} \mathrm{mim}\right]\left[\mathrm{Tf}_{2} \mathrm{~N}\right]$ ) in a reference soil (Lufa 2.2). They observed that the addition of clays could facilitate the sorption but decrease the desorption for all tested ILs. Particularly, the smectite was found to be stronger than kaolinite in adsorbing ILs. This is because the smectite possesses higher specific surface and higher negative surface charge.

2.3.3. Adsorption by ion exchange resins. Ion exchange resins have been widely used in various fields such as waste water treatment ${ }^{\mathbf{1 4 7}}$ and catalytic reaction. ${ }^{\mathbf{1 4 8}}$ As early as 2001, Anthony et $a .^{21}$ postulated that a combined anionic and cationic ion exchange resin would perform better than activated carbon for the adsorption of $\left[\mathrm{C}_{4} \mathrm{mim}\right]\left[\mathrm{PF}_{6}\right]$. Subsequently, Vijayaraghavan et al. ${ }^{149}$ evaluated the sorption of $\left[\mathrm{C}_{4} \mathrm{mim}\right][\mathrm{Cl}]$ onto different adsorbents, i.e., two ACs, an ion exchange resin (Amberlite IRN-150), a dried activated sludge as well as a fermentation waste. Higher uptake $\left(179.4 \mathrm{mg} \mathrm{g}^{-1}\right)$ of the IL was obtained with the adsorption by the ion exchange resin than that by the two ACs. While little ionic liquids were found to be adsorbed on the activated sludge and fermentation waste.
Binder et al. ${ }^{150}$ utilized a cation exchange resin (Dowex®50WX4) for separation of $\left[\mathrm{C}_{2} \mathrm{mim}\right][\mathrm{Cl}]$ from corn stover hydrolysis mixture. The $\mathrm{H}^{+}$ions in resin were totally exchanged with cationic part of $\left[\mathrm{C}_{2} \mathrm{mim}\right][\mathrm{Cl}]$. Then the $\left[\mathrm{C}_{2} \mathrm{mim}\right]$-exchanged resin was used as stationary phase in an ion exclusion liquid chromatography, where $\left[\mathrm{C}_{2} \mathrm{mim}\right][\mathrm{Cl}]$ in the mixture was excluded from the resin, while the sugars (glucose and xylose) were retained. Subsequently, Mai et al. ${ }^{151}$ implemented this method in ion exclusion simulated moving bed (SMB) chromatography for continuous recovery of glucose, xylose and $\left[\mathrm{C}_{2} \mathrm{mim}\right][\mathrm{Ac}]$ (with recovery ratio of $71.38,99.37$ and $98.92 \%$, respectively) from biomass hydrolyzate.

Effect of ILs structure. Influence of the chemical structures of imidazolium based ILs on the adsorption behavior onto ion exchange resins was studied by $\mathrm{Li}$ et $a l .{ }^{\mathbf{1 5 2}}$ It is found that the adsorption of ILs on resins was almost independent on the anions $\left([\mathrm{Cl}]^{-},\left[\mathrm{PF}_{6}\right]^{-}\right.$and $\left.\left[\mathrm{Tf}_{2} \mathrm{~N}\right]^{-}\right)$of the ILs. However, increasing the length of alkyl chains was observed to facilitate the adsorption of ILs on the resins. They believed that this adsorption was attributed to the high attractive van der Waals and polar interactions between the ILs and the resins.

Effect of characteristics of resins. Characteristics of resins, such as functional groups, crosslinking degree and ionic form, etc., may influence the adsorption of ILs. Choi et al. ${ }^{153}$ tested twelve ion exchange resins with different functional groups (i.e., thiourea, iminodiacetic acid, amino phosphonic acid, carboxylic acid and sulfonic acid) in recovering 1-ethyl-3methylimidazolium acetate $\left(\left[\mathrm{C}_{2} \mathrm{mim}\right][\mathrm{Ac}]\right)$. During the adsorption process, the cations of ILs were exchanged with the $\mathrm{H}^{+}$ions and adsorbed onto the resin, while the anions of IL were remained in the aqueous solution without being adsorbed. It was found that the highest uptake (578.2-616.2 $\mathrm{mg} \mathrm{g}^{-1}$ ) of $\left[\mathrm{C}_{2} \mathrm{mim}\right]$ was obtained by sulfonic acid resins (e.g., Amberlite IR120, Dowex HCR-W2, Dowex 50WX8-400, etc.). Similarly, He et $a .^{61}$ used five ion exchange resins for the recovery of benzothiazolium ILs. The strong acidic ion exchange resin $(732(\mathrm{H}))$ with sulfonic acid showed the highest adsorption capacity of over $310 \mathrm{mg} \mathrm{g}^{-1}$ for all the three tested ILs. What's more, the particle size and crosslinking degree of resins exerted slight influence on the adsorption performance. ${ }^{153} \mathrm{He}$ et al. ${ }^{61}$ also supplemented that the resin in $\mathrm{H}^{+}$form possessed greater adsorption capacity than that in $\mathrm{Na}^{+}$form. The resin with gel type performed better than that of microporous type.

Regeneration and reuse of resins. Regeneration of ion exchange resins is crucial for efficient recovery of the adsorbed ILs and reuse of the resins. Ma et al. ${ }^{154}$ proposed a two solid-phase recycling method for the recovery of $\left[\mathrm{C}_{4} \mathrm{mim}\right][\mathrm{Ac}]$ from Schisandra chinensis fruits extract by macroporous resin (HPD 5000) and ion exchange resin (SK1B). The exhausted ion exchange resin was eluted with $2.0 \mathrm{M} \mathrm{HCl}$ followed by $2.0 \mathrm{M}$ $\mathrm{NaOH}$ and finally with distilled water, in which way the resin was regenerated and converted to its initial $\mathrm{Na}^{+}$type. He et al. ${ }^{\mathbf{1}}$ screened different desorbents to improve the desorption performance of ion exchange resin (732) that was loaded with benzothiazolium IL ([HBth][TfO]). It indicated that the 732 resin could be reused for at least three times when using $\mathrm{HCl}-\mathrm{EtOH}-$ $\mathrm{H}_{2} \mathrm{O}$ mixture solution $(18: 8: 74, \mathrm{v} / \mathrm{v} / \mathrm{v})$. There was no obvious 


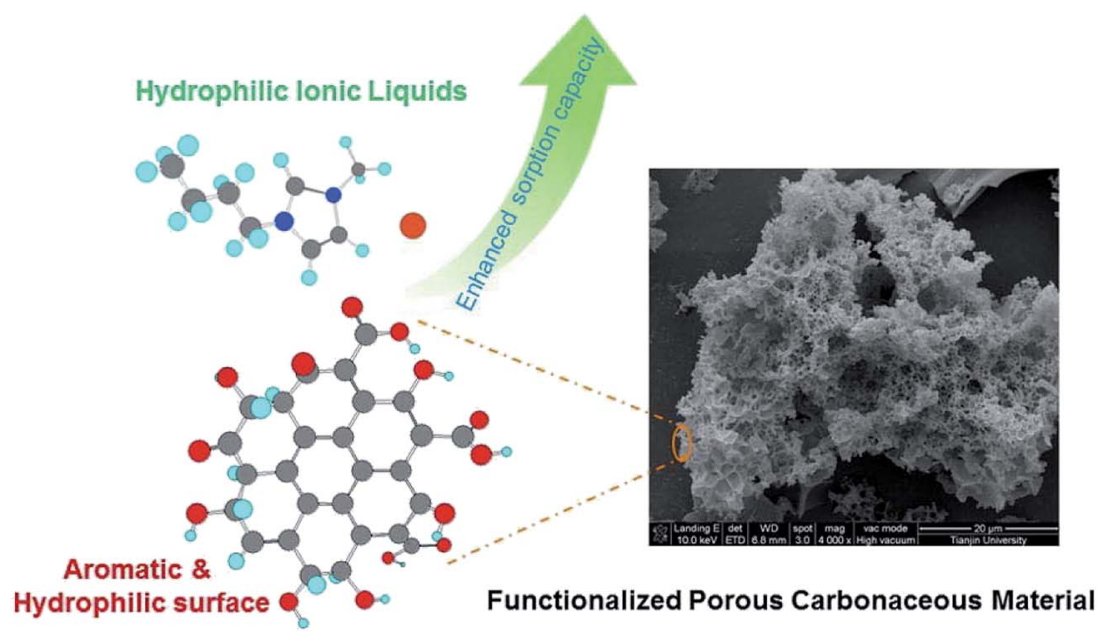

Fig. 8 Enhanced sorption of hydrophilic ionic liquids from aqueous solution on functionalized porous carbonaceous material. Reproduced with permission from ref. 156. Copyright 2014 Elsevier Ltd.

change in the composition and cation structure of IL after the third recycling. However, there exists a change in the anions of IL during the adsorption-desorption cycle. In other words, during the adsorption, cations are adsorbed onto the resin, but the anions of IL are still remained in the solution. During the subsequent desorption process, the adsorbed cations are exchanged by the $\mathrm{Na}^{+}$or $\mathrm{H}^{+}$ions and desorbed into new solution. In this way, another IL that is consisted of original cations and anions of the desorbents is obtained, which presents an inherent drawback of this method.

2.3.4. Adsorption by other adsorbents. In addition to the above three main types of adsorbents, other adsorbents such as carbonaceous materials, bacterial biosorbents and biochars have also been applied for the recovery or removal of ILs.

Carbonaceous materials. The carbonaceous function material loaded with carboxylic groups, which was prepared by hydrothermal carbonization of cellulose in the presence of acrylic acid, was used to recover $\left[\mathrm{C}_{4} \mathrm{mim}\right][\mathrm{Cl}]$ from aqueous solution. ${ }^{155}$ In spite of being low surface area of $20 \mathrm{~m}^{2} \mathrm{~g}^{-1}$, the prepared carbonaceous microspheres exhibited adsorption capacity $\left(0.171 \mathrm{mmol} \mathrm{g}^{-1}\right)$ comparable to that of commercial ACs with high surface area of $980 \mathrm{~m}^{2} \mathrm{~g}^{-1}\left(0.206 \mathrm{mmol} \mathrm{g}^{-1}\right)$. The microspheric particles could be regenerated by $\mathrm{HCl}$ aqueous solution for at least 3 times without losing their adsorption capacity. Later, to obtain carbon materials that possess both large surface area and a high number of oxygenated groups, Qi et al. ${ }^{156}$ synthesized the carbonaceous microsphere materials by chemically modified with $\mathrm{KOH}$ to increase the porosity, surface area and oxygen content (Fig. 8). The chemically modified carbonaceous microsphere showed efficient adsorption capacity $\left(0.294 \mathrm{mmol} \mathrm{g}^{-1}\right)$ for hydrophilic IL $\left(\left[\mathrm{C}_{4} \mathrm{mim}\right][\mathrm{Br}]\right)$ due to the increased polar oxygenated surface groups. Similarly, the zeolite-templated carbon (ZTC) was also synthesized which showed higher adsorption capacity $\left(3.40 \mathrm{mmol} \mathrm{g}^{-1}\right)$ for long alkyl-chained IL, i.e., 1-hexadecyl-3-methylimidazolium chloride $\left(\left[\mathrm{C}_{16} \mathrm{mim}\right][\mathrm{Cl}]\right) .{ }^{49}$ Zhang et al. ${ }^{29}$ reported the preparation of an ordered mesoporous carbon (OMC) modified by oxidation with nitric acid. This OMC was used to remove the hydrophilic IL $\left(\left[\mathrm{C}_{4} \mathrm{mim}\right][\mathrm{Cl}]\right)$ from water. The IL-loaded OMC was regenerated by mixing with $100 \mathrm{~mL}$ of $0.01 \mathrm{M} \mathrm{HCl}$ solution for $12 \mathrm{~h}$ and exhibited stable adsorption behavior within five consecutive adsorption-desorption cycles.

Biosorbents. Biosorbents mainly include bacteria, fungi, algae, industrial wastes, agricultural wastes and other polysaccharide materials. ${ }^{157}$ During the past years, the biochars which are derived from industrial and agricultural wastes have been suggested as potential ILs adsorbents. Shi et al. ${ }^{158}$ conducted the adsorption of imidazolium-type ILs onto two biochars derived from straw and wood (denoted as SBB and WBB, respectively). The adsorption of ILs on SBB and WBB was found to be $\mathrm{pH}$-dependent and could be promoted by trivalent anions $\left(\mathrm{PO}_{4}{ }^{3-}\right)$. Basically, the biochars could be regenerated using $\mathrm{HCl}$ solution. Yu et al. ${ }^{159}$ produced modified biochars from agricultural wastes, such as peanut shell, corn stalk and wheat straw (denoted as PB-K-N, CB-K-N and WB-K-N) to remove [ $\mathrm{C}_{4} \mathrm{mim}$ ] [Cl]. Their results showed that the adsorption capacity decreased in the order of PB-KN $>$ CB-K-N $>$ WB-K-N, which was in accordance with the order of total acidic functional groups of

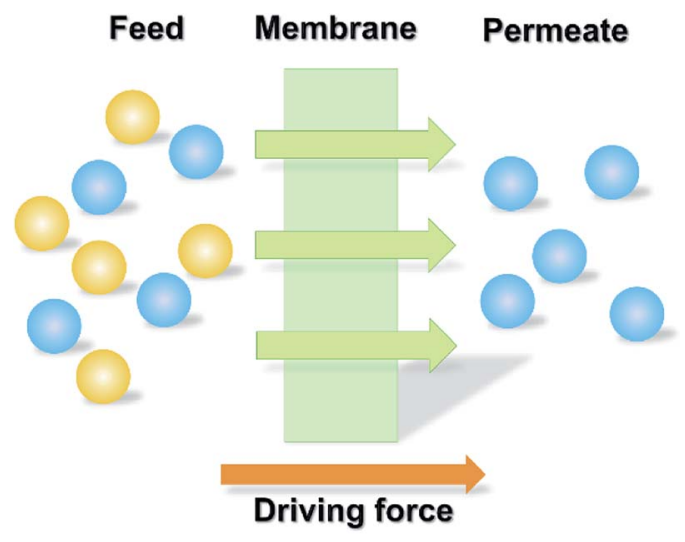

Fig. 9 Selective permeability of the membranes. 


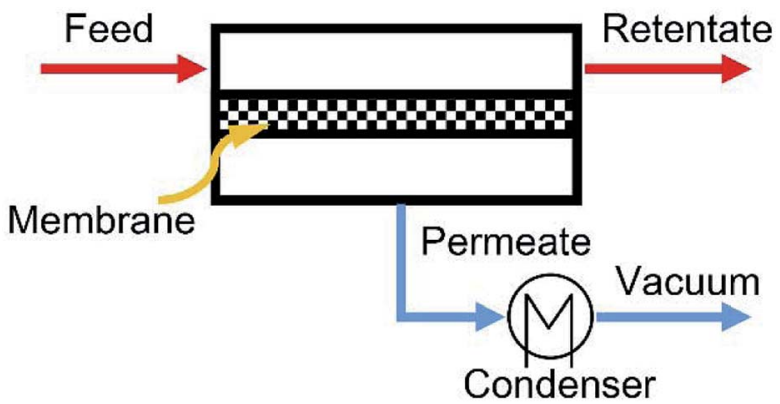

Fig. 10 Schematic diagram of pervaporation process. Reproduced with permission from ref. 170. Copyright 2016 Elsevier Ltd.

these modified biochars. Subsequently, Yu et al. ${ }^{160}$ compared the adsorption of $\left[\mathrm{C}_{4} \mathrm{mim}\right][\mathrm{Cl}]$ on two biochar adsorbents derived from bamboo, i.e., intermediate biochar (BB-K) being pyrolyzed and modified biochar (BB-K-N) being pyrolyzed and oxidized. Among them, the modified biochar (BB-K-N) which had abundant micropores, high specific surface area and oxygen-containing functional groups showed superior adsorption capacity of $0.625 \mathrm{mmol} \mathrm{g}^{-1}$ for $\left[\mathrm{C}_{4} \mathrm{mim}\right][\mathrm{Cl}], 38.3 \%$ higher than that on BB-K. In addition, the bacterial biosorbents have also been investigated for recovery of ILs. Won et al. ${ }^{161}$ employed five types of bacterial biosorbents for the removal of $\left[\mathrm{C}_{2} \mathrm{mim}\right]$ [Ac] from aqueous media. The best result was obtained with Escherichia coli biomass, with a maximum uptake of $72.6 \mathrm{mg} \mathrm{g}^{-1}$ at $\mathrm{pH} 7$ within $10 \mathrm{~min}$. Moreover, more than $91.3 \%$ of $\left[\mathrm{C}_{2} \mathrm{mim}\right]$ cations could be readily desorbed from the biosorbent by being contacted with $99.7 \%$ pure acetic acid solution.

\subsection{Membrane separation}

During the past few years, membrane processes have been widely used for the recovery and purification of substances taking advantage of the selective permeability of the membranes (Fig. 9). ${ }^{162,163}$ For the recovery of ILs, the membranebased methodology has also been employed owing to its relatively low energy consumption and simple operation.

2.4.1. Pressure-driven membrane techniques. Pressuredriven membrane techniques such as microfiltration (MF) ${ }^{164}$ nanofiltration $(\mathrm{NF})^{30,56,72,75,165,166}$ and reverse osmosis $(\mathrm{RO})^{167}$ have been reported to be promising methods for the separation of ILs, among which the nanofiltration is one of the most studied processes. Nanofiltration membranes can isolate charged and neutral compounds, or mono- and divalent ions. ${ }^{168}$ The ILs can be either permeated through the membrane or retained on the feed side of the membrane. Kröckel et al. ${ }^{30}$ used a nanofiltration membrane (Desal DVA 00) to separate the $\left[\mathrm{C}_{4} \mathrm{mim}\right]\left[\mathrm{BF}_{4}\right]$ and bromophenol blue in aqueous solution, as well as the separation of 1,3-dimethylimidazolium methylsulfate ([Mmim][MS]) from lactose. In both cases, the ILs penetrated through the membrane. The retention of the dye and the lactose was $99 \%$ and almost $98 \%$ respectively. In another study performed by Han et al. ${ }^{75}$ two ILs (tetradecyl (trihexyl) phosphonium chloride (CYPHOS IL 101) and PEG-5 cocomonium methylsulfate (ECOENG500)) were rejected by nanofiltration membranes (STARMEMTM 120 and 122). It was found that over $95 \%$ of ILs were remained at the feed side of the nanofiltration membrane.

Operation conditions such as the feed concentration and pressure for the nanofiltration process have been investigated. Abels et al. ${ }^{72}$ used two commercially polyamide (Desal DK and Desal DL) and one polyimide (Starmem 240) membrane to separate saccharides and 1,3-dimethylimidazolium dimethylphosphate ([Mmim][DMP]) of various feed concentrations. The IL was permeated while saccharides were retained by the membranes. However, for all three tested membranes, it was found that a severe decline of permeate flux happened at higher concentrations of IL. This was ascribed to the occurrence of high osmotic pressures, resulting in low permeation of the ILs. Nevertheless, it was feasible to recover IL with purity of $80 \%$ by using both polyamide and polyimide membranes. The effect of applied pressure gradient on the rejection of IL (i.e., 1-butyl-3methylpyridinium tetrafluoroborate $\left.\left(\left[\mathrm{C}_{4}-3-\mathrm{mpy}\right]\left[\mathrm{BF}_{4}\right]\right)\right)$ by nanofiltration membrane (NF 270-400) was studied by Hazarika et al. ${ }^{56}$ The solution flux was found to be increased with the applied pressure. More than $50 \%$ rejection of IL was obtained eventually. Similarly, when using two nanofiltration membranes (NF90 and NF27) to concentrate [Amim][Cl], $\left[\mathrm{C}_{4} \mathrm{mim}\right][\mathrm{Cl}]$ and $\left[\mathrm{C}_{4} \mathrm{mim}\right]\left[\mathrm{BF}_{4}\right]$ in the $\mathrm{IL}-\mathrm{H}_{2} \mathrm{O}$ system, ${ }^{\mathbf{1 6 6}}$ the permeate flux was found to be improved with the increased applied pressure. For the two membranes, the retention of IL was decreased in the order of: $\left[\mathrm{C}_{4} \mathrm{mim}\right][\mathrm{Cl}]>\left[\mathrm{C}_{4} \mathrm{mim}\right]\left[\mathrm{BF}_{4}\right]>[\mathrm{Amim}]$ $[\mathrm{Cl}]$, which was inversely proportion to the IL diffusion coefficients in water. The $\left[\mathrm{C}_{4} \mathrm{mim}\right][\mathrm{Cl}]$ could be concentrated from its

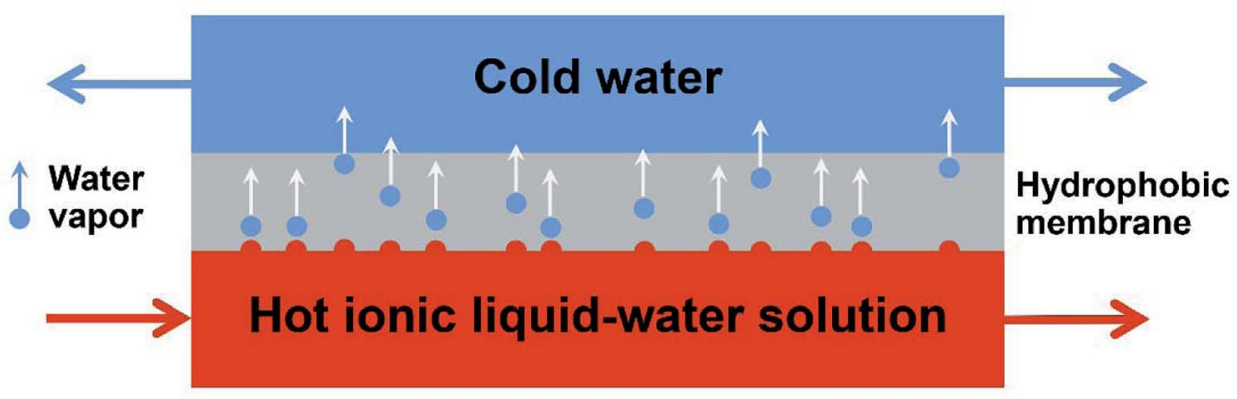

Fig. 11 Direct contact membrane distillation process. Reproduced with permission from ref. 68. Copyright 2015 Elsevier Ltd. 
initial content of $5 \mathrm{wt} \%$ to $18.85 \mathrm{wt} \%$ using NF90, resulting in a recovery ratio of about $96 \%$.

In the study of Haerens et al., ${ }^{167}$ two reverse osmosis membranes (FilmTec 102326 and FilmTec BW30XLE) and three nanofiltration membranes (FilmTec NF90, FilmTec NF207 and DK) were used to concentrate 5 vol\% Ethaline200 (a deep eutectic solvent which was prepared by mixing choline chloride and ethylene glycol in the ratio of $1: 2$ ) aqueous solution. They found that the rejection of Ethaline 200 by FilmTec NF90 and FilmTec NF207 membranes was very low $(<20 \%)$. The Desal DK, FilmTec BW30XLE and FilmTec 102326 membranes retained $88.0 \%, 90.5 \%$ and $91.1 \%$ of the IL respectively. After the separation, the maximum concentration of Ethaline200 was 30 vol\%. Haerens et $a .^{167}$ pointed out that the method mentioned above could be used as a preconcentration process for other separation techniques which require a concentrated IL solution.

2.4.2. Pervaporation. Generally, the pervaporation (PV) process works as: the membrane downstream side is maintained under vacuum, while the membrane upstream side which is in contact with the liquid feed is kept at ambient pressure. The volatile solute is preferentially partitioned into a dense, non-porous membrane, the driving force of which is the chemical potential gradient (Fig. 10). ${ }^{\mathbf{1 6 9 , 1 7 0}}$ The pervaporation has been attempted to separate ILs from mixtures. ${ }^{\mathbf{1 7 1} 172}$

The first application of pervaporation for the selective removal of volatile substances from ILs was reported by Schäfer and coworkers. ${ }^{171}$ They tested different hydrophilic and hydrophobic polymeric membranes, i.e., poly(octylmethyl-siloxane) (POMS), polyether block amide (PEBA) and poly(vinyl alcohol) (PVA) to recover volatile solutes from $\left[\mathrm{C}_{4} \mathrm{mim}\right]\left[\mathrm{PF}_{6}\right]$, with recovery efficiency of $99.2 \%$ for all solutes tested. Sun et al. ${ }^{172}$ evaluated a commercially available pervaporation system for dehydration and recycling of $\left[\mathrm{C}_{2} \mathrm{mim}\right][\mathrm{Ac}]$ which was used for lignocellulosic pretreatment. The separation factor (defined as eqn (2)) as high as 1500 was observed, resulting in over $99.9 \mathrm{wt} \%$ recovery of $\left[\mathrm{C}_{2} \mathrm{mim}\right][\mathrm{Ac}]$ from aqueous solution.

$$
\mathrm{SF}_{\mathrm{w}-\mathrm{IL}}=\frac{X_{\mathrm{w}, \mathrm{P}} / X_{\mathrm{IL}, \mathrm{P}}}{X_{\mathrm{w}, \mathrm{F}} / X_{\mathrm{IL}, \mathrm{F}}}
$$

where $\mathrm{SF}_{\mathrm{w}-\mathrm{IL}}$ denotes $\mathrm{H}_{2} \mathrm{O}$-IL separation factor; $X_{\mathrm{w}, \mathrm{P}}$ is mass fraction of $\mathrm{H}_{2} \mathrm{O}$ in the permeate side; $X_{\mathrm{IL}, \mathrm{P}}$ stands for mass fraction of IL in the permeate side; $X_{\mathrm{w}, \mathrm{F}}$ refers to mass fraction of $\mathrm{H}_{2} \mathrm{O}$ in the feed; $X_{\mathrm{IL}, \mathrm{F}}$ represents mass fraction of IL in the feed.

2.4.3. Membrane distillation. Membrane distillation (MD) is a kind of thermally driven membrane technique for removing water vapor from salts or other non-volatile components. During the MD process, a hydrophobic and porous membrane is applied. The hydrophobic membrane displays a barrier for polar solvents of the liquid phase such as water, while the vapor phase (e.g., water vapor) is still allowed to pass through the membrane.

The MD operation can be divided into four classes: (i) direct contact membrane distillation (DCMD), (ii) air-gap membrane distillation (AGMD), (iii) sweep gas membrane distillation (SGMD) and (iv) vacuum membrane distillation (VMD). The DCMD has been used for concentration of ILs from aqueous solution recently. ${ }^{68,173,174}$ The driving force of DCMD is the difference in the vapor pressure of a solution at different temperatures. ${ }^{175}$ During the DCMD process, the mixed feed solution is heated to a higher temperature than that in the permeate solution on the opposite side of the membrane. The hot water vapor molecules pass through the membrane and are

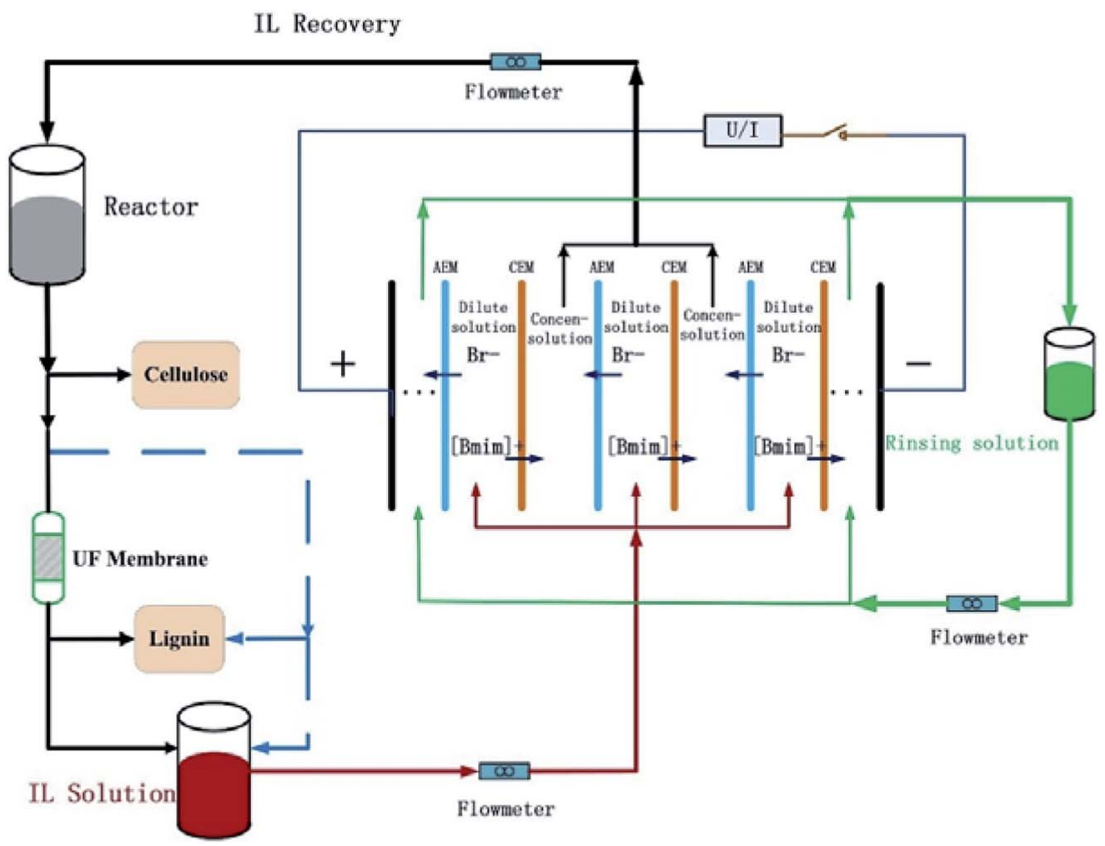

Fig. 12 Procedure for IL-based biomass fractionation and IL recovery via the hybrid of electrodialysis with ultrafiltration. Reproduced with permission from ref. 179. Copyright 2015 Elsevier Ltd. 
condensed on the distillate side, while the salt or other contaminant ions are remained on the feed side (Fig. 11). The primary application of membrane distillation to concentrate ILs aqueous solution was reported by Lynam et al. ${ }^{68}$ Two ILs $\left(\left[\mathrm{C}_{2} \mathrm{mim}\right][\mathrm{Ac}]\right.$ and 1-ethyl-3-methylimidazolium formate $\left(\left[\mathrm{C}_{2} \mathrm{mim}\right]\left[\mathrm{O}_{2} \mathrm{CH}\right]\right)$ ) were concentrated from $5 \mathrm{wt} \%$ to $50 \mathrm{wt} \%$. Subsequently, another technique, VMD, was proposed by $\mathrm{Wu}$ et $a l .{ }^{173}$ to separate and concentrate the aqueous solution of $\left[\mathrm{C}_{4} \mathrm{mim}\right][\mathrm{Cl}]$. In their work, a polyacrylonitrile-based (PANbased) hydrophobic membrane was prepared and utilized. A final IL concentration of $65.5 \mathrm{wt} \%$ with a total recovery over 99.5\% was achieved. However, they found that due to the high viscosity and high polarity of hydrophilic ILs, membrane fouling would happen during the membrane distillation process, which is an essential issue to be investigated. After careful tests, $\mathrm{Wu}$ et al. ${ }^{\mathbf{1 7 3}}$ pointed out possible membrane fouling mechanisms, including the $\left[\mathrm{C}_{4} \mathrm{mim}\right][\mathrm{Cl}]$ deposition, the top layer wetting and the internal pore wetting. The deposited foulants could be removed readily by water flushing. However, once the wetting happened, it was difficult to realize a complete cleaning for the wetted membrane. Further research by the same group revealed that the chemical properties of membrane surface exerted more significant impact on membrane fouling than the surface morphology. ${ }^{\mathbf{1 7 4}}$

2.4.4. Electrodialysis. With ion-exchange membranes as the separation medium and electric potential as the driving force, the electrodialysis (ED) has been employed in many fields. The electrodialysis is composed of dilute and concentrated compartments with alternating cation and anion exchange membranes in a stack. During ED process, cations are preferentially transported through the cation exchange membranes and anions through the anion exchange membranes. As a result, both cations and anions are accumulated in the concentrate compartment. In this way, the salt solution is concentrated. ${ }^{\mathbf{1 7 6}}$

Technically, the electrodialysis could be effective for IL recovery due to the electrolyte nature of IL. ${ }^{176-179}$ Wang et al. ${ }^{177}$ employed electrodialysis to recover $\left[\mathrm{C}_{4} \mathrm{mim}\right][\mathrm{Cl}]$ from water. The highest recovery ratio could reach $85.2 \%$. Trinh et al. ${ }^{176}$ performed the recovery of $\left[\mathrm{C}_{4} \mathrm{mim}\right][\mathrm{Cl}]$ with electrodialysis treatment from the aqueous mixture obtained after cellulose fractionation. Results indicated that the performance of electrodialysis was decreased owing to the deposition of foulants (mainly lignin depolymerization products) on the ion exchange membranes. Considering this fouling phenomenon, Liang et $a l .{ }^{179}$ proposed a hybrid membrane-based methodology of electrodialysis in combination with ultrafiltration to recover the $\left[\mathrm{C}_{4} \mathrm{mim}\right][\mathrm{Br}]$ after biomass fractionation, shown in Fig. 12. Ultrafiltration was employed to remove the residual lignin in IL solutions at first, which could reduce the major pollutant from lignin derivative that would locate at the anion exchange membrane. The highest overall IL recovery ratio reached $75.2 \%$.

\subsection{Aqueous two-phase extraction}

Aqueous two-phase extraction (ATPE) is based on the formation of the aqueous two-phase systems (ATPS), also known as aqueous biphasic systems (ABS). The ATPS could be formed when two immiscible phases (both soluble in water), e.g., polymer/polymer, polymer/salt or salt/salt, etc., are brought into the contact with each other above the critical concentration at a specific temperature. ${ }^{\mathbf{1 8 0}}$ The aqueous two-phase extraction has proven to be a rapid, low-cost and scalable technology for separation and purification of antibiotics, enzymes, therapeutic proteins, etc. ${ }^{\mathbf{1 8 1 - 1 8 3}}$ Through the aqueous two-phase extraction, the ILs aqueous solution could be separated into two phases,

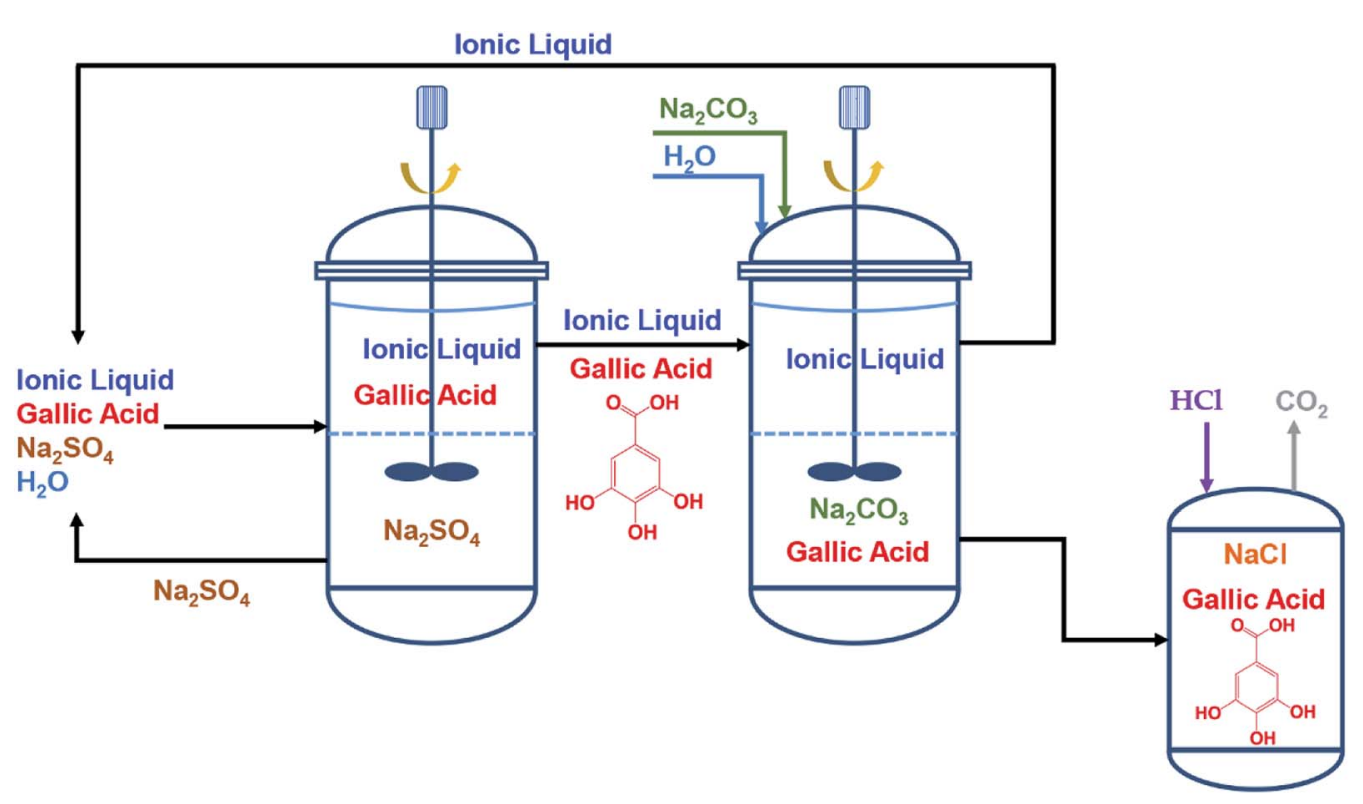

Fig. 13 Flow chart of the two-step approach for a IL-recyclable ATPS extraction of gallic acid: 1 st step - ATPS using $\mathrm{Na}_{2} \mathrm{SO}_{4}$ extracts the biomolecule into the IL-rich phase; 2 nd step - ATPS using $\mathrm{Na}_{2} \mathrm{CO}_{3}$ leads to the back-extraction and recovery of gallic acid from the IL phase. Finally, the IL is regenerated for a subsequent reutilization in a new cycle. Reproduced with permission from ref. 191. Copyright 2014 The Royal Society of Chemistry. 


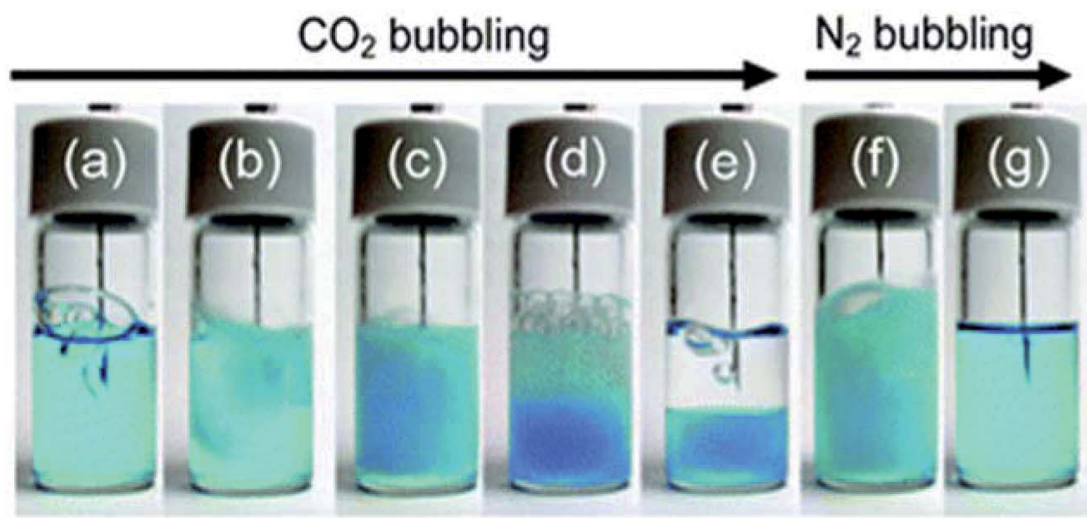

Fig. 14 Phase change of the IL/water mixture driven by $\mathrm{CO}_{2} / \mathrm{N}_{2}$ gas bubbling. $\mathrm{CO}_{2}$ gas was bubbled into the mixture: (a) $\mathrm{CO}_{2}$ gas bubbling just started, (b), (c), (d), and (e) correspond to 1, 2, 3, and 5 min after bubbling, respectively. Then, $\mathrm{N}_{2}$ gas was bubbled for (f) 1 min and (g) 10 min, respectively. IL phase was coloured by Nile blue. All the processes were carried out at $20^{\circ} \mathrm{C}$. The bubbled gas was leaked through another syringe (not seen). Reproduced with permission from ref. 63. Copyright 2011 The Royal Society of Chemistry.

allowing the ILs to be concentrated or recovered in the IL-rich phase. Generally, the two phases could be formed through adding chemicals or changing temperature.

2.5.1. ATPE based on chemicals addition. Preparation of IL-based ATPS was first suggested by Gutowski and coworkers. ${ }^{31}$ With the addition of concentrated solution of potassium phosphate $\left(\mathrm{K}_{3} \mathrm{PO}_{4}\right)$, the $\left[\mathrm{C}_{4} \mathrm{mim}\right][\mathrm{Cl}]$ could be induced to form two aqueous phases. The upper phase was rich in ILs while the lower phase was rich in $\mathrm{K}_{3} \mathrm{PO}_{4}$. Since then, other types of ILbased ATPS have been reported based on a series of different additions, e.g., inorganic salts, carbohydrates and carbon dioxide $\left(\mathrm{CO}_{2}\right)$, shown as below.

Inorganic salts. A variety of inorganic salts, i.e., potassium salts, ${ }^{31,62,184-189}$ sodium salts ${ }^{190,191}$ and aluminum salts, ${ }^{192,193}$ etc., have been used for the preparation of IL-based ATPS. Deng et al. ${ }^{186}$ employed ATPS based on 1-allyl-3-methylimidazolium chloride $([\mathrm{Amim}][\mathrm{Cl}])$ and potassium salts $\left(\mathrm{K}_{3} \mathrm{PO}_{4}, \mathrm{~K}_{2} \mathrm{HPO}_{4}\right.$ and $\mathrm{K}_{2} \mathrm{CO}_{3}$ ) for the recovery of $[\mathrm{Amim}][\mathrm{Cl}]$. They observed that different salts exerted different effects on the recovery of [Amim] [Cl]. The recovery efficiency decreased in the order of $\mathrm{K}_{3} \mathrm{PO}_{4}>$ $\mathrm{K}_{2} \mathrm{HPO}_{4}>\mathrm{K}_{2} \mathrm{CO}_{3}$. Similar results were obtained by Li et al. ${ }^{190}$ They used ATPS with sodium salts $\left(\mathrm{Na}_{3} \mathrm{PO}_{4}, \mathrm{Na}_{2} \mathrm{CO}_{3}, \mathrm{Na}_{2} \mathrm{SO}_{4}\right.$, $\mathrm{NaH}_{2} \mathrm{PO}_{4}$ and $\mathrm{NaCl}$ ) to recover $\left[\mathrm{C}_{4} \mathrm{mim}\right]\left[\mathrm{BF}_{4}\right]$ with the recovery efficiency of $98.77 \%$. Neves et al. ${ }^{192}$ initially proposed a recovery of imidazolium-, pyridinium-, and phosphonium-based ILs from aqueous solution making use of two aluminium-based salts $\left(\mathrm{Al}_{2}\left(\mathrm{SO}_{4}\right)_{3}\right.$ and $\left.\mathrm{AlK}\left(\mathrm{SO}_{4}\right) 12 \mathrm{H}_{2} \mathrm{O}\right)$. At least $96 \%$ of the ionic liquids could be recovered.

The formation and stability of IL-based ATPS are found to be dependent on the structures of ILs such as cation types, lengths of alkyl chain and the anions. Bridges et al. ${ }^{62}$ investigated the effect of cationic cores of ILs on the formation of ATPS. Five species $\left(\mathrm{K}_{3} \mathrm{PO}_{4}, \mathrm{~K}_{2} \mathrm{HPO}_{4}, \mathrm{~K}_{2} \mathrm{CO}_{3},\left(\mathrm{NH}_{4}\right)_{2} \mathrm{SO}_{4}\right.$ and $\left.\mathrm{KOH}\right)$ were selected to induce the phase separation of imidazolium-, pyridinium-, quaternary ammonium- and phosphonium-based ILs. The ability of ILs to form ATPS could be enhanced through increasing the hydrophobicity of cationic core, i.e., $\left[\mathrm{P}_{4444}\right][\mathrm{Cl}]>$ $\left[\mathrm{N}_{4444}\right][\mathrm{Cl}]>\left[\mathrm{C}_{4}-\mathrm{Py}\right][\mathrm{Cl}]>\left[\mathrm{C}_{4} \mathrm{mim}\right][\mathrm{Cl}]$. The positive charge on imidazolium- and pyridinium-based ILs is more delocalized over the ring compared to the quaternary ammonium- and phosphonium-based ILs, which allows the imidazolium and pyridinium cores to interact with water and thus disfavours the phase separation. Ventura et al. ${ }^{\mathbf{1 8 5}}$ evaluated the formation of ATPS based on imidazolium-, pyridinium-, pyrrolidinium- and piperidinium-based ILs with the salts $\left(\mathrm{K}_{2} \mathrm{HPO}_{4}\right.$ or a mixture of $\mathrm{K}_{2} \mathrm{HPO}_{4} / \mathrm{KH}_{2} \mathrm{PO}_{4}$ ). Results showed that six-membered ILs (pyrrolidinium and piperidinium) were more easily to form the ATPS than five-membered ILs (imidazolium and pyridinium), which could be ascribed to the difference in the charge density and molar volume of these cationic cores. Neves et al. ${ }^{\mathbf{1 9 3}}$ studied the effect of alkyl chain length on the ATPS formation involving hydrophilic imidazolium-based ILs and $\mathrm{K}_{3} \mathrm{PO}_{4}$. They found that increasing the length of alkyl chain of ILs could increase the phase separation capability. They believed that it was ascribed to the longer alkyl chain ILs which were more hydrophobic and thus aggregate more easily during the phase separation. Furthermore, Pei et al. ${ }^{\mathbf{1 8 4}}$ found that the phase-forming ability of the ILs follows the order: $\left[\mathrm{C}_{4} \mathrm{mim}\right][\mathrm{Br}]>\left[\mathrm{C}_{4} \mathrm{mim}\right][\mathrm{Cl}],\left[\mathrm{C}_{6} \mathrm{mim}\right]$ $[\mathrm{Br}]>\left[\mathrm{C}_{6} \mathrm{mim}\right][\mathrm{Cl}]$, indicating that bromide-based ILs presented higher aptitude to form ATPS than their chloride-based counterparts. This observation was in good agreement with the data reported by Coutinho and co-workers. ${ }^{194}$

Cláudio et al. ${ }^{191}$ proposed a two-step ATPS scheme to recover the ionic liquids. They conducted an IL-recyclable extraction to extract a kind of antioxidant (gallic acid). As shown in Fig. 13, the gallic acid was firstly extracted into the IL-rich phase using $\mathrm{Na}_{2} \mathrm{SO}_{4}$-based ATPS. Subsequently, the IL-rich phase containing gallic acid was separated and formed a new ATPS with the addition of $\mathrm{Na}_{2} \mathrm{CO}_{3}$. Almost all of gallic acids were stripped and obtained through this back-extraction. While the ILs were regenerated for subsequent reuse. They evidenced that in each cycle among four sequential partitioning experiments, the recovery of ionic liquids could reach up to $94 \%$ or even $95 \%$.

Carbohydrates. Although the addition of inorganic salts could be successfully applied to form ATPS, the concentration of inorganic salts in the salt-rich phase was often very high, even 


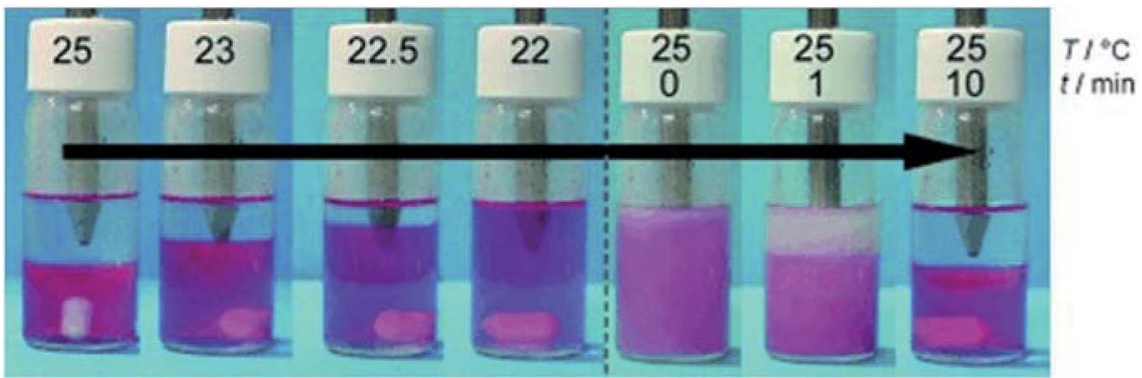

Fig. 15 Temperature dependence of the phase behavior of a $\left[\mathrm{P}_{4444}\right]$-[Tf-Leu]/water mixture. Reproduced with permission from ref. 200. Copyright 2007 Wiley-VCH.

resulting in secondary treatment or environmental problem. To avoid this problem, great attempts have been made to seeking the covalent compound, i.e., carbohydrates, for inducing phase separation of ILs aqueous solution. ${ }^{195,196} \mathrm{Wu}$ et $a{ }^{195}$ firstly proposed an ATPS composed of hydrophilic ILs ([Amim][Cl], $\left.[\mathrm{Amim}][\mathrm{Br}],\left[\mathrm{C}_{4} \mathrm{mim}\right]\left[\mathrm{BF}_{4}\right]\right)$ and sucrose. An upper IL-rich phase and a lower sucrose-rich phase were generated eventually. However, the recoveries of ILs were not satisfying, just $74 \%$ for $\left[\mathrm{C}_{4} \mathrm{mim}\right]\left[\mathrm{BF}_{4}\right], 65 \%$ for $[\mathrm{Amim}][\mathrm{Br}]$ and $63 \%$ for $[\mathrm{Amim}][\mathrm{Cl}]$. Their subsequent work ${ }^{\mathbf{1 9 6}}$ applied four types of saccharides (sucrose, glucose, xylose and fructose) to form ATPS with $\left[\mathrm{C}_{4} \mathrm{mim}\right]\left[\mathrm{BF}_{4}\right]$. It was found that the highest recovery for $\left[\mathrm{C}_{4} \mathrm{mim}\right]\left[\mathrm{BF}_{4}\right]$ was only $74 \%$. Although the IL-carbohydrate-ATPS is more environmentally friendly compared with the ILinorganic salt-ATPS, the extraction efficiency still needs to be enhanced.

In addition to the two IL-based ATPS induced by inorganic salt and carbohydrate, other chemicals such as polymers ${ }^{\mathbf{1 9 7}}$ and amino acid ${ }^{\mathbf{1 9 8}}$ have also been studied to form ATPS. However, most of the work are still in the lab.

Carbon dioxide. Carbon dioxide $\left(\mathrm{CO}_{2}\right)$ is nontoxic, cheap and recyclable, thus it is often used as the trigger for process switching in many cases. Introduction of $\mathrm{CO}_{2}$ can induce either the formation of IL-based ATPS, ${ }^{53,199}$ or the direct phase transition of the IL/water mixture. ${ }^{63}$ Xiong et al. ${ }^{53}$ investigated the phase separation of aqueous solutions of ILs and amines upon

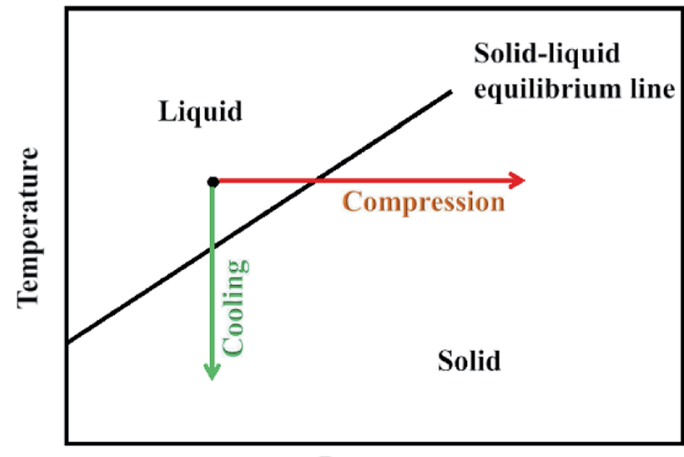

Pressure

Fig. 16 Schematic drawing of compression and cooling. Reproduced with permission from ref. 202. Copyright 2010 American Chemical Society. the introduction of $\mathrm{CO}_{2}$ at $25{ }^{\circ} \mathrm{C}$ and ambient pressure. The formed ATPS consisted of an ammonium-salt-rich upper phase and an IL-rich lower phase. It was found that the phase separation ability of the ammonium salts decreased in the order: 1,2-propylenediamine $>$ monoethanolamine $>$ diethanolamine $>N$-methylmonoethanolamine $>N$-methyl-diethanolamine $>$ triethanolamine (i.e., 1,2-PDA > MEA > DEA > MMEA > MDEA > TEA). For a specific amine, the recovery efficiency of the ILs decreased in the order: 1-butyl-3-methy-limidazolium tetrafluoroborate $>$ 1-butylpyridinium tetrafluoroborate $>1$-butylpyridinium trifluoromethanesulfonate (i.e., $\left[\mathrm{C}_{4} \mathrm{mim}\right]\left[\mathrm{BF}_{4}\right]>$ $\left[\mathrm{C}_{4}\right.$-py $]\left[\mathrm{BF}_{4}\right]>\left[\mathrm{C}_{4}\right.$-py $\left.][\mathrm{TfO}]\right)$, which was correlated with the hydrophobicity of these ILs. The one-step recovery efficiency of ILs could reach up to $99 \%$ in the presence of primary or secondary amines. Moreover, it was found that the phase separation of the tetrabutylphosphonium $\mathrm{N}$-trifluoromethanesulfonyl leucine $\left(\left[\mathrm{P}_{4444}\right][\mathrm{Tf}-\mathrm{Leu}]\right) /$ water mixture could be induced by bubbling $\mathrm{CO}_{2}$ at $20{ }^{\circ} \mathrm{C}$ and atmospheric pressure. ${ }^{63}$ As shown in Fig. 14, the IL phase was coloured by Nile blue. After injection of $\mathrm{CO}_{2}$, the clear and homogeneous solution (Fig. 14a) turned turbid with bubbling time (Fig. 14bd). The mixture was separated after $5 \mathrm{~min}$ (Fig. 14e). The separated phase could be changed back to homogeneous state when $\mathrm{N}_{2}$ gas was bubbled to remove the $\mathrm{CO}_{2}$ (Fig. 14e-g).

2.5.2. ATPE based on changing temperature. Phase separation in mixtures involving ILs and water can also be induced by changing temperature. For some IL-water mixtures which possess a lower critical solution temperature (LCST), phase separation occurs when the temperature is above LCST. Fukumoto et $a .^{200}$ synthesized tetrabutylphosphonium $\mathrm{N}$-trifluoromethanesulfonyl leucine $\left(\left[\mathrm{P}_{4444}\right][\mathrm{Tf}-\mathrm{Leu}]\right)$ that exhibited LCST type phase separation with water. As exhibited in Fig. 15, the IL phase was colored by Nile red that was insoluble in the aqueous phase. The isolated mixture at $25{ }^{\circ} \mathrm{C}$ was cooled gradually to $22^{\circ} \mathrm{C}$ with stirring, forming a single phase. Further increase of the temperature to $25{ }^{\circ} \mathrm{C}$ would induce phase separation again after 10 minutes. Different from this binary LCST type systems, recently, Passos et $a l^{201}$ synthesized a thermos-reversible IL-based ATPS. This system was a ternary mixture of $N, N$-dimethyl- $N$ - $\left(N^{\prime}, N\right.$ dimethylaminoethyl) ammonium chloride $\left(\left[\mathrm{N}_{11[2(\mathrm{~N} 11)] 0}\right][\mathrm{Cl}]\right)$, poly(propylene) glycol (PPG) and $\mathrm{H}_{2} \mathrm{O}$. It showed single phase at $25{ }^{\circ} \mathrm{C}$ but being separated into different phases when the temperature was increased to 


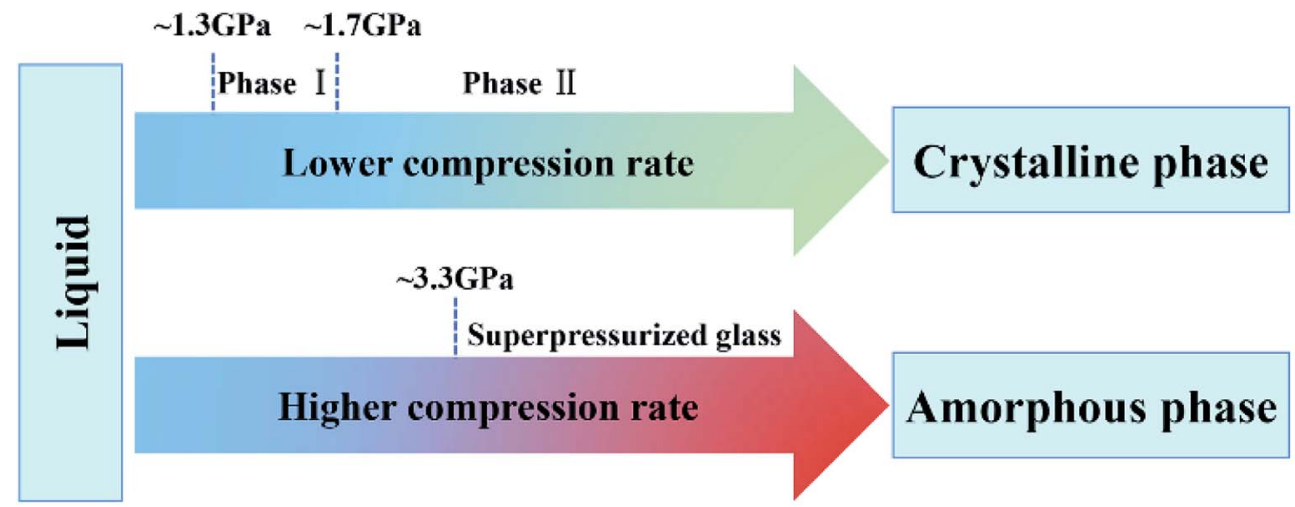

Fig. 17 Pressure-induced phase transitions of $\left[\mathrm{C}_{2} \mathrm{mim}\right][\mathrm{TfO}]$. Reproduced with permission from ref. 214. Copyright 2015 American Chemical Society.

$45{ }^{\circ} \mathrm{C}$. The range of operation temperature could be determined based on the ternary mixture composition to meet the requirement of a specific process.

\subsection{Crystallization}

Crystallization is a natural or artificial process by which the atoms or molecules are highly organized into a structure known as crystal. Generally, crystallization can be attained by means of cooling or compression, as illustrated in Fig. $16^{202}$ Different methods including temperature- and pressure-induced crystallization have been recently investigated for purification of ILs.

2.6.1. Solution crystallization. Solution crystallization refers to a methodology where pure compound is crystallized out from liquid mixtures by cooling or evaporation. This method has been applied to separate ILs from the impurities those are generated during the synthesis of ILs. For example, two ILs, 1-ethyl-3-methylimidazolium nitrite $\left(\left[\mathrm{C}_{2} \mathrm{mim}\right]\left[\mathrm{NO}_{2}\right]\right)$ and 1-ethyl-3-methylimidazolium sulfate $\left(\left[\mathrm{C}_{2} \mathrm{mim}\right]_{2}\left[\mathrm{SO}_{4}\right]\right)$ with melting points of $55^{\circ} \mathrm{C}$ and $70{ }^{\circ} \mathrm{C}$ respectively, were synthesized by Wilkes et al. ${ }^{71}$ via metathesis reaction of $\left[\mathrm{C}_{2} \mathrm{mim}\right][\mathrm{I}]$ and the corresponding silver salts. To determine their crystal structures, crystals of these two ILs were obtained by being dissolved in a saturated methyl cyanide-aether solution followed by cooling. Similarly, the $\left[\mathrm{C}_{2} \mathrm{mim}\right][\mathrm{Br}]$ was synthesized as a slightly yellow solid due to the existence of impurities in IL. ${ }^{203}$ The purification of $\left[\mathrm{C}_{2} \mathrm{mim}\right][\mathrm{Br}]$ could be achieved by means of recrystallization. After dissolving $\left[\mathrm{C}_{2} \mathrm{mim}\right][\mathrm{Br}]$ in a small quantity of acetonitrile and toluene, the solution was then cooled to $-18{ }^{\circ} \mathrm{C}$ in a freezer. By this way, the IL was crystallized out while impurities were remained in solution.

2.6.2. Melt crystallization. Melt crystallization works by cooling down a melt in a controlled way so that a fraction of the melt is crystallized. ${ }^{204}$ This method has been proved to be applicable for purification of organic chemicals as well as ILs. A diversity of impurities in ILs have been efficiently removed by different melt crystallization techniques such as zone melting and layer melt crystallization.

Zone melting. During the zone melting, a molten zone traverses a long ingot of impure solid with a specific velocity. ${ }^{205}$ As the molten region moves along, it melts the solid at its forward edge and leaves a wake of purer substance solidified behind it, while the impurities concentrate in the melt and are moved to one end of the ingot. Choudhury et al. ${ }^{54}$ was the first to determine the features (e.g., nature of hydrogen bonding between the cation and anion, anion disorder and crystal packing, etc.) of the crystal structures of five ILs (1-ethyl-3methylimidazolium tetrafluoroborate $\left(\left[\mathrm{C}_{2} \mathrm{mim}\right]\left[\mathrm{BF}_{4}\right]\right)$, 1-butyl3-methylimidazolium hexafluorophosphate $\left(\left[\mathrm{C}_{4} \mathrm{mim}\right]\left[\mathrm{PF}_{6}\right]\right)$, 1butyl-3-methylimidazolium trifluoromethylsulfonate $\left(\left[\mathrm{C}_{4} \mathrm{mim}\right]\right.$ [TfO]), 1-hexylpyridinium bis(trifluoromethanesulfonyl)amide $\left(\left[\mathrm{C}_{6}-\mathrm{py}\right]\left[\mathrm{Tf}_{2} \mathrm{~N}\right]\right)$ and 1-butyl-1-methylpyrrolidinium bis(trifluoromethanesulfonyl)amide ([Bmpyr $\left.]\left[\mathrm{Tf}_{2} \mathrm{~N}\right]\right)$ ). A small sample of an IL was cooled down to $-150{ }^{\circ} \mathrm{C}$ at $6{ }^{\circ} \mathrm{C} \min ^{-1}$ to turn into a solid followed by being heated at steps of $10{ }^{\circ} \mathrm{C}$. The single crystals of five ILs grew from their melts eventually. In their subsequent work, ${ }^{206}$ the single crystals of another two ILs $\left(\left[\mathrm{C}_{2} \mathrm{mim}\right][\mathrm{TfO}]\right.$ and $\left.\left[\mathrm{C}_{2} \mathrm{mim}\right]\left[\mathrm{Tf}_{2} \mathrm{~N}\right]\right)$ were generated by using a zone-melting technique. Similar results have been obtained by Konig et al. ${ }^{32}$ when purifying the $\left[\mathrm{C}_{2} \mathrm{mim}\right][\mathrm{Cl}]$ and $\left[\mathrm{C}_{2} \mathrm{mim}\right][\mathrm{Br}]$ through melt crystallization with the purity up to $99.9 \mathrm{wt} \%$.

Layer melt crystallization. Layer melt crystallization could be achieved by freezing a melt under controlled conditions of a heat exchange, where a solid layer of crystals is generated adjacent to a cooled surface. ${ }^{\mathbf{2 0 7}}$ The layer melt crystallization was also successfully applied for the purification of some ILs. Konig et $a l .{ }^{32}$ conducted the static layer crystallization at lab scale for purification of $\left[\mathrm{C}_{2} \mathrm{mim}\right][\mathrm{Cl}]$ and $\left[\mathrm{C}_{2} \mathrm{mim}\right][\mathrm{Br}]$. The content of impurity (1-methylimidazole) in IL decreased from $5 \mathrm{wt} \%$ to $1.5 \mathrm{wt} \%$, and high pure $(>99 \%)\left[\mathrm{C}_{2} \mathrm{mim}\right][\mathrm{Cl}]$ was obtained after the crystallization. As for the $\left[\mathrm{C}_{2} \mathrm{mim}\right][\mathrm{Br}]$, for the first time of crystallization, the purity of IL was increased from $87 \mathrm{wt} \%$ to $97 \mathrm{wt} \%$. To enhance the purification, Solà Cervera et al. ${ }^{208}$ proposed a complete recycling concept for the $\left[\mathrm{C}_{2} \mathrm{mim}\right]\left[\mathrm{Tf}_{2} \mathrm{~N}\right]$ $\mathrm{AlCl}_{3}$-based electrolytes in aluminum electrodeposition, the central part of which was the application of layer melt crystallization technique for purification of the spent electrolyte. Two main compounds in the spent electrolyte $\left(\left[\mathrm{C}_{2} \mathrm{mim}\right][\mathrm{Cl}]\right.$ and $\mathrm{AlCl}_{3}$ ) were recovered through crystallization of the component $\left[\mathrm{C}_{2} \mathrm{mim}\right]\left[\mathrm{AlCl}_{4}\right]$. The impurities decreased to pretty low concentrations with ILs recovery yields of at least $65 \%$.

2.6.3. Pressure-induced crystallization. In addition to changing the temperature, it is feasible to crystalize ILs by 

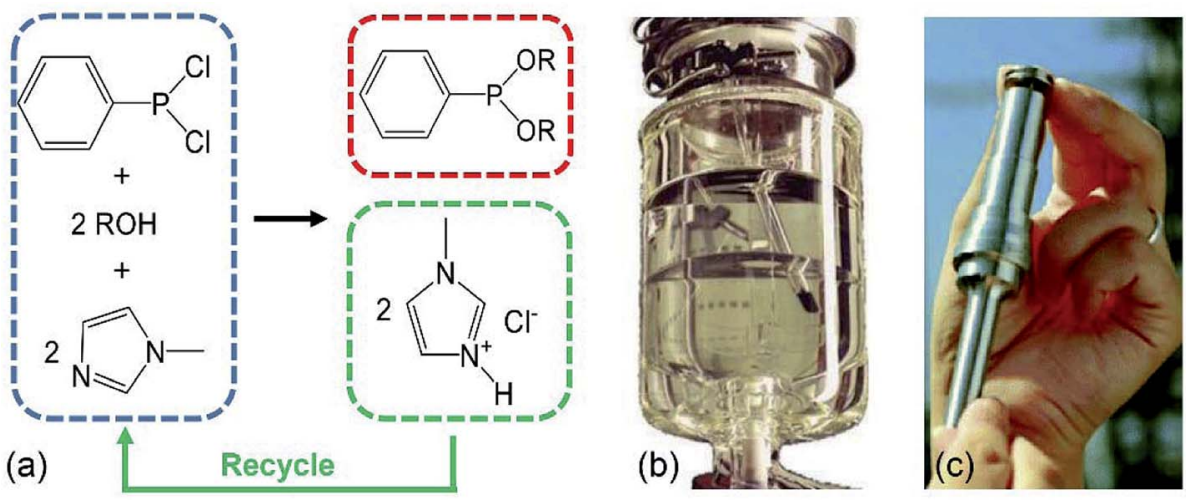

Fig. 18 The BASIL process: (a) schematic of the synthesis route of alkoxyphenylphosphines; ${ }^{221}$ (b) the BASIL reactor. After the reaction two clear liquid phases are obtained: the upper being the pure product the lower being the ionic liquid; ${ }^{43}$ (c) the BASIL jet stream reactor. ${ }^{39}$

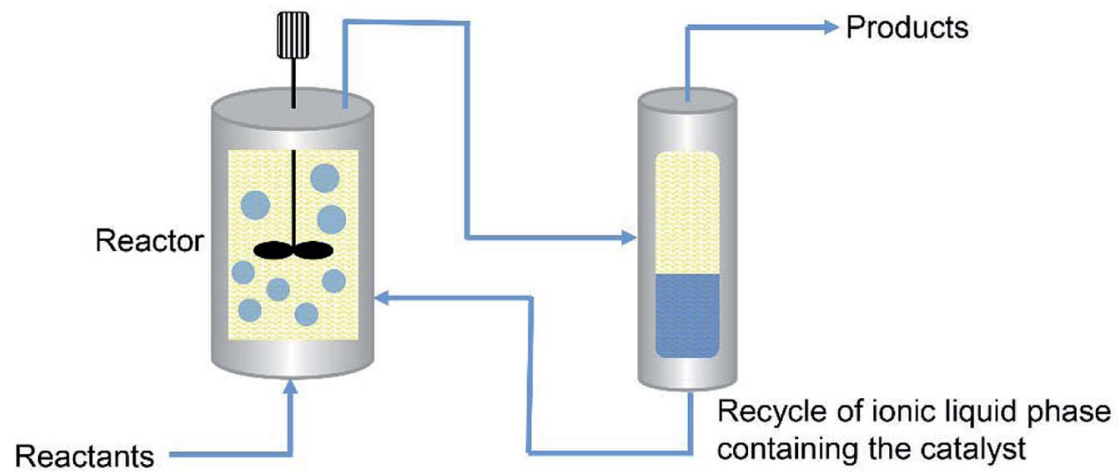

Fig. 19 Schematic of the Difasol process. Reproduced with permission from ref. 222. Copyright 2007 Institut français du pétrole.

elevating pressure. ${ }^{202,209-216}$ In the work of Su et al., ${ }^{202}$ the $\left[\mathrm{C}_{4} \mathrm{mim}\right]\left[\mathrm{PF}_{6}\right]$ was crystallized under the pressure of up to $2 \mathrm{GPa}$. It was found that the structural changes in the crystalline and liquid states under high pressure might also be associated with conformational changes in the butyl chain of IL. This study indicated the possibility of purifying and recovering ILs by using high pressure. However, some ILs may not be crystallized under high pressure. For instance, Su et al. ${ }^{217}$ investigated the crystallization behavior of $\left[\mathrm{C}_{4} \mathrm{mim}\right]\left[\mathrm{BF}_{4}\right]$. They found that even under the pressure up to $30 \mathrm{GPa}$, the $\left[\mathrm{C}_{4} \mathrm{mim}\right]\left[\mathrm{BF}_{4}\right]$ was not built up the crystal. Instead, the amorphization of IL was observed in their study. Additionally, in a recent work by Li et al., ${ }^{214}$ they observed that the pressure induced phase transitions of $\left[\mathrm{C}_{2} \mathrm{mim}\right][\mathrm{TfO}]$ were dependent on the compression rate, shown in Fig. 17. At lower compression rate of $\sim 0.3 \mathrm{GPa} \mathrm{h}^{-1}$, two crystalline phases formed successively with increasing pressure. While, at higher compression rate of $\sim 1.2 \mathrm{GPa} \mathrm{h}^{-1}$, the $\left[\mathrm{C}_{2} \mathrm{mim}\right]$ [TfO] behaved as a superpressurized glass above $3.3 \mathrm{GPa}$.

\subsection{Force field}

For some specific ILs systems, dispersions formed by hydrophobic ILs or solutions of magnetic ILs, other methods based on the employment of gravity field, centrifugation ${ }^{66}$ and magnetic fields ${ }^{33,59,218-220}$ have been proposed for recovery of ILs.
2.7.1 Gravity separation. The separation of two immiscible liquids by gravity field is based on the differences in the specific weight of liquids. The gravity separation process has the advantages of no additional chemicals, low manufacturing and operating cost, easy to scale-up, etc. Thus, it is an attractive method in industry for separation and recovery of ILs.

A successful example of an industrial process using ionic liquid is the BASIL (Biphasic Acid Scavenging utilizing Ionic Liquids) process developed by BASF for the production of the alkoxyphenylphosphine (Fig. 18a). ${ }^{43,221}$ In this process, the dichlorophenylphosphine was reacted with ethanol and 1methylimidazole. The ionic liquid, i.e., 1-methylimidazolium chloride $([\mathrm{Hmim}][\mathrm{Cl}])$, was formed as a by-product. After reaction, two liquid phases were formed: an upper phase of pure product (diethoxyphenylphosphine) and a lower phase of ionic liquid, which could be easily removed by gravity separation (Fig. 18b). ${ }^{43}$ Subsequently, the ionic liquid was deprotonated by reacting with sodium hydroxide to reform the 1-methylimidazole. The BASIL process is now run in a small jet reactor (Fig. 18c) with a capacity and yield of $690000 \mathrm{~kg} \mathrm{~m}^{-3} \mathrm{~h}^{-1}$ and $98 \%$, respectively. ${ }^{39}$

The IFP (France) has developed a biphasic process named Difasol, where the chloroaluminate(III) ionic liquid is used as solvent for the nickel-catalysed dimerisation reactions. ${ }^{222}$ The process was operated in a pilot plant. As shown in Fig. 19, 


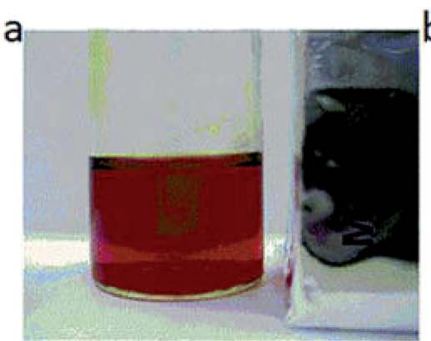

$\mathrm{T}=24^{\circ} \mathrm{C}$

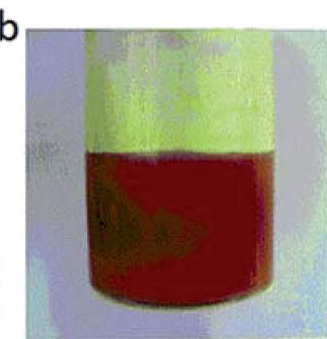

$\mathrm{T}=50^{\circ} \mathrm{C}, \mathrm{t}=20 \mathrm{~min}$

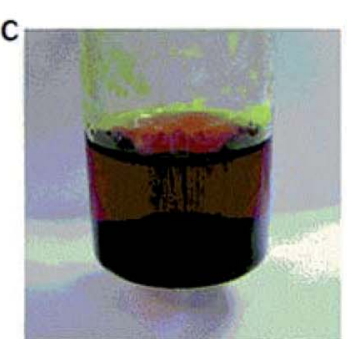

$\mathrm{T}=50^{\circ} \mathrm{C}, \mathrm{t}=30 \mathrm{~min}$

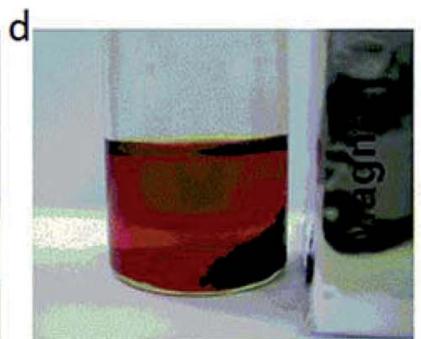

$\mathrm{T}=50^{\circ} \mathrm{C}$

Fig. 20 Heating [DBU-Bu] $\left[\mathrm{FeBrCl}_{3}\right.$ ] solution from $24{ }^{\circ} \mathrm{C}$ to $50{ }^{\circ} \mathrm{C}$ and magnetic separation of [DBU-Bu] $\left[\mathrm{FeBrCl}\right.$ ] from water at $50{ }^{\circ} \mathrm{C}$. Reproduced with permission from ref. 59. Copyright 2016 the Royal Society of Chemistry.

a representative industrial feed $\left(\mathrm{C}_{4}\right.$ raffinate $\left.\mathrm{II}\right)$, composed of $70 \mathrm{wt} \%$ butene (27 wt\% of which is 1-butene) and $1.5 \mathrm{wt} \%$ isobutene (the remainder being $n$-butane and isobutane) was introduced continuously into the mechanically stirred type reactor containing the ionic liquid and the nickel catalyst. The reactor was operated full of liquid. The effluent (a mixture of the two liquid phases) left the reactor via an overflow and was transferred to a phase separator. The separation of the ionic liquid from the product occurred rapidly and completely (favoured by the difference in densities). The ionic liquid phase containing the catalyst was recycled to the reactor, while the product was transferred to the washing and distillation section. After continuous run of 5500 hours, the volume of the ionic liquid phase did not change and no ionic liquid was detected in the product. The conversion of butenes was maintained above $70 \mathrm{wt} \%$ and the octene selectivity was around $95 \mathrm{wt} \%$.

The University of Petroleum (China) developed an alkylation process of isobutane and $\mathrm{C}_{4}$ olefins for manufacturing alkylate oil, ${ }^{223}$ where a composite catalyst is used based on the chloroaluminate ionic liquid and metal compounds. After the reaction, the ionic liquid and the alkylation product would form two phases, which could be readily separated.

2.7.2 Centrifugation. Birdwell et $a .^{66}$ studied the separation of aqueous dispersions of hydrophobic ILs by using a centrifugal contactor. Even though some systems were not separated well under gravity settling, application of the centrifugal contactor technology allowed all of the studied systems to be separated. Especially, the rapid separations could be achieved under low interfacial tensions, low viscosities and large density differences.

2.7.3 Magnetic separation. Magnetic ILs are generally obtained by incorporating high-spin transition metal ions into the structure of conventional ILs, which show a strong response to magnetic field. ${ }^{224}$ This feature provides the possibility of using a magnetic field to recover ILs. By mixing $\left[\mathrm{C}_{4} \mathrm{mim}\right][\mathrm{Cl}]$ and $\mathrm{FeCl}_{3}$, Hayashi et al. ${ }^{33}$ firstly synthesized a magnetic IL (1-butyl3-methylimidazolium tetrachloroferrate $\left.\left(\left[\mathrm{C}_{4} \mathrm{mim}\right]\left[\mathrm{FeCl}_{4}\right]\right)\right)$. In later study of Lee et al., ${ }^{218}$ the recovery of $\left[\mathrm{C}_{4} \mathrm{mim}\right]\left[\mathrm{FeCl}_{4}\right]$ from its water solution has been investigated. It is found that the $\left[\mathrm{C}_{4} \mathrm{mim}\right]\left[\mathrm{FeCl}_{4}\right]$ could be successfully separated from the two phase mixture where the concentration of IL was over $50 \%(\mathrm{v} / \mathrm{v})$ by the magnetic field at $1 \mathrm{~T}$. However, the obtaining of pure IL from the homogeneous mixtures was found to be limited when the IL concentration was less than $20 \%(\mathrm{v} / \mathrm{v})$. The difficulty in separating this hydrophilic magnetic IL from diluted aqueous solution may be due to the low magnetic susceptibility and strong interaction with water molecules. ${ }^{220}$ Inspired from this finding, Zhao et al. ${ }^{59}$ synthesized the thermoresponsive magnetic ILs (dodecyltrimethyl-ammonium tetrachloroferrate $\left(\left[\mathrm{N}_{1,1,1,12}\right]\left[\mathrm{FeCl}_{4}\right]\right)$ and 8-butyl-1,8-diazabicyclo[5.4.0]undec-7ene bromotrichloroferrate ([DBU-Bu] $\left.\left[\mathrm{FeBrCl}_{3}\right]\right)$ ), which showed lower critical solution temperature of $60{ }^{\circ} \mathrm{C}$ and $50{ }^{\circ} \mathrm{C}$ respectively. As presented in Fig. 20, the $25 \mathrm{wt} \%$ [DBU-Bu] $\left[\mathrm{FeBrCl}_{3}\right]$ aqueous solution was semi-transparent at $24{ }^{\circ} \mathrm{C}$. When applying external magnetic field, the ionic liquids could not be separated from the solution. However, when being heated up to the LCST $\left(50{ }^{\circ} \mathrm{C}\right.$ ) for $20 \mathrm{~min}$, the homogeneous solution turned turbid. Dark droplets were formed at the bottom after $30 \mathrm{~min}$. Then the droplets were easily attracted to the side of the vial by magnetic field. However, the concentration of $[\mathrm{DBU}-\mathrm{Bu}]\left[\mathrm{FeBrCl}_{3}\right]$ in the solution dropped to only $16.5 \mathrm{wt} \%$ eventually, indicating the incomplete recovery of ILs.

\subsection{Combined methods}

Due to the complexity of chemical reactions or separation systems in practical processes, the single method may not meet the satisfaction of total recovery of ILs or cannot reach the requirement of purity. To improve the recovery or purification efficiency, several techniques would be utilized in conjunction during a specific process. Herein, examples for combining different methods to recover ILs are slightly presented here.

As mentioned above, the ILs have been used as solvents or catalysts in a wide array of reactions. After completion of the reaction, ILs can be separated from both non-volatile and volatile products or impurities by extraction with organic solvents followed by distillation..$^{225,226}$ In some cases, the filtration is also needed to separate the solid chemicals at first. ${ }^{52,67}$ For instance, Khan et $a .^{52}$ conducted one-pot conversion of cellulose to levulinic acid using dicationic IL (1,1-bis(3methylimidazolium-1-yl) butane hydrogensulfate $\left(\left[\mathrm{C}_{4}(\mathrm{mim})_{2}\right]\right.$ $\left.\left.\left[2\left(\mathrm{HSO}_{4}\right)\left(\mathrm{H}_{2} \mathrm{SO}_{4}\right)_{2}\right]\right)\right)$ as a catalyst. The reaction mixture was diluted with deionized water followed by passing through Teflon filter paper. After filtration of the insoluble humin, the ethyl acetate was added to the mixture for extraction of levulinic acid, obtaining an upper phase containing levulinic acid and 


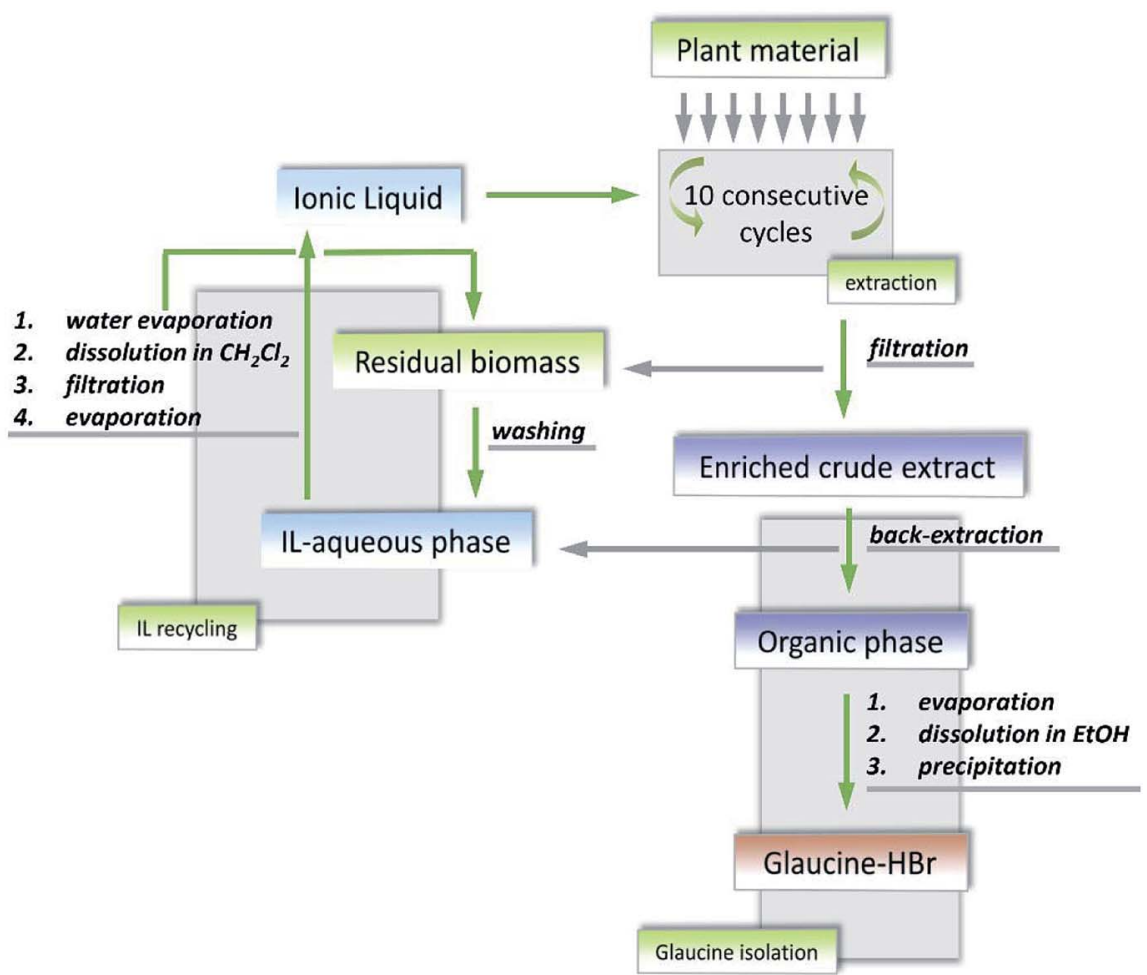

Fig. 21 Block diagram for the production of glaucine from plant material and recovery of ionic liquids. Reproduced with permission from ref. 67. Copyright 2015 Elsevier Ltd.

lower phase containing IL and water. The IL from lower aqueous phase was recovered using vacuum rotary. According to the NMR and FTIR spectral analysis, no extra peak appeared in the used IL, confirming the purity and stability of IL under the experimental conditions. Moreover, IL was recycled up to 4 times with less than $5 \%$ weight loss. Another example for ILs recycling by combination of filtration, extraction and evaporation was given by Bogdanov et al. ${ }^{67}$ Their study aimed at regenerating 1-butyl-3-methylimidazolium acesulfamate ([ $\left.\mathrm{C}_{4} \mathrm{mim}\right][$ Ace $\left.]\right)$ which was used to extract the bioactive alkaloids $S$-(+)-glaucine from aerial parts of $G$. flavum Crantz (Papaveraceae). The whole process is depicted in Fig. 21. When the IL-

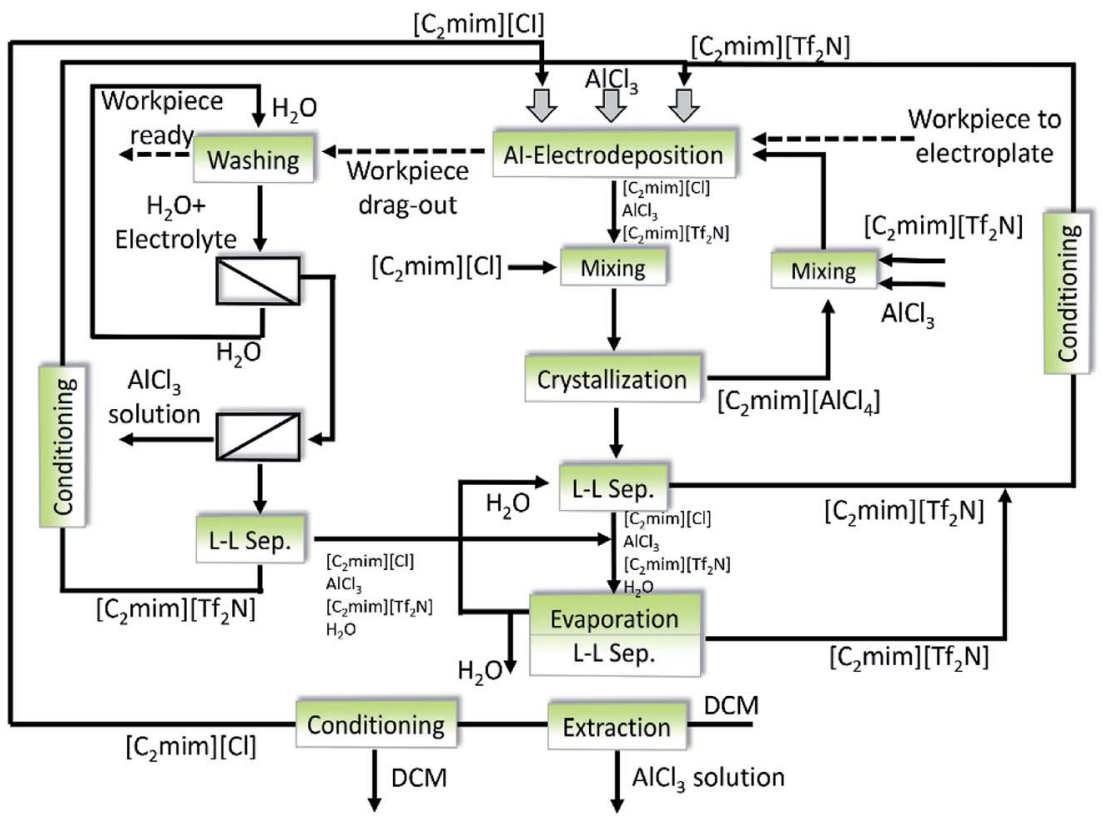

Fig. 22 Complete recycling concept for the $\left[\mathrm{C}_{2}\right.$ mim] $\left[\mathrm{Tf}_{2} \mathrm{~N}\right]-\mathrm{AlCl}_{3}$-based electrolytes in aluminum electrodeposition. Reproduced with permission from ref. 208. Copyright 2010 WILEY-VCH. 


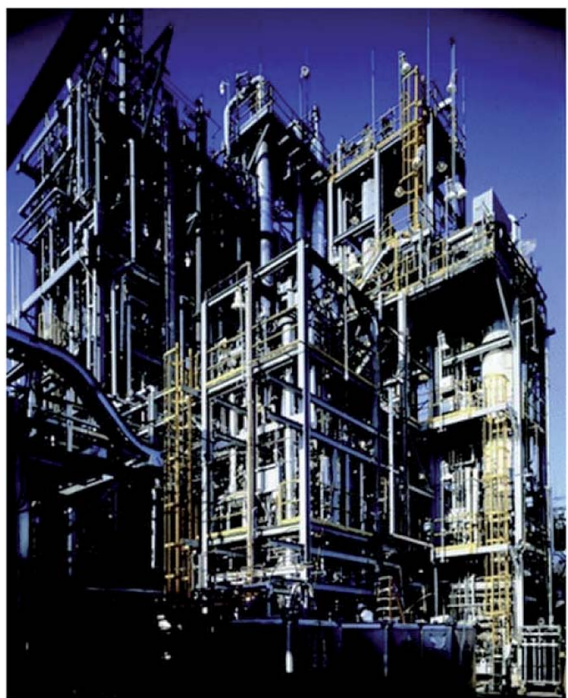

Fig. 23 Texas Eastman Division EpB Chemical Semiworks Plant, Longview, Texas. ${ }^{39}$

supported solid-liquid extraction for plant material was finished, the residual biomass was filtered and collected for recovery and regeneration of the rest IL residing in the matrix pores of biomass. The IL in the enriched crude glaucine was extracted with chloroform. After phase separation, the upper ILaqueous phase was set aside for subsequent IL regeneration. As for the block of IL regeneration, the collected residual biomass was washed by water. The IL aqueous solution obtained after washing was mixed with the materials came from extraction. After water removal under reduced pressure, the residue was dissolved in dry dichloromethane followed by the filtration of the solution and the evaporation of organic solvent successively. Finally the residue was mainly consisted of $\left[\mathrm{C}_{4} \mathrm{mim}\right][$ Ace $]$. The IL was successfully recovered and reused in ten consecutive extraction cycles without loss of performance. However, this procedure is limited for industrial application due to the requirements of organic solvents like chloroform and dichloromethane with toxicity, thus screening more benign solvents is becoming much more essential.

Solà Cervera et al. ${ }^{208}$ designed an integral recycling concept for $\left[\mathrm{C}_{2} \mathrm{mim}\right]\left[\mathrm{NTf}_{2}\right]-\mathrm{AlCl}_{3}$-based electrolytes which was used for the electrodeposition of aluminum. Fig. 22 displays a complete flow sheet of recycling steps, which can be divided into three parts: the first part is crystallization of the spent electrolyte, the second is correlated with further extraction of the residue after crystallization, while the third part is about the two step nanofiltration for concentration and separation of the ionic components in the washing stream. (i) After completion of the electrodeposition process, two main components in the spent electrolyte $\left(\left[\mathrm{C}_{2} \mathrm{mim}\right][\mathrm{Cl}]\right.$ and $\left.\mathrm{AlCl}_{3}\right)$ are recovered and purified by layer melt crystallization in the form of $\left[\mathrm{C}_{2} \mathrm{mim}\right]\left[\mathrm{AlCl}_{4}\right]$. To change the electrolyte composition to the region where the compound of $\left[\mathrm{C}_{2} \mathrm{mim}\right]\left[\mathrm{AlCl}_{4}\right]$ can be crystallized in a high yield, the $\left[\mathrm{C}_{2} \mathrm{mim}\right][\mathrm{Cl}]$ needs to be added into the spent electrolyte before crystallization. To generate a reusable electrolyte with the same composition as the fresh electrolyte, different amounts of $\left[\mathrm{C}_{2} \mathrm{mim}\right]\left[\mathrm{Tf}_{2} \mathrm{~N}\right]$ and $\mathrm{AlCl}_{3}$ have to be added to the crystallization product. It was found that the impurities could be decreased to pretty low concentrations with ionic liquids recovery at least $65 \%$ where the compound of $\left[\mathrm{C}_{2} \mathrm{mim}\right]\left[\mathrm{AlCl}_{4}\right]$ can be crystallized in a high yield, the $\left[\mathrm{C}_{2} \mathrm{mim}\right]\left[\mathrm{AlCl}_{4}\right]$ has been added into the spent electrolyte before crystallization. To generate a reusable electrolyte with the same composition as the fresh electrolyte, different amounts of $\left[\mathrm{C}_{2} \mathrm{mim}\right]\left[\mathrm{Tf}_{2} \mathrm{~N}\right]$ and $\mathrm{AlCl}_{3}$ have to be added to the crystallization product. It was found that the impurities could be decreased to pretty low concentrations with ionic liquids recovery of at least $65 \%$. (ii) The residue of the crystallization such as additives, decomposition products apart from $\left[\mathrm{C}_{2} \mathrm{mim}\right][\mathrm{Cl}], \mathrm{AlCl}_{3}$ and $\left[\mathrm{C}_{2} \mathrm{mim}\right]$ $\left[\mathrm{Tf}_{2} \mathrm{~N}\right]$ are hydrolyzed by adding water, where most of $\left[\mathrm{C}_{2} \mathrm{mim}\right]$ $\left[\mathrm{Tf}_{2} \mathrm{~N}\right]$ are recovered with the lower organic phase. If necessary, $\left[\mathrm{C}_{2} \mathrm{mim}\right]\left[\mathrm{Tf}_{2} \mathrm{~N}\right]$ can be further purified by vacuum distillation or crystallization (conditioning step in Fig. 22). After hydrolysis of these residue, the recovery of valuable component (i.e., $\left[\mathrm{C}_{2} \mathrm{mim}\right]$ [Cl]) from aqueous solution is achieved by multistage extraction with dichloromethane. (iii) After aluminum coating is completed, a part of the electrolyte will remain adhered to the workpiece, which also needs to be recovered and recycled. Water as a washing media is proposed to clean the workpiece and recover the electrolyte. The washing stream firstly passes through one nanofiltration membrane, where water is recovered. The concentrated IL solution (retentate) is subsequently fed into the second different membrane in which $\mathrm{Al}^{3+}$ and $\left[\mathrm{C}_{2} \mathrm{mim}\right]^{+}$ions are separated. During the whole recycling process, only waste solutions containing aluminum salts, very low concentrations of the ILs and some impurities are generated. However, it is just a semiquantitative concept, which needs to be further applied and validated.

The Eastman Chemical Company had been running a process for the isomerisation of 3,4-epoxy-1-butene to 2,5dihydrofuran between 1996 and 2004, during which a combination of distillation and extraction was employed for the ionic liquids recovery. ${ }^{39,227}$ This process was operated in a plant with capacity of 1400 metric tons per year (Fig. 23). The mixture of a Lewis acid (trialkyltin iodide) and a Lewis basic (tetraalkylphosphonium ionic liquid $\left(\left[\mathrm{P}_{8,8,8,18}\right][\mathrm{I}]\right)$ ) was used as the catalyst. After reaction, the 2,5-dihydrofuran and one of the byproduct (crotonaldehyde) were distilled out in a wiped-film evaporator. Another by-product (oligomer) was extracted from the catalysts with hydrocarbon in a continuous, counter-current and liquid-liquid extractor. After distillation of the hydrocarbon, the catalysts could be reused for isomerisation. The plant is now idle due to the declined market for the product.

\section{Discussions on the recovery and purification technologies for ionic liquids}

As mentioned above, there are different methods for the recovery and purification of ionic liquids. However, due to the 
differences in the properties of ionic liquids, the compositions of ionic liquids solutions and the specific requirements of operational cost, each of the technologies for the recovery and purification of ionic liquids from solutions possesses its optimal application scope. Accordingly, it is necessary to know the applicable scope of each method before the process design. Characteristics, advantages and disadvantages of different ILs recovery methods are summarized in Table 4 . The ILs and their corresponding recovery methods which are mentioned in the review are presented in Tables 5 and 6.

Distillation is considered to be an easily operated method for recovery of ILs. The distillation process could be conducted through vaporization of the water or other volatile solvents (e.g., methanol, acetone, etc.), where ILs (either hydrophilic or hydrophobic) are remained as the residue. This is especially suitable to separate high concentration ILs solutions and usually ILs with high purity could be obtained. The distillation could also be carried out through the reaction of ILs (e.g., 1,3substituted imidazolium ILs). However, it would increase the operational difficulty, and often the impurities would occur in the recovered ILs. Furthermore, although some aprotic ILs could be distilled as intact ion pairs without decomposition, the harsh distillation conditions would cause the increased operation costs. The traditional distillation is a common method in industrial application. However, it often exhibits high energy consumption and a risk of thermal decomposition of the substances. Therefore, the pre-concentration of the ILs solution may be an attractive option to run the distillation process in a more energy-saving way.

Extraction is a relatively simple and low-cost method which shows potential in recovering ILs from solutions containing non-volatile or thermally sensitive substances. Extraction with water is suitable to separate the hydrophilic compounds from hydrophobic ILs (e.g., $\left[\mathrm{C}_{4} \mathrm{mim}\right]\left[\mathrm{PF}_{6}\right]$ and $\left.\left[\mathrm{C}_{4} \mathrm{mim}\right]\left[\mathrm{Tf}_{2} \mathrm{~N}\right]\right)$. However, it is limited by the hydrophilicity of ILs. Extraction with organic solvents could be employed to separate either hydrophobic (e.g. $\left[\mathrm{C}_{4} \mathrm{mim}\right]\left[\mathrm{PF}_{6}\right]$ ) or hydrophilic ILs (e.g., $\left.\left[\mathrm{C}_{2} \mathrm{mim}\right][\mathrm{Ac}]\right)$, and it could also be used in different fields (organic synthesis reaction, extraction separation, biomass pretreatment, etc.). However, the use of organic solvents would cause the cross-contamination and other environment problems. As a kind of nontoxic and easy to separate solvent, the $\mathrm{scCO}_{2}$ is able to separate a series of organic solutes (e.g., naphthalene, phenol, benzoic acid, methanol and hexane, etc.) from the hydrophobic ILs (e.g., $\left.\left[\mathrm{C}_{4} \mathrm{mim}\right]\left[\mathrm{PF}_{6}\right]\right)$. For the mixture of IL and some polar organic compounds (e.g., ethanol and acetone), it is feasible to use $\mathrm{scCO}_{2}$ as the solvent only when the concentration of these organic compounds is pretty low (e.g., $10 \mathrm{~mol} \%$ ). High pressure $\mathrm{CO}_{2}$ could lead to the phase separation of some ILs $\left(\left[\mathrm{C}_{4} \mathrm{mim}\right]\left[\mathrm{PF}_{6}\right],[\mathrm{PDmim}]\left[\mathrm{Tf}_{2} \mathrm{~N}\right],\left[\mathrm{C}_{4} \mathrm{mim}\right]\left[\mathrm{BF}_{4}\right]\right.$ and $\left[\mathrm{C}_{4} \mathrm{mim}\right][\mathrm{TfO}]$, etc.) aqueous solution. However, high ILs recovery efficiency is difficult to be achieved. Moreover, the high equipment costs should be considered when applying the $\mathrm{scCO}_{2}$ technology for ILs recovery.

As a low energy consuming method, the adsorptiondesorption combined process would be a potential choice to recover ionic liquids, which is especially suitable for low concentration or diluted ILs aqueous solutions. The activated carbon is the mostly studied adsorbent. It has been used to adsorb a variety of ILs with different anions $\left(\left[\mathrm{Tf}_{2} \mathrm{~N}\right]^{-},\left[\mathrm{PF}_{6}\right]^{-}\right.$, $[\mathrm{TfO}]^{-},\left[\mathrm{BF}_{4}\right]^{-},[\mathrm{TFA}]^{-},[\mathrm{Cl}]^{-}$and $[\mathrm{Br}]^{-}$, etc.) and cations (ammonium, phosphonium, pyridinium, imidazolium and pyrrolidinium, etc.). The soils and sediments also show adsorption capacity for some hydrophilic $\left(\left[\mathrm{C}_{n} \mathrm{mim}\right]\left[\mathrm{BF}_{4}\right]\right.$, $\left[\mathrm{C}_{n} \mathrm{mim}\right][\mathrm{Cl}]$ and $\left[\mathrm{C}_{4}-4-\mathrm{mPy}\right][\mathrm{Cl}]$, etc.) and hydrophobic ILs (e.g., $\left.\left[\mathrm{C}_{4} \mathrm{mim}\right]\left[\mathrm{Tf}_{2} \mathrm{~N}\right]\right)$. The ion exchange resin could be used recover the cations of ILs $\left(\left[\mathrm{C}_{n} \mathrm{mim}\right][\mathrm{Cl}],\left[\mathrm{C}_{n} \mathrm{mim}\right][\mathrm{Ac}],\left[\mathrm{C}_{\mathrm{n}} \mathrm{mim}\right]\left[\mathrm{BF}_{4}\right]\right.$ and benzothiazolium ILs, etc.) from the aqueous solution or other solutions (e.g., ILs and glucose mixture solution). However, there exists an inherent drawback in this method that the anions of ILs could not be adsorbed and remain in the original solution. Additionally, other adsorbents such as carbonaceous materials, bacterial biosorbents and biochars have also been studied for the separation of some imidazolium based ILs $\left(\left[\mathrm{C}_{n} \mathrm{mim}\right][\mathrm{Cl}], \quad\left[\mathrm{C}_{2} \mathrm{mim}\right][\mathrm{Ac}]\right.$, etc. $)$. Basically, the adsorptiondesorption method would be good candidate for the preconcentration step of ILs, which could be further combined with distillation or other processes to lower the energy consumption. Furthermore, other efforts such as understanding of the adsorption mechanisms (thermodynamics and kinetics), improvement of the desorption efficiency and the adsorbent recyclability are still in need.

The method of membrane separation is of low energy demand and high selectivity. The pressure-driven membrane technique has been studied for recovery of different ILs $\left(\left[\mathrm{C}_{4} \mathrm{mim}\right][\mathrm{Cl}],\left[\mathrm{C}_{4} \mathrm{mim}\right]\left[\mathrm{BF}_{4}\right],[\mathrm{Mmim}][\mathrm{DMP}],[\mathrm{Mmim}][\mathrm{MS}],\left[\mathrm{C}_{4}-3-\right.\right.$ mpy $]\left[\mathrm{BF}_{4}\right]$, CYPHOS IL 101, ECOENG500 and Ethaline200, etc.). Whereas, the permeate flux may be decreased during the pressure-driven membrane process due to the concentration polarization. Separation of volatile components such as water from ILs (e.g., $\left.\left[\mathrm{C}_{4} \mathrm{mim}\right]\left[\mathrm{PF}_{6}\right],\left[\mathrm{C}_{2} \mathrm{mim}\right][\mathrm{Ac}]\right)$ by pervaporation is independent on the osmotic pressure, but large membrane area may be required due to the low membrane flux. During the membrane distillation, water vapor permeates the hydrophobic membrane while ILs (e.g., $\left[\mathrm{C}_{2} \mathrm{mim}\right]\left[\mathrm{O}_{2} \mathrm{CH}\right],\left[\mathrm{C}_{2} \mathrm{mim}\right][\mathrm{Ac}]$ and $\left.\left[\mathrm{C}_{4} \mathrm{mim}\right][\mathrm{Cl}]\right)$ are remained. Additionally, electrodialysis could be applied to concentrate hydrophilic ILs (e.g., $\left[\mathrm{C}_{4} \mathrm{mim}\right][\mathrm{Cl}]$, $\left.\left[\mathrm{C}_{4} \mathrm{mim}\right][\mathrm{Br}]\right)$ from aqueous solutions. It is worth noticing that concentrated ILs solutions, but not pure ILs are obtained after the membrane separation, thus the membrane technology could also be employed as a preconcentration process and combined with other methods such as distillation or extraction. Moreover, to facilitate the industrialization step of the recovery of ILs by membrane separation, more attempts should be made to reduce the membrane cost, decrease the membrane fouling and improve the membrane separation performance, etc.

The aqueous two-phase extraction, which is based on the formation of aqueous two-phase systems with no use of organic solvents, is regarded as an environmentally friendly method to recover hydrophilic ILs from aqueous solutions. Adding inorganic salts or carbohydrates could induce the phase separation of water and a variety of ILs (e.g., $\left[\mathrm{C}_{4} \mathrm{mim}\right]\left[\mathrm{BF}_{4}\right],\left[\mathrm{C}_{n} \mathrm{mim}\right][\mathrm{Br}]$, $\left[\mathrm{C}_{n} \operatorname{mim}\right][\mathrm{Cl}], \quad\left[\mathrm{P}_{4444}\right][\mathrm{Cl}], \quad\left[\mathrm{N}_{4444}\right][\mathrm{Cl}]$ and $\left[\mathrm{C}_{4}-\mathrm{Py}\right][\mathrm{Cl}]$, etc. $)$. However, this method could result in the increasing content of 

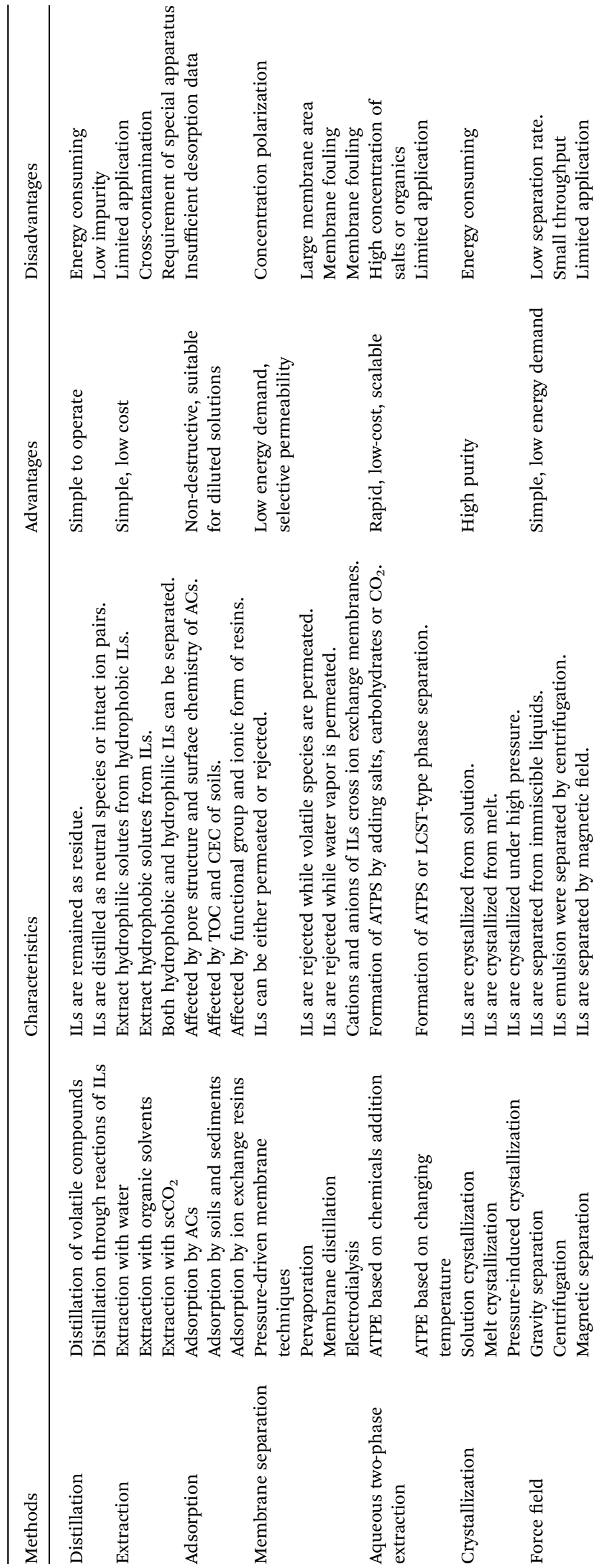


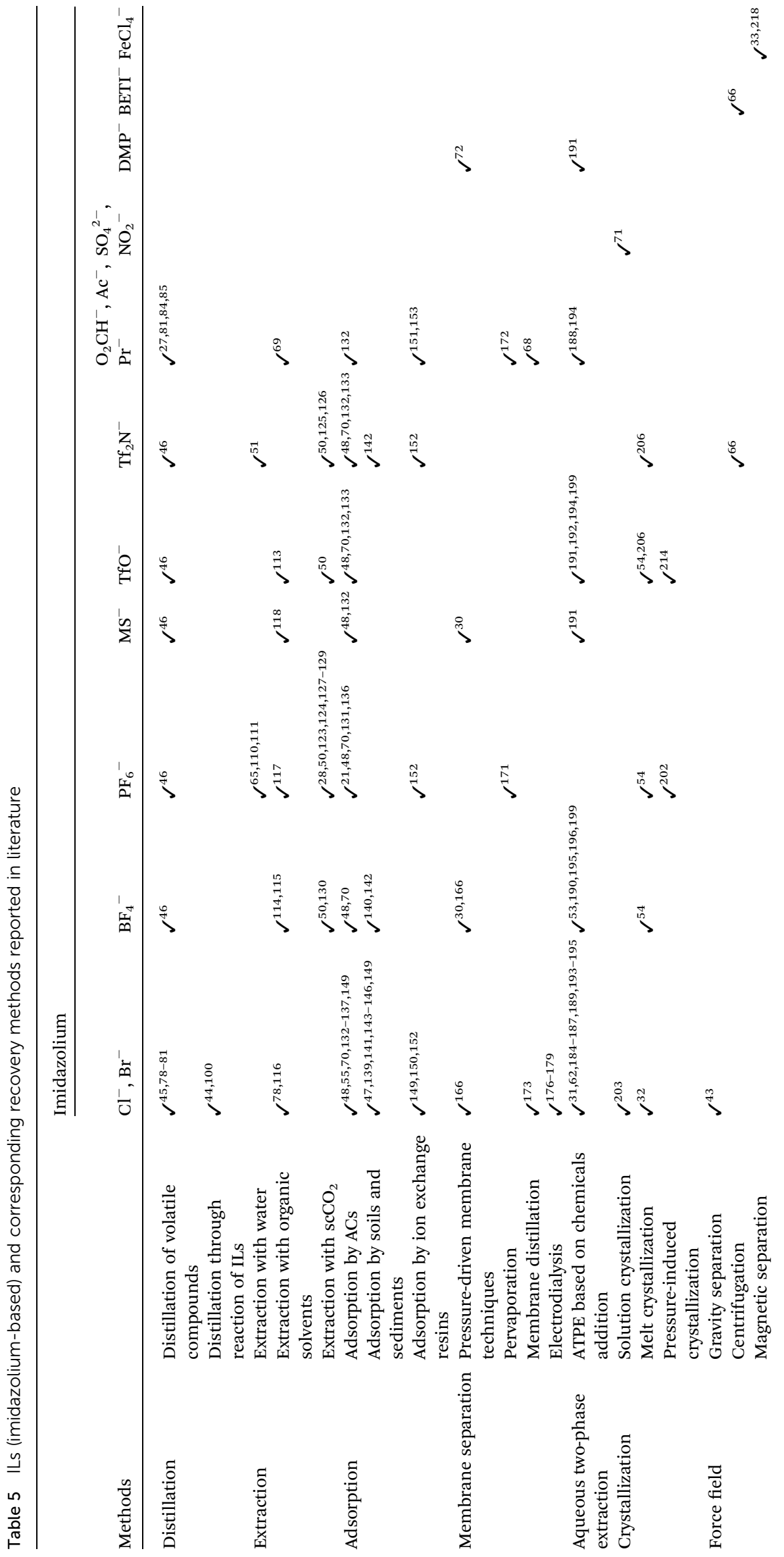




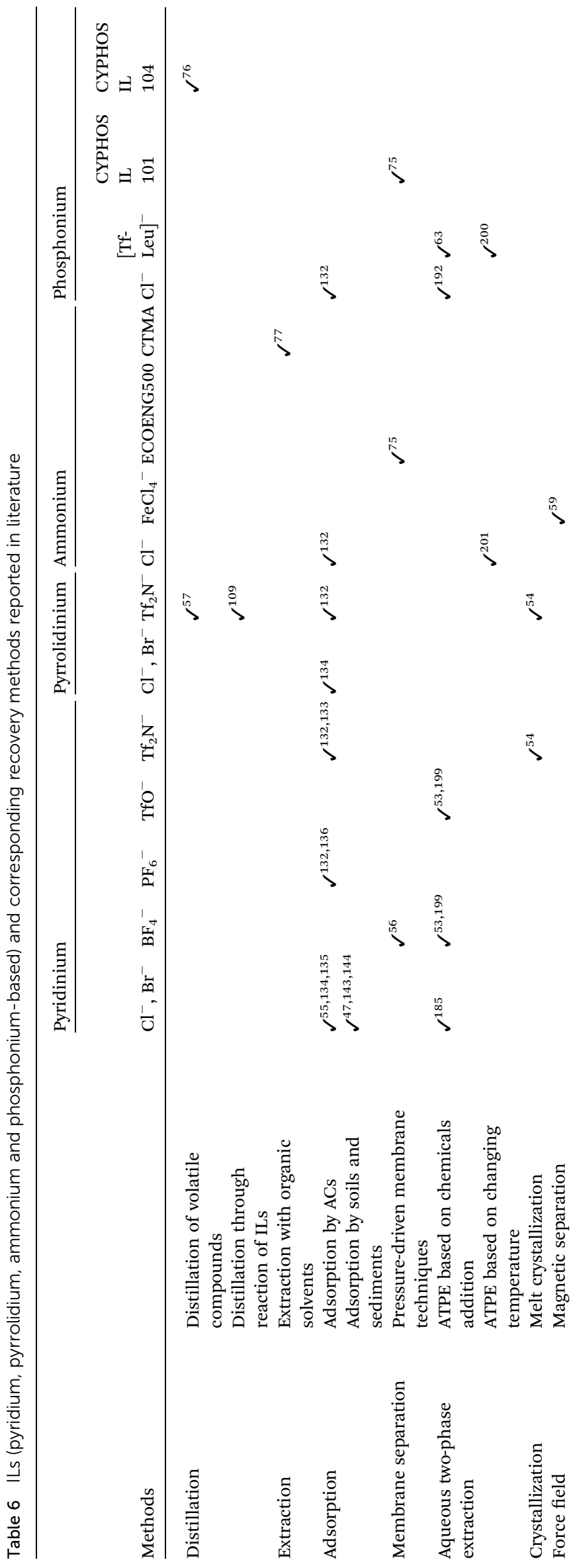


inorganic ions or organic compounds in aqueous solution. For aqueous solutions of some ILs (e.g., $\left[\mathrm{C}_{4} \mathrm{mim}\right]\left[\mathrm{BF}_{4}\right],\left[\mathrm{C}_{4}-\mathrm{py}\right]\left[\mathrm{BF}_{4}\right]$ and $\left[\mathrm{C}_{4}\right.$-py][TfO]) and amines, the ATPS could be formed upon the introduction of $\mathrm{CO}_{2}$ at ambient conditions. For aqueous solution of ILs prepared from amino acids (e.g., $\left[\mathrm{P}_{4444}\right][$ Tf-Leu $\left.]\right)$, the ILs could be separated directly from water when $\mathrm{CO}_{2}$ is bubbled. With regard to ILs that exhibit LCST phenomenon (e.g., $\left.\left[\mathrm{P}_{4444}\right][\mathrm{Tf}-\mathrm{Leu}]\right)$ or thermo-reversible behaviour (e.g., $\left[\mathrm{N}_{11}\right.$ $[2(\mathrm{~N} 11)] 0][\mathrm{Cl}])$, the direct phase separation or ATPS could be formed by changing the temperature. During the aqueous twophase extraction, the recovery efficiency of ILs is still limited, which may be improved by further exploration of the thermodynamic models, seeking new IL-based aqueous two-phase systems, etc.

Crystallization could be used to obtain ILs with high purity. Crystals of some ILs (e.g., $\left.\left[\mathrm{C}_{2} \mathrm{mim}\right]\left[\mathrm{NO}_{2}\right],\left[\mathrm{C}_{2} \mathrm{mim}\right][\mathrm{Br}]\right)$ could be formed by solution crystallization. The melt crystallization is suitable to purify a variety of ILs such as $\left[\mathrm{C}_{2} \mathrm{mim}\right][\mathrm{Cl}],\left[\mathrm{C}_{4} \mathrm{mim}\right]$ $\left[\mathrm{BF}_{4}\right],\left[\mathrm{C}_{4} \mathrm{mim}\right]\left[\mathrm{PF}_{6}\right],\left[\mathrm{C}_{4} \mathrm{mim}\right][\mathrm{TfO}],\left[\mathrm{C}_{6}-\mathrm{py}\right]\left[\mathrm{Tf}_{2} \mathrm{~N}\right]$, etc. In addition, some ILs (e.g., $\left.\left[\mathrm{C}_{4} \mathrm{mim}\right]\left[\mathrm{PF}_{6}\right],\left[\mathrm{C}_{2} \mathrm{mim}\right][\mathrm{TfO}]\right)$ would crystallize under high pressure. However, purification of ILs by crystallization is also an energy consuming procedure.

Separation by force field is sometimes an easy method to be operated. The gravity separation has been the most widely used method to recover IL from immiscible liquids in industry, which is due to advantages of simple operation, low cost and no chemical additions. The centrifugation is suitable to recover hydrophobic ILs from dispersions or emulsions, but it is restricted by the low production. Furthermore, separation under the magnetic field could only be applied to recover magnetic ILs (e.g. , $\left[\mathrm{C}_{4} \mathrm{mim}\right]\left[\mathrm{FeCl}_{4}\right],\left[\mathrm{N}_{1,1,1,12}\right]\left[\mathrm{FeCl}_{4}\right]$, etc.).

\section{Conclusions and perspectives}

Ionic liquids have been widely investigated and applied in many fields, including catalyst processing, material synthesis, extraction, desulfurization, hydrogenation, etc. However, due to their hygroscopicity or dissolution to the solvents, they are often contaminated by different chemicals, such as salts, water, hydrocarbon solvents, etc. Now, the recovery and purification of ionic liquids would be one of the biggest challenges before their industrial applications. From the energy and resources saving point of view, it is urgent and necessary to recover the ILs from the waste solutions, which is also a significant aspect for the industrialization of ionic liquids. During the last decades, different technologies, i.e., distillation, extraction, adsorption, membrane separation, aqueous two-phase extraction, crystallization and external force field separation, have been investigated for the recovery and purification of ILs either in lab or in pilot scale.

Although some single methods would perform well in separating the ionic liquids from the solutions, most of their efficiencies are limited, resulting in low purity of the product or high cost or high energy input. More efforts should be made to optimize the ionic liquid recovery process in the future. On one hand, more in-depth and comprehensive fundamental researches of the separation technologies are required, e.g., the thermodynamic and kinetic analysis in the distillation and adsorption, optimization of the mass and heat transfer during the extraction, exploration of the deactivation and regeneration mechanisms of the membrane, energy optimization of the separation processes, etc. On the other hand, selecting and designing the combined recovery process is an attractive choice for the recovery of ILs. A comprehensive evaluation of the combined process should be conducted by considering the characteristics of ionic liquids (e.g., concentration, hydrophilicity and hydrophobicity, thermal sensitivity, etc.), the energy consumption, the equipment costs and the requirement of product purity, etc.

\section{Conflicts of interest}

There are no conflicts to declare.

\section{Acknowledgements}

This work was financially supported by the National Natural Science Foundation of China (No. 21506155, No. 41471258).

\section{References}

1 T. Welton, Chem. Rev., 1999, 99, 2071-2084.

2 J. P. Hallett and T. Welton, Chem. Rev., 2011, 111, 35083576.

3 R. Hayes, G. G. Warr and R. Atkin, Chem. Rev., 2015, 115, 6357-6426.

4 C. Austen Angell, Y. Ansari and Z. Zhao, Faraday Discuss., 2012, 154, 9-27.

5 D. Mecerreyes, Prog. Polym. Sci., 2011, 36, 1629-1648.

6 J. Pereira, P. S. Barber, S. P. Kelley, P. Berton and R. D. Rogers, Phys. Chem. Chem. Phys., 2017, 19, 2693426943.

7 A. Nusaibah Masri, A. Mutalib Mi and J. M. Leveque, Ind. Eng. Manage., 2016, 05, 388-395.

8 Z. Zhang, N. Kang, J. Wang, H. Sui, L. He and X. Li, Chem. Eng. Sci., 2018, 181, 264-271.

9 J. Ding and D. W. Armstrong, Chirality, 2005, 17, 281-292.

10 K. Takechi, Y. Kato and Y. Hase, Adv. Mater., 2015, 27, 25012506.

11 R. Sheldon, Chem. Commun., 2001, 23, 2399-2407.

12 W. Zheng, W. Xie, W. Sun and L. Zhao, Chem. Eng. Sci., 2017, 166, 42-52.

13 A. Castro Grijalba, E. F. Fiorentini and R. G. Wuilloud, J. Chromatogr. A., 2017, 1491, 117-125.

14 S. Riaño and K. Binnemans, Green Chem., 2015, 17, 29312942.

15 J. Eßer, P. Wasserscheid and A. Jess, Green Chem., 2004, 6, 316-322.

16 M. H. Ibrahim, M. Hayyan, M. A. Hashim and A. Hayyan, Renewable Sustainable Energy Rev., 2017, 76, 1534-1549.

17 P. A. Z. Suarez, J. E. L. Dullius, S. Einloft, R. F. De Souza and J. Dupont, Polyhedron, 1996, 15, 1217-1219.

18 L. Chen, C. Fink, Z. Fei, P. J. Dyson and G. Laurenczy, Green Chem., 2017, 19, 5435-5441. 
19 J. Fuller, R. T. Carlin and R. A. Osteryoung, J. Electrochem. Soc., 1997, 144, 3881-3886.

20 A. Basile, A. I. Bhatt and A. P. O'Mullane, Nat. Commun., 2016, 7, ncomms11794.

21 J. L. Anthony, E. J. Maginn and J. F. Brennecke, J. Phys. Chem. B, 2001, 105, 10942-10949.

22 H. Luo, Sep. Sci. Technol., 2005, 40, 1245-1265.

23 P. M. Dean, J. Turanjanin, M. Yoshizawa-Fujita, D. R. MacFarlane and J. L. Scott, Cryst. Growth Des., 2009, 9, 1137-1145.

24 J. L. Shamshina, P. S. Barber and R. D. Rogers, Expert Opin. Drug Delivery, 2013, 10, 1367-1381.

25 S. P. F. Costa, A. M. O. Azevedo, P. Pinto and M. Saraiva, ChemSusChem, 2017, 10, 2321-2347.

26 M. Wagner and C. Hilgers, Ionic Liquids in Synthesis, WileyVCH, Weinheim, 2008, vol. 1, pp. 26-45.

27 P. Weerachanchai and J. M. Lee, Bioresour. Technol., 2014, 169, 336-343.

28 L. A. Blanchard, D. Hancu, E. J. Beckman and J. F. Brennecke, Nature, 1999, 399, 28-29.

29 L. Zhang, W. Cao, P. J. J. Alvarez, X. Qu, H. Fu, S. Zheng, Z. Xu and D. Zhu, Appl. Surf. Sci., 2018, 440, 821-829.

30 J. Kröckel and U. Kragl, Chem. Eng. Technol., 2003, 26, 11661168.

31 K. E. Gutowski, G. A. Broker, H. D. Willauer, J. G. Huddleston, R. P. Swatloski, J. D. Holbrey and R. D. Rogers, J. Am. Chem. Soc., 2003, 125, 6632-6633.

32 A. König, M. Stepanski, A. Kuszlik, P. Keil and C. Weller, Chem. Eng. Res. Des., 2008, 86, 775-780.

33 S. Hayashi and H. o. Hamaguchi, Chem. Lett., 2004, 33, 1590-1591.

34 M. J. Earle and K. R. Seddon, Pure Appl. Chem., 2000, 72, 1391-1398.

35 T. Welton, Chem. Rev., 1999, 99, 2071-2083.

36 S. Keskin, D. Kayrak-Talay, U. Akman and Ö. Hortaçsu, J. Supercrit. Fluids, 2007, 43, 150-180.

37 P. Wasserscheid and W. Keim, Angew. Chem., 2000, 39, 3772.

38 C. Yue, D. Fang, L. Liu and T. F. Yi, J. Mol. Liq., 2011, 163, 99-121.

39 N. V. Plechkova and K. R. Seddon, Chem. Soc. Rev., 2008, 37, 123-150.

40 H. Olivier-Bourbigou, L. Magna and D. Morvan, Appl. Catal., A, 2010, 373, 1-56.

41 Y. Qiao, W. Ma, N. Theyssen, C. Chen and Z. Hou, Chem. Rev., 2017, 117, 6881-6928.

42 S. P. M. Ventura, F. A. Silva, M. V. Quental, D. Mondal, M. G. Freire and J. A. P. Coutinho, Chem. Rev., 2017, 117, 6984-7052.

43 K. R. Seddon, Nat. Mater., 2003, 2, 363.

44 A. J. Jeapes, R. C. Thied, K. R. Seddon, W. R. Pitner, D. W. Rooney, E. J. Hatter and T. Welton, WO Pat., 0115175, 2000.

45 K. Huang, R. Wu, Y. Cao, H. Li and J. Wang, Chin. J. Chem. Eng., 2013, 21, 577-584.

46 S. H. Ha, N. L. Mai and Y. M. Koo, J. Chromatogr. A., 2010, 1217, 7638-7641.
47 P. Stepnowski, W. Mrozik and J. Nichthauser, Environ. Sci. Technol., 2007, 41, 511-516.

48 J. Lemus, J. Palomar, F. Heras, M. A. Gilarranz and J. J. Rodriguez, Sep. Purif. Technol., 2012, 97, 11-19.

49 L. Zhang, J. Zhang, H. Fu, H. Zhang, H. Liu, Y. Wan, S. Zheng and Z. Xu, Microporous Mesoporous Mater., 2018, 260, 59-69.

50 A. M. Scurto, S. N. V. K. Aki and J. F. Brennecke, Chem. Commun., 2003, 572-573.

51 Y. Chen, H. Wang, Y. Pei and J. Wang, Sep. Purif. Technol., 2017, 178, 261-268.

52 A. S. Khan, Z. Man, M. A. Bustam, C. F. Kait, A. Nasrullah, Z. Ullah, A. Sarwono, P. Ahamd and N. Muhammad, J. Cleaner Prod., 2018, 170, 591-600.

53 D. Xiong, H. Wang, Z. Li and J. Wang, ChemSusChem, 2012, 5, 2255-2261.

54 A. R. Choudhury, N. Winterton, A. Steiner, A. I. Cooper and K. A. Johnson, J. Am. Chem. Soc., 2005, 127, 16792-16793.

55 A. Farooq, L. Reinert, J. M. Levêque, N. Papaiconomou, N. Irfan and L. Duclaux, Microporous Mesoporous Mater., 2012, 158, 55-63.

56 S. Hazarika, N. N. Dutta and P. G. Rao, Sep. Purif. Technol., 2012, 97, 123-129.

57 D. Dennewald, W. R. Pitner and D. Weuster-Botz, Process Biochem., 2011, 46, 1132-1137.

58 A. Parviainen, R. Wahlström, U. Liimatainen, T. Liitiä, S. Rovio, J. K. J. Helminen, U. Hyväkkö, A. W. T. King, A. Suurnäkki and I. Kilpeläinen, $R S C A d v ., 2015,5$, 6972869737.

59 Q. Zhao, T. S. Herng, C. X. Guo, D. Zhao, J. Ding and X. Lu, RSC Adv., 2016, 6, 15731-15734.

60 H. Luo, Y. Hu, R. Wang, W. Fan and G. Nan, Chem. Eng. Res. Des., 2018, 130, 29-34.

61 A. He, B. Dong, X. Feng and S. Yao, J. Mol. Liq., 2017, 227, 178-183.

62 N. J. Bridges, K. E. Gutowski and R. D. Rogers, Green Chem., 2007, 9, 177-183.

63 Y. Kohno, H. Arai and H. Ohno, Chem. Commun., 2011, 47, 4772-4774.

64 A. W. King, J. Asikkala, I. Mutikainen, P. Jarvi and I. Kilpelainen, Angew. Chem., Int. Ed. Engl., 2011, 50, 6301-6305.

65 J. G. Huddleston, H. D. Willauer, R. P. Swatloski, A. E. Visser and R. D. Rogers, Chem. Commun., 1998, 1765-1766.

66 J. F. Birdwell, J. McFarlane, R. D. Hunt, H. Luo, D. W. DePaoli, D. L. Schuh and S. Dai, Sep. Sci. Technol., 2006, 41, 2205-2223.

67 M. G. Bogdanov, R. Keremedchieva and I. Svinyarov, Sep. Purif. Technol., 2015, 155, 13-19.

68 J. G. Lynam, G. I. Chow, C. J. Coronella and S. R. Hiibel, Chem. Eng. J., 2016, 288, 557-561.

69 P. Weerachanchai, K. H. Lim and J. M. Lee, Bioresour. Technol., 2014, 156, 404-407.

70 J. Palomar, J. Lemus, M. A. Gilarranz and J. J. Rodriguez, Carbon, 2009, 47, 1846-1856.

71 J. S. Wilkes and M. J. Zaworotko, J. Chem. Soc., Chem. Commun., 1992, 965-967. 
72 C. Abels, C. Redepenning, A. Moll, T. Melin and M. Wessling, J. Membr. Sci., 2012, 405-406, 1-10.

73 Y. Beste, M. Eggersmann and H. Schoenmakers, Chem.-Ing.Tech., 2005, 77, 1800-1808.

74 U. Kreher, A. Rosamilia, C. Raston, J. Scott and C. Strauss, Molecules, 2004, 9, 387.

75 S. Han, H. T. Wong and A. G. Livingston, Chem. Eng. Res. Des., 2005, 83, 309-316.

76 M. Blahušiak, Š. Schlosser, J. Cvengroš and J. Marták, Chem. Pap., 2011, 65, 603-607.

77 M. A. Valdés Vergara, I. V. Lijanova, N. V. Likhanova, O. Olivares Xometl, D. Jaramillo Vigueras and A. J. Morales Ramirez, Sep. Purif. Technol., 2015, 155, 110117.

78 D. Kralisch, D. Reinhardt and G. Kreisel, Green Chem., 2007, 9, 1308.

79 N. Jia, S. Li, M. Ma, R. Sun and L. Zhu, Carbohydr. Res., 2011, 346, 2970-2974.

80 J. Ding, G. Xu, R. Han and Y. Ni, Bioresour. Technol., 2016, 199, 228-234.

81 J. Xu, B. Liu, H. Hou and J. Hu, Bioresour. Technol., 2017, 234, 406-414.

82 R. Y. Saleh, US Pat., 6320083, 2000.

83 M. Maase, M. Budich, G. Großmann and L. Szarvas, US Pat., 7605297, 2009.

84 K. Mundsinger, A. Müller, R. Beyer, F. Hermanutz and M. R. Buchmeiser, Carbohydr. Polym., 2015, 131, 34-40.

85 W. Ahmad, A. Ostonen, K. Jakobsson, P. Uusi-Kyyny, V. Alopaeus, U. Hyväkkö and A. W. T. King, Chem. Eng. Res. Des., 2016, 114, 287-298.

86 L. E. Najder, Ind. Eng. Chem. Res., 1964, 56, 26-30.

87 J. F. Fernandez, J. Neumann and J. Thoming, Curr. Org. Chem., 2011, 15, 1992-2014.

88 P. Wasserscheid and T. Welton, Industrial Applications of Ionic Liquids, Wiley-VCH Verlag GmbH \& Co. KGaA, 2008, ch. 9.

89 H. Li, J. Cui, J. Liu, X. Li and X. Gao, AIChE J., 2016, 63, 1328-1337.

90 W. Liu, P. Yin, X. Liu, W. Chen, H. Chen, C. Liu, R. Qu and Q. Xu, Energy Convers. Manage., 2013, 76, 1009-1014.

91 G. Bond, R. B. Moyes and D. A. Whan, Catal. Today, 1993, 17, 427-437.

92 H. Li, Y. Qu, Y. Yang, S. Chang and J. Xu, Bioresour. Technol., 2016, 199, 34-41.

93 J. Pan, T. Muppaneni, Y. Sun, H. K. Reddy, J. Fu, X. Lu and S. Deng, Fuel, 2016, 178, 49-55.

94 P. Rattanadecho and N. Makul, Drying Technol., 2016, 34, 138.

95 J. Cvengroš, J. Lutišan and M. Micov, Chem. Eng. J., 2000, 78, 61-67.

96 L. Fregolente, E. Moraes, P. Martins, C. Batistella, M. Maciel, A. Afonso and M. Reis, IChemE, 2006, 152, 648-656.

97 P. Keil, M. Kick and A. König, Chem. Ing. Tech., 2012, 84, 859-866.

98 M. J. Earle and K. R. Seddon, WO Pat., 0177081, 2001.

99 M. Maase and K. Massonne, US Pat., 7501522, 2009.
100 M. Maase, US Pat., 7754053, 2010.

101 D. R. MacFarlane, J. M. Pringle, K. M. Johansson, S. A. Forsyth and M. Forsyth, Chem. Commun., 2006, 1905-1917.

102 A. Parviainen, A. W. King, I. Mutikainen, M. Hummel, C. Selg, L. K. Hauru, H. Sixta and I. Kilpelainen, ChemSusChem, 2013, 6, 2161-2169.

103 Z. J. Chen, H. W. Xi, K. H. Lim and J. M. Lee, Angew. Chem., Int. Ed. Engl., 2013, 52, 13392-13396.

104 Z. J. Chen, H. W. Xi, K. H. Lim and J. M. Lee, ACS Sustainable Chem. Eng., 2015, 3, 325-333.

105 G. Li, Z. Xue, B. Cao, C. Yan and T. Mu, ACS Sustainable Chem. Eng., 2016, 4, 6258-6262.

106 C. P. Maschmeier and H. Baltruschat, Electrochim. Acta, 1992, 37, 759-761.

107 U. P. Kreher, A. E. Rosamilia, C. L. Raston, J. L. Scott and C. R. Strauss, Org. Lett., 2003, 5, 3107-3110.

108 R. Vijayaraghavan and D. R. MacFarlane, ACS Sustainable Chem. Eng., 2014, 2, 1724-1728.

109 M. J. Earle, J. M. Esperanca, M. A. Gilea, J. N. Lopes, L. P. Rebelo, J. W. Magee, K. R. Seddon and J. A. Widegren, Nature, 2006, 439, 831-834.

110 A. E. Visser, R. P. Swatloski and R. D. Rogers, Green Chem., 2000, 2, 1-4.

111 G. T. Wei, Z. S. Yang and C. J. Chen, Anal. Chim. Acta, 2003, 488, 183-192.

112 C. Mukesh, D. Mondal, M. Sharma and K. Prasad, Chem. Commun., 2013, 49, 6849-6851.

113 M. J. Earle, P. B. McCormac and K. R. Seddon, Green Chem., 1999, 1, 23-25.

114 C. J. Mathews, P. J. Smith and T. Welton, Chem. Commun., 2000, 1249-1250.

115 S. T. Handy and X. L. Zhang, Org. Lett., 2001, 3, 233-236.

116 C. Moreau, A. Finiels and L. Vanoye, J. Mol. Catal. A: Chem., 2006, 253, 165-169.

117 T. Fukuyama, M. Shinmen, S. Nishitani, M. Sato and I. Ryu, Org. Lett., 2002, 4, 1691-1694.

118 K. Titze-Frech, N. Ignatiev, M. Uerdingen, P. S. Schulz and P. Wasserscheid, Eur. J. Org. Chem., 2013, 2013, 6961-6966.

119 J. F. Pereira, L. A. Flores, H. Wang and R. D. Rogers, Chemistry, 2014, 20, 15482-15492.

120 J. F. Brennecke, Chem. Ind., 1996, 21, 831-834.

121 H. Zhao, S. Xia and P. Ma, J. Chem. Technol. Biotechnol., 2005, 80, 1089-1096.

122 L. A. Blanchard, Z. Y. Gu and J. F. Brennecke, J. Phys. Chem. $B, 2001,105,2437-2444$.

123 L. A. Blanchard and J. F. Brennecke, Ind. Eng. Chem. Res., 2001, 40, 287-292.

124 W. Wu, J. Zhang, B. Han, J. Chen, Z. Liu, T. Jiang, J. He and W. Li, Chem. Commun., 2003, 1412-1413.

125 S. Mekki, C. M. Wai, I. Billard, G. Moutiers, J. Burt, B. Yoon, J. S. Wang, C. Gaillard, A. Ouadi and P. Hesemann, Chemistry, 2006, 12, 1760-1766.

126 J. Fu, Q. Chen and X. Shen, Sci. China: Chem., 2014, 58, 545550.

127 A. Rao and B. S. Tomar, Sep. Purif. Technol., 2016, 161, 159164. 
128 A. M. Scurto, S. N. V. K. Aki and J. F. Brennecke, J. Am. Chem. Soc., 2002, 124, 10276-10277.

129 Z. Zhang, W. Wu, Z. Liu, B. Han, H. Gao and T. Jiang, Phys. Chem. Chem. Phys., 2004, 6, 2352-2357.

130 Z. Zhang, W. Wu, H. Gao, B. Han, B. Wang and Y. Huang, Phys. Chem. Chem. Phys., 2004, 6, 5051-5055.

131 J. Lemus, J. Palomar, M. A. Gilarranz and J. J. Rodriguez, Ind. Eng. Chem. Res., 2013, 52, 2969-2976.

132 J. Lemus, C. M. Neves, C. F. Marques, M. G. Freire, J. A. Coutinho and J. Palomar, Environ. Sci.: Processes Impacts, 2013, 15, 1752-1759.

133 C. M. Neves, J. Lemus, M. G. Freire, J. Palomar and J. A. Coutinho, Chem. Eng. J., 2014, 252, 305-310.

134 S. Hassan, L. Duclaux, J. M. Leveque, L. Reinert, A. Farooq and T. Yasin, J. Environ. Manage., 2014, 144, 108-117.

135 H. Guedidi, I. Lakehal, L. Reinert, J. M. Lévêque, N. Bellakhal and L. Duclaux, Arabian J. Chem., 2017, DOI: 10.1016/j.arabjc.2017.04.006.

136 J. Lemus, C. Moya, M. A. Gilarranz, J. J. Rodriguez and J. Palomar, J. Environ. Chem. Eng., 2017, 5, 5347-5351.

137 I. Ushiki, M. Tashiro and R. L. Smith, Fluid Phase Equilib., 2017, 441, 17-23.

138 S. Asadabadi and J. Saien, Colloids Surf., A, 2016, 489, 3645.

139 D. J. Gorman-Lewis and J. B. Fein, Environ. Sci. Technol., 2004, 38, 2491-2495.

140 P. Stepnowski, Aust. J. Chem., 2005, 58, 170-173.

141 S. Studzinska, M. Sprynskyy and B. Buszewski, Chemosphere, 2008, 71, 2121-2128.

142 M. Matzke, K. Thiele, A. Muller and J. Filser, Chemosphere, 2009, 74, 568-574.

143 W. Mrozik, A. Kotlowska, W. Kamysz and P. Stepnowski, Chemosphere, 2012, 88, 1202-1207.

144 L. Reinert, K. Batouche, J. M. Lévêque, F. Muller, J. M. Bény, B. Kebabi and L. Duclaux, Chem. Eng. J., 2012, 209, 13-19.

145 Y. Min, Y. Zhou, M. Zhang, H. Qiao, Q. Huang and T. Ma, J. Taiwan Inst. Chem. Eng., 2015, 53, 153-159.

146 J. J. Beaulieu, J. L. Tank and M. Kopacz, Chemosphere, 2008, 70, 1320-1328.

147 H. Sui, J. Zhou, G. Ma, Y. Niu, J. Cheng, L. He and X. Li, Appl. Sci., 2018, 8, 1611.

148 X. Jin, P. Bobba, N. Reding, Z. Song, P. S. Thapa, G. Prasad, B. Subramaniam and R. V. Chaudhari, Chem. Eng. Sci., 2017, 168, 189-203.

149 K. Vijayaraghavan, T. P. T. Pham, C. W. Cho, S. W. Won, S. B. Choi, M. Juan, S. Kim, Y. R. Kim, B. W. Chung and Y. S. Yun, Ind. Eng. Chem. Res., 2009, 48, 7283-7288.

150 J. B. Binder and R. T. Raines, Proc. Natl. Acad. Sci. U. S. A., 2010, 107, 4516-4521.

151 N. L. Mai, N. T. Nguyen, J. I. Kim, H. M. Park, S. K. Lee and Y. M. Koo, J. Chromatogr. A., 2012, 1227, 67-72.

152 L. Li, Y. Wang and X. Qi, RSC Adv., 2015, 5, 41352-41358.

153 S. B. Choi, S. W. Won and Y. S. Yun, Chem. Eng. J., 2013, 214, 78-82.

154 C. H. Ma, Y. G. Zu, L. Yang and J. Li, J. Chromatogr. B: Biomed. Sci. Appl., 2015, 976-977, 1-5.
155 X. Qi, L. Li, T. Tan, W. Chen and R. L. Smith Jr, Environ. Sci. Technol., 2013, 47, 2792-2798.

156 X. Qi, L. Li, Y. Wang, N. Liu and R. L. Smith, Chem. Eng. J., 2014, 256, 407-414.

157 K. Vijayaraghavan and Y. S. Yun, Biotechnol. Adv., 2008, 26, 266-291.

158 K. Shi, Y. Qiu, L. Ben and M. K. Stenstrom, Ecotoxicol. Environ. Saf., 2016, 130, 155-162.

159 F. Yu, L. Sun, Y. Zhou, B. Gao, W. Gao, C. Bao, C. Feng and Y. Li, Chemosphere, 2016, 165, 94-99.

160 F. Yu, Y. Zhou, B. Gao, H. Qiao, Y. Li, E. Wang, L. Pang and C. Bao, J. Taiwan Inst. Chem. Eng., 2016, 67, 318-324.

161 S. W. Won, S. B. Choi, J. Mao and Y. S. Yun, J. Hazard. Mater., 2013, 244-245, 130-134.

162 M. Mulder, Basic Principles of Membrane Technology, Springer, Netherlands, 1996.

163 M. Xie, H. K. Shon, S. R. Gray and M. Elimelech, Water Res., 2016, 89, 210-221.

164 Q. Gan, M. Xue and D. Rooney, Sep. Purif. Technol., 2006, 51, 185-192.

165 P. Wasserscheid, U. Kragl and J. Kröckel, WO Pat., 03039719, 2002.

166 J. Wang, J. Luo, X. Zhang and Y. Wan, Sep. Purif. Technol., 2016, 165, 18-26.

167 K. Haerens, S. Van Deuren, E. Matthijs and B. Van der Bruggen, Green Chem., 2010, 12, 2182.

168 A. I. Schäefer, A. G. Fane and T. D. Waite, Nanofiltration: Principles and Applications, Elsevier Advanced Technology, 2005.

169 J. Neel, Introduction to Pervaporation, Pervaporation Membrane Separation Processes, Elsevier, Amsterdam, 1991.

170 Y. K. Ong, G. M. Shi, N. L. Le, Y. P. Tang, J. Zuo, S. P. Nunes and T. S. Chung, Prog. Polym. Sci., 2016, 57, 1-31.

171 T. Schäfer, C. M. Rodrigues, C. A. M. Afonso and J. G. Crespo, Chem. Commun., 2001, 1622-1623.

172 J. Sun, J. Shi, N. V. S. N. Murthy Konda, D. Campos, D. Liu, S. Nemser, J. Shamshina, T. Dutta, P. Berton, G. Gurau, R. D. Rogers, B. A. Simmons and S. Singh, Biotechnol. Biofuels, 2017, 10, 154.

173 H. Wu, F. Shen, J. Wang, J. Luo, L. Liu, R. Khan and Y. Wan, J. Membr. Sci., 2016, 518, 216-228.

174 H. H. Wu, F. Shen, J. F. Wang and Y. H. Wan, J. Membr. Sci., 2018, 550, 436-447.

175 A. H. AlAnezi, A. O. Sharif, M. I. Sanduk and A. R. Khan, Int. J. Water, 2013, 7, 317.

176 L. T. P. Trinh, Y. J. Lee, J. W. Lee, H. J. Bae and H. J. Lee, Sep. Purif. Technol., 2013, 120, 86-91.

177 X. Wang, Y. Nie, X. Zhang, S. Zhang and J. Li, Desalination, 2012, 285, 205-212.

178 X. Liang, Y. Fu and J. Chang, Bioresour. Technol., 2017, 245, 760-767.

179 X. Liang, Y. Fu and J. Chang, Bioresour. Technol., 2016, 220, 289-296.

180 P. A. Albertsson, Cell Biochemistry and Function, Wiley, 1986, pp. 233-234.

181 C. Ladd Effio, L. Wenger, O. Ötes, S. A. Oelmeier, R. Kneusel and J. Hubbuch, J. Chromatogr. A., 2015, 1383, 35-46. 
182 P. Guo, Y. El Gohary, K. Prasadan, C. Shiota, X. Xiao, J. Wiersch, J. Paredes, S. Tulachan and G. K. Gittes, J. Virol. Methods, 2012, 183, 139-146.

183 M. Rito-Palomares, J. Chromatogr. B: Biomed. Sci. Appl., 2004, 807, 3-11.

184 Y. Pei, J. Wang, L. Liu, K. Wu and Y. Zhao, J. Chem. Eng. Data, 2007, 52, 2026-2031.

185 S. P. M. Ventura, S. G. Sousa, L. S. Serafim, Á. S. Lima, M. G. Freire and J. A. P. Coutinho, J. Chem. Eng. Data, 2011, 56, 4253-4260.

186 Y. Deng, T. Long, D. Zhang, J. Chen and S. Gan, J. Chem. Eng. Data, 2009, 54, 2470-2473.

187 Y. Deng, J. Chen and D. Zhang, J. Chem. Eng. Data, 2007, 52, 1332-1335.

188 K. Shill, S. Padmanabhan, Q. Xin, J. M. Prausnitz, D. S. Clark and H. W. Blanch, Biotechnol. Bioeng., 2011, 108, 511-520.

189 K. M. Lee, G. C. Ngoh and A. S. M. Chua, Ind. Crops Prod., 2015, 77, 415-423.

190 C. Li, J. Han, Y. Wang, Y. Yan, J. Pan, X. Xu and Z. Zhang, J. Chem. Eng. Data, 2010, 55, 1087-1092.

191 A. F. M. Cláudio, C. F. C. Marques, I. Boal-Palheiros, M. G. Freire and J. A. P. Coutinho, Green Chem., 2014, 16, 259-268.

192 C. M. S. S. Neves, M. G. Freire and J. A. P. Coutinho, $R S C$ Adv., 2012, 2, 10882.

193 C. M. Neves, S. P. Ventura, M. G. Freire, I. M. Marrucho and J. A. Coutinho, J. Phys. Chem. B, 2009, 113, 5194-5199.

194 S. P. M. Ventura, C. M. S. S. Neves, M. G. Freire, I. M. Marrucho, J. Oliveira and J. A. P. Coutinho, J. Phys. Chem. B, 2009, 113, 9304-9310.

195 B. Wu, Y. M. Zhang and H. P. Wang, J. Chem. Eng. Data, 2008, 53, 983-985.

196 B. Wu, Y. M. Zhang and H. P. Wang, J. Phys. Chem. B, 2008, 112, 6426-6429.

197 H. Rodriguez, M. Francisco, M. Rahman, N. Sun and R. D. Rogers, Phys. Chem. Chem. Phys., 2009, 11, 1091610922.

198 M. Domínguez-Pérez, L. I. Tomé, M. G. Freire, I. M. Marrucho, O. Cabeza and J. A. Coutinho, Sep. Purif. Technol., 2010, 72, 85-91.

199 D. Xiong, Z. Li, H. Wang and J. Wang, Green Chem., 2013, 15, 1941.

200 K. Fukumoto and H. Ohno, Angew. Chem., Int. Ed. Engl., 2007, 46, 1852-1855.

201 H. Passos, A. Luis, J. A. Coutinho and M. G. Freire, Sci. Rep., 2016, 6, 20276.

202 L. Su, M. Li, X. Zhu, Z. Wang, Z. Chen, F. Li, Q. Zhou and S. Hong, J. Phys. Chem. B, 2010, 114, 5061-5065.

203 P. Nockemann, K. Binnemans and K. Driesen, Chem. Phys. Lett., 2005, 415, 131-136.
204 J. Ulrich, Melt Crystallization: Fundamentals, Equipment and Applications, Shaker, 2003.

205 J. L. Solà Cervera, P. Keil and A. König, Chem. Eng. Technol., 2010, 33, 821-826.

206 A. R. Choudhury, N. Winterton, A. Steiner, A. I. Cooper and K. A. Johnson, CrystEngComm, 2006, 8, 742-745.

207 R. Guardani, S. M. S. Neiro, H. Bülau and J. Ulrich, Chem. Eng. Sci., 2001, 56, 2371-2379.

208 J. L. Solà Cervera and A. Koenig, Chem. Eng. Technol., 2010, 33, 1977-1988.

209 H. Chang, J. Jiang, J. Su, C. Chang and S. Lin, J. Phys. Chem. A, 2007, 111, 9201-9206.

210 H. Chang, C. Chang, J. Su, W. Chu, J. Jiang and S. Lin, Int. J. Mol. Sci., 2006, 7, 417-424.

211 L. Su, L. Li, Y. Hu, C. Yuan, C. Shao and S. Hong, J. Chem. Phys., 2009, 130, 184503.

212 T. Takekiyo, N. Hatano, Y. Imai, H. Abe and Y. Yoshimura, High Pressure Res., 2011, 31, 35-38.

213 T. Takekiyo, Y. Imai, N. Hatano, H. Abe and Y. Yoshimura, Chem. Phys. Lett., 2011, 511, 241-246.

214 H. Li, Z. Wang, L. Chen, J. Wu, H. Huang, K. Yang, Y. Wang, L. Su and G. Yang, J. Phys. Chem. B, 2015, 119, 14245-14251.

215 F. Capitani, F. Trequattrini, O. Palumbo, P. Roy, P. Postorino and A. Paolone, J. Raman Spectrosc., 2017, 48, 1819-1827.

216 L. C. Chen, L. Haining, X. Zhu, L. Su, K. Yang, C. S. Yuan, G. Yang and X. Li, J. Mol. Struct., 2017, 1137, 610-614.

217 L. Su, X. Zhu, Z. Wang, X. Cheng, Y. Wang, C. Yuan, Z. Chen, C. Ma, F. Li, Q. Zhou and Q. Cui, J. Phys. Chem. $B, 2012,116,2216-2222$.

218 S. H. Lee, S. H. Ha, C. Y. You and Y. M. Koo, Korean J. Chem. Eng., 2007, 24, 436-437.

219 T. Chatzimitakos, C. Binellas, K. Maidatsi and C. Stalikas, Anal. Chim. Acta, 2016, 910, 53-59.

220 M. Wang, B. Li, C. Zhao, X. Qian, Y. Xu and G. Chen, Korean J. Chem. Eng., 2010, 27, 1275-1277.

$221 \mathrm{H}$. Olivier-Bourbigou, L. Magna and D. Morvan, Appl. Catal., A, 2010, 373, 1-56.

222 B. Gilbert, H. Olivier-Bourbigou and F. Favre, Oil Gas Sci. Technol., 2007, 62, 745-759.

223 Z. Liu, C. Xu and C. Huang, US Pat., 7285698, 2007.

224 E. Santos, J. Albo and A. Irabien, RSC Adv., 2014, 4, 4000840018.

225 E. Dal and N. L. Lancaster, Org. Biomol. Chem., 2005, 3, 682686.

226 A. Y. Arzephoni, M. R. Naimi-Jamal, A. Sharifi, M. S. Abaee and M. Mirzaei, J. Chem. Res., 2013, 37, 216-218.

227 G. W. Phillips, S. N. Falling, S. A. Godleski and J. R. Monnier, US Pat., 5315019, 1994. 